\title{
Repräsentation einer Leerstelle, oder: Auszug ins Reale. Zur politischen Bedeutung des biblischen Exodus, der historisch nicht stattgefunden hat
}

\author{
Peter Zeillinger
}

The article reads the invention of the Exodus-Narrative in its historical context of the religious and political system of the Ancient Near East. It reconstructs the revolutionary different approach to political power and theological foundation in the development of the Moses- and Exodus-Narrative and its innerbiblical Fortschreibung. For this development, it is most decisive that the Exodus-Narrative is not based on a historical migration-movement from point $A$ to point $B$, but located in a historical confrontation with the political powers at that time. The foundation of a strict monotheistic understanding of theology and the invention of a "textual authority" that diverged from the status of scripture in the Ancient Near East and which can be reconstructed through the structure of the Exodus-Narrative and its canonical form as the Torah of Moses, has laid the foundation for the identity of Israel and the basis for the three Monotheistic Religions. The article's argument is development strictly in correspondence with contemporary exegetical and historical research (esp. E. Otto and Chr. Dohmen) and is brought together with contemporary accounts to political thought from poststructuralist and deconstructive philosophers like Derrida, Levinas, Badiou and Agamben. The outcome of this study is articulated as a contribution to an affirmative reading of the so-called "crisis of representation".

Crisis of Representation; Exodus-Narrative; Biblical Exegesis; Textuality; Political Theology; Sovereignty; Future Antérieur; Derrida; Badiou; Levinas

Peter Zeillinger is a Catholic Theologian (Fundamental Theology) and Philosopher. He works as an assistant at the Theologische Kurse of the Austrian Bishops Conference in Vienna, and is a lecturer at the Departments of Philosophy and Political Theory at the University of Vienna. From 1994-1997 he was the last assistant of J.B. Metz, founder of the New Political Theology, during his guest professorship in Vienna. - Research interests: Contemporary French Philosophy, deconstruction, poststructuralism, political theory, rereading of Occidental Political Thought by the monotheistic textual traditions (OT, NT, Talmud, Qur'an). - Recent Publications: "Offenbarung als Ereignis. Zeitgenössische Philosophie, die Rede von Gott und das Sprechen der Bibel”, in: SaThZ 21.1 (2017), 25-101; "Disillusioning Reason - Rethinking Faith. Paul, Performative Speech Acts and the Political History of the Occident in Agamben and Foucault", in: G.-J. van der Heiden et al. (eds.), Saint Paul and Philosophy (de Gruyter 2017), 95-113; "Dekonstruktive Bibellektüre. Aufmerksamkeiten für die Textualität monotheistischer Schriften”, in: U. Rotн / J. SEIP (Hg.), Schriftinszenierungen (München 2016), 143-164. 
Repräsentation einer Leerstelle, oder: Auszug ins Reale

\author{
Für Eckart Otto, \\ in dessen Werk ich das Projekt \\ einer „neuen Politischen Theologie“ \\ meines Lehrers Johann Baptist Metz erkenne.
}

Ein Text ist nur dann ein Text, wenn er dem ersten Blick, dem ersten, der daher kommt, das Gesetz seiner Zusammensetzung und die Regel seines Spiels verbirgt.

Jacques Derrida Platons Pharmazie (1968), 71.

\title{
0. Vorbemerkung: Die Krise der Repräsentation und das Nicht-Repräsentierbare ${ }^{1}$
}

Ich beginne mit einer These, die sich im Folgenden zu bewähren haben wird: Die vielerorts beschworene politische „Krise der Repräsentation“ ${ }^{\prime 2}$ betrifft nicht den Vollzug von repräsentierendem Handeln, sondern die Identifizierung der Relata, also die Bestimmung des Repräsentierenden bzw. des Repräsentierten. Nicht der Akt des Repräsentierens, nicht das Repräsentieren selbst ist fragwürdig geworden, sondern die Bestimmung jener Instanzen, die „repräsentierend“ handeln, sowie die Klärung dessen, was genau dabei repräsentiert wird. Und vor allem: Wo findet sich jener Standpunkt, von dem aus zu entscheiden wäre, dass eine Repräsentationsbeziehung tatsächlich statthat? Die Frage nach der Möglichkeit und Wirklichkeit politischer Repräsentation ist somit zugleich eine Frage nach dem Grund und der Letztinstanz, auf die sich repräsentierendes Handeln bezieht.

1 Zur besseren Lesbarkeit sei hier eine Übersicht über die Gliederung des Beitrags vorangestellt: 0. Vorbemerkung: Die Krise der Repräsentation und das Nicht-Repräsentierbare; 1. Einleitung: Die Exoduserzählung und ihre politische Rezeption; 2. Über einen kulturellen und politischen Bruch im Alten Orient und die Vermeidung von Missverständnissen; 3. Der historische Kontext der Entstehung des Exodus-Narrativs; 4. Der politische Hintergrund der Exoduserzählung: die altorientalische Königs- und Herrschaftsideologie; 5. Was genau wurde im Exodus-Narrativ »erfunden«?, a) Die leere Stelle der Souveränität, b) Die Textualisierung der Macht, c) Die Repräsentation der Zukunft; 6. Auszug ins Reale: Die Struktur der Exoduserzählung und die zeitgenössische Politische Philosophie.

2 Die Grundgedanken dieses Beitrags wurden zunächst auf Englisch im Mai 2017 auf Sizilien im Rahmen eines Symposiums zur politischen Bedeutung des Exodus („The Pertinence of Exodus“, Univ. of Messina, organized by Sandro Gorgone and Laurin Mackowitz) vorgetragen, sowie im Juni 2017 auf einem Symposium zum Thema „Crisis of Representation“ im Stift Melk. Die Vorbemerkung ist dem Kontext des Melker Symposiums geschuldet. Zur Krisenthematik verweise ich auf die Ausführungen des dabei anwesenden amerikanischen Kollegen Carl Raschke in seinem Einleitungskapitel zu: Carl A. Raschke, Force of God. Political Theology and the Crisis of Liberal Democracy (New York: Columbia UP, 2015). 
Klassische Bestimmungen von Repräsentation - insbesondere im politischen und juridischen Kontext - betonen die Vorsilbe re-, die auf eine Wieder-Holung, ein Wieder-präsent-machen einer vorgängigen, anderswo präsenten, nun aber abwesenden Gegebenheit verweist. In ihrer zum Standardwerk politischer Repräsentation gewordenen Studie The Concept of Representation (1967) formuliert Hanna F. Pitkin in diesem Sinn eine Minimaldefinition von Repräsention:

„representation means, as the word's etymological origins indicate, re-presentation, a making present again.“3

Pitkin schließt damit unter anderem an die erstmals 1929 erschienene Habilitationsschrift Das Wesen der Repräsentation ${ }^{4}$ von Gerhard Leibholz an, dessen Umschreibung sich ebenfalls an der Etymologie orientiert und ähnlich knapp ausfällt:

„Rein sprachlich gesehen bedeutet Repräsentieren, daß etwas nicht real Präsentes wieder präsent, d. h. existentiell wird, etwas, was nicht gegenwärtig ist, wieder anwesend gemacht wird. Durch die Repräsentation wird somit etwas als abwesend und zugleich doch gegenwärtig gedacht.“ (ebd. 26)

Leibholz betont dazu noch in einer nicht unwichtigen Nachbemerkung, dass es „Voraussetzung der Repräsentation [ist], daß das Repräsentierte eine selbständige Wesenheit ist" (ebd.). Ohne eine nähere Bestimmung des Repräsentierten hängt auch die Legitimation einer Repräsentation in der Luft. Damit wird zugleich deutlich, inwiefern ein politisches Denken, das auf einem solcherart umschriebenen Repräsentationsverständnis aufbaut, unweigerlich in eine Krise gerät, wenn entweder über eines oder über beide der Relata oder aber über die sie verbindende Repräsentationsbeziehung keine klare Aussage getroffen werden kann. Repräsentation als Wieder-Holung eines Abwesenden beinhaltet stets eine Art Versprechen, eine Wirklichkeit nachträglich in einem identifizierbaren Rückbezug zu vergegenwärtigen. Worin aber läge das Vertrauen in dieses Versprechen begründet? An dieser Frage entscheidet sich die Plausibilität und Wirkmächtigkeit einer Repräsentationsbeziehung. Repräsentation bringt eine „,als ob“-Präsenz zum Ausdruck, die mit der Identifizierbarkeit der Instanz, in deren Namen sie handelt, steht und fällt. Wie aber ließe sich die abwesende Präsenz jemals als unmittelbare Gegebenheit identifizieren? Das klassische Repräsentationsverständnis gerät daher zu eben jenem Zeitpunkt in die Krise als die

3 Hanna Fenichel Pitkin, The Concept of Representation (Berkeley-Los AngelesLondon: Univ. of California Press, 1972 [1967]), hier: 8. Siehe dazu auch ihren „Appendix On Etymology“, ebd. 241-252.

4 Gerhard Leiвнolz, Das Wesen der Repräsentation und der Gestaltwandel der Demokratie im 20. Jahrhundert (Berlin: de Gruyter, ${ }^{3} 1966$ [1929]). 
bislang „als zureichend empfundenen Repräsentationssysteme (insbesondere die Sprachen) sich als der „Wirklichkeit“ nicht mehr adäquat [erwiesen] und somit Repräsentation ihre die Ordnung der Dinge verbürgende Allgemeingültigkeit als Erkenntnisform verliert. “5

Im Zentrum der folgenden Überlegungen zu den Grundlagen des Politischen steht nun aber nicht die Genealogie oder die Frage nach dem Umgang mit den Krisenphänomenen politischer Repräsentation heute, sondern eine andere Bestimmung von Repräsentation und damit auch ein anderer Zugang zum Politischen. Der französische Philosoph Jacques Derrida hat 1980 in seinem Eröffnungsvortrag im Rahmen einer Konferenz zum Thema La représentation in Straßburg einen beachtenswerten Hinweis auf einen Diskurs jenseits der für die Geschichte des abendländischen Denkens so zentralen Repräsentationsthematik gegeben. ${ }^{6}$ Seine kritische Lektüre von Heideggers Verständnis der Neuzeit als einer Epoche des „Vor-stellens“ (frz. re-présentation) ${ }^{7}$ führte Derrida dazu, über die Geschichte der Repräsentation und schließlich auch über ihre Krise hinaus zu fragen. In einer zusammenfassenden und zugleich eröffnenden Formulierung heißt es: „Jenseits einer Abschließung (clôture) der Repräsentation [...] habe ich versucht, einen Weg nachzuzeichnen, der sich auf ein Denken der Sendung/ Schickung (envoi) hin öffnet, die sich [...] noch nicht als Schickung des Seins durch die Anwesenheit*, die Präsenz und dann die Repräsentation hindurch mit sich selbst versammelte." ${ }^{\text {8 }}$ Woraus würde ein solches Denken jedoch bestehen? Worauf würde es zielen? Und inwiefern würde es sich der abendländischen Geschichte der Repräsentation entziehen? Derridas Vortrag schließt mit einigen Hinweisen, die es künftig zu verfolgen gilt:

„Die Grenze der Repräsentation zu denken heißt, das Nichtrepräsentierte oder das Nichtrepräsentierbare zu denken [...] über die Repräsentation hinaus zu denken, um die Repräsentation von ihrer Grenze her zu denken [...].| Ich nenne hier das riesige Problem des Verbots bezüglich der Darstellung (représentation), bezüglich dessen, was man von einer jüdischen oder islamischen Welt ausgehend mehr oder weniger legitim (ein anderes unerhörtes Problem) mit „représentation/Darstellung“ übersetzen könnte.“ (Derrida, Sendung, 137 f)

5 Kerstin Behnke, Repräsentation V. Krise der Repräsentation, in: Historisches Wörterbuch der Philosophie 8 (1992), 846-853, hier: 846.

6 Jacques Derrida, Sendung (1980), in: Psyche. Erfindungen des Anderen I (Wien: Passagen, 2012), 95-142. - Der französische Vortragstitel „Envoi“ (vom frz. Verb envoyer, „schicken“) kann auch als „Schickung“ übersetzt werden und spielt unter anderem auf Heideggers Darlegungen zum „Geschick des Seins“ an. (Vgl. dazu die Anmerkung des Übersetzers, ebd. 213 f Anm. 4.)

7 Insbesondere in: Martin Heidegger, Die Zeit des Weltbildes (1938), in: Holzwege ([= GA 5]; Frankfurt/M.: Klostermann, $\left.{ }^{7} 1994\right), 75-113$.

8 Derrida, Sendung, 139. 
Eine Überwindung der Aporien der Repräsentation und damit auch der Krise der politischen Repräsentation anhand der (damit als eminent politisch ausgewiesenen) Frage nach dem „Nichtdarstellbaren (l'irreprésentable)“ (ebd. 137) - dies ist Derridas Hinweis, den er zudem mit der Thematik des biblischen und islamischen Repräsentations- bzw. Darstellungsverbot verbindet, das im Deutschen gemeinhin etwas ungenau und missverständlich als „Bilderverbot“ bezeichnet wird. Diesem Hinweis soll im Folgenden nachgegangen werden. Dass es Derrida nicht um eine blinde Rezeption theologischer Vorstellungen gegangen sein kann, sollte jedem Leser seines Werkes klar sein. Worauf genau könnte sich Derridas Hinweis auf die biblischen bzw. monotheistischen Traditionen aber bezogen haben? Die weiteren Ausführungen möchten eine eigenständige Hinführung dazu aufzeigen und die sogenannte „Krise der Repräsentation“ in eine produktive Grundlegung des Politischen überführen.

\section{Einleitung: Die Exoduserzählung und ihre politische Rezeption}

Im Folgenden wird eine scheinbar rein theologische Quelle im Zentrum der Überlegungen stehen: die biblische Exoduserzählung. Allerdings ist hier gerade nicht ihre theologische Bedeutung von Interesse, sondern die Aufmerksamkeit gilt der Beziehung dieses Textes und seiner Komposition zum geschichtlichen Kontext ihrer Entstehung. Erst von dieser geschichtlichen Lektüre her kann der eminent politische Anspruch, den dieses Narrativ erhebt, deutlich werden. Dieser Anspruch und die politische Relevanz ergeben sich dabei nicht so sehr vom offensichtlichen Inhalt der Erzählung als solchem - der Befreiung des Volkes Israel aus der Zwangsherrschaft in Ägypten bis hin zum Einzug in das „Gelobte Land“-, vielmehr wird erst eine genauere Beachtung und Berücksichtigung der außergewöhnlichen textuellen Gestalt und literarischen Struktur, die diese bekannte Gesamterzählung geprägt haben, den noch heute relevanten politischen Kontext erkennen lassen.

In der Rezeptionsgeschichte, insbesondere auch in der jüngeren politischen Rezeption, ist das Exodus-Motiv immer wieder für eine politische Interpretation herangezogen worden. ${ }^{9}$ Auffällig ist dabei, wie sehr gerade diese ausdrücklich

9 Bemerkenswert ist zunächst die breite Rezeption von Michael WALzER, Exodus und Revolution (Berlin: Rotbuch, 1988 [amer. 1985]). Siehe dazu nun: Michael KüHNLEIN (Hg.), Exodus, Exilpolitik und Revolution. Zur Politischen Theologie Michael Walzers (Tübingen: Mohr Siebeck, 2017). - Vgl. aber auch die Diskussion des Exodus-Motivs in zeitgenössischen linken Politiktheorien: Paolo Virno, Exodus (Wien-Berlin: Turia+ Kant, 2010); Chantal Mouffe, Exodus und Stellungskrieg. Die Zukunft radikaler Politik (Wien: Turia+Kant, 2005) - mit einer hilfreichen differenzierenden Einführung von Oliver Marchart („Der Auszug aus Ägypten. Eine Einleitung,“ in: ebd. 7-23.) -, sowie 
politische Rezeption noch von einem sehr traditionellen Verständnis des biblischen Exodus als dem historischen Modell einer realen Auszugsbewegung geprägt ist und daran-zum Teil in kritischer Absetzung vom theologischen Narrativ der Etablierung einer neuen Ordnung - anzuknüpfen versucht. Die folgenden Überlegungen wollen dagegen aufzeigen, worin die grundlegende politische Kritik des Exodus-Motivs in seinem geschichtlichen Kontext konkret bestanden hat, an die heutige politische Theorie vermutlich direkter anknüpfen könnte als an das Modell einer kollektiven Auszugsbewegung.

Allerdings stehen einige Grundannahmen dieser - sich meist vom biblischen Text mehr oder weniger weit entfernenden - politischen Rezeption des Exodus durchaus im Fluchtpunkt einer langen Traditionsgeschichte. In traditionellen Bezugnahmen auf den Exodus - insbesondere dort, wo das erzählte Ereignis einer göttlichen Intervention vor etwa dreitausend Jahren als geschichtliches Modell einer politischen Befreiung im Sinne eines realen „Auszugs“ aus einer Unterdrückungssituation verstanden wird, - gehen viele der politischen Bezüge, die dem Narrativ innewohnen, bereits im Ansatz verloren. Wenn es tatsächlich um eine einmalige geschichtliche Einführung eines Modells politischer Befreiung ginge, so wäre zwar die Analyse dieser historischen Erfahrung von größter Bedeutung und der Modell-Charakter wäre von den geschichtlichen Ereignissen nicht zu trennen. Worin genau würde dann jedoch der politische Anknüpfungspunkt in der Gegenwart bestehen? Lassen sich die politischen Erfahrungen einer altorientalischen Kultur so ohne weiteres in eine andere Zeit und einen anderen politischen Kontext übertragen? Wird demgegenüber der Name „Exodus“ aber bloß als Metapher verwendet und damit das Exodus-Motiv lediglich als Chiffre für eine allgemeine Idee politischer Befreiung verstanden, die zufällig erstmals in der Kultur des Alten Israel erkennbar geworden ist, dann bliebe der historische Kontext ohne weitere Relevanz für die Gegenwart. Lediglich das Motiv würde aufgegriffen werden. Allerdings bliebe dann ungeklärt, was genau die Entstehung dieses Motivs an Neuem in die Geschichte eingebracht hat und in die heutigen politischen Debatten einbringen könnte. Für eine ernsthafte „Politik des Exodus“ bleibt es daher unverzichtbar, das „Exodus-Motiv“ anhand der überlieferten Texte und zugleich im Kontext ihrer geschichtlichen Entstehung in seiner Relevanz für die Gegenwart verstehbar werden zu lassen. Eine solche Aufgabe sieht sich jedoch einer bemerkenswerten Schwierigkeit ausgesetzt, die es sorgfältig zu bedenken gilt und die den Ausgangspunkt der weiteren Überlegungen bildet.

Isabell LoREY, Figuren des Immunen. Elemente einer politischen Theorie (Zürich: diaphanes, 2011), bes. $17 \mathrm{ff}$ („Exodus und Konstituierung“); DiEs., Die Regierung der Prekären (Mit e. Vorwort v. Judith Butler; Wien-Berlin: Turia+Kant, 2012), bes. 127ff; Klaus Neundlinger, Social Media und \#brennender Dornbusch. Politisch-theologische Skizze zum Exodusbegriff, in: Isabell Lorey / Roberto Nigro / Gerald Raunig (Hg.), Inventionen 2. Exodus, Reale Demokratie, Immanenz, Territorium, Maßlose Differenz, Biopolitik (Zürich: diaphanes, 2012), 27-41. 
Peter Zeillinger

\section{2. Über einen kulturellen und politischen Bruch im Alten Orient und die Vermeidung von Missverständnissen}

Heute ist es sowohl für den theologischen wie auch den säkularen wissenschaftlichen Diskurs selbstverständlich, dass alle biblischen Texte als nachträglich von Menschen komponierte Dokumente gelten, die zudem mehrfach überarbeitet und redigiert wurden bevor sie in einem sowohl theologisch wie auch kulturell relevanten Sinn als „kanonisch“ und damit nicht weiter veränderbar galten. ${ }^{10}$

10 Das Verständnis der Entstehung der biblischen Texte musste im Laufe der letzten hundert Jahre vor dem Hintergrund eines zunehmenden Wissens um die geschichtlichen Entwicklungen im Alten Orient, auf Grund von zahlreichen inner- und außerbiblischen Textfunden sowie einer sich von unhinterfragten Vorstellungen befreienden Textauslegung grundlegend revidiert werden. (Vgl. dazu den Überblick in: Konrad Schmid, Der Pentateuch und seine Theologiegeschichte, in: ZThK 111 (2014), 239-270.) Selbst wenn ein wissenschaftlicher Konsens im Detail auch heute noch nicht zu erreichen ist, lassen sich doch die wichtigsten geschichtlichen und kulturellen Eckdaten so zusammenfassen, dass eine „Literaturgeschichte“ der Hebräischen Bibel in den wesentlichen Grundzügen möglich geworden ist. - Zum gegenwärtigen Stand der Nachzeichnung der Entstehungsgeschichte der biblischen Texte siehe nun: Konrad Schmid, Literaturgeschichte des Alten Testaments. Eine Einführung (Darmstadt: Wissenschaftliche Buchgesellschaft, 2008); sowie aus dem englischsprachigen Raum mit einer vergleichenden Zusammenschau mehrerer Entwürfe: Joachim SCHAPER, The Literary History of the Hebrew Bible, in: The New Cambridge History of the Bible Vol. I: From the Beginnings to 600 (hg.v. James Carleton PAget / Joachim SchaPer; Cambridge: Cambridge UP, 2013), 105-144. Zur Entstehung der Exoduserzählung und ihrer Motive vgl. Konrad ScHмID, Erzväter und Exodus. Untersuchungen zur doppelten Begründung der Ursprünge Israels innerhalb der Geschichtsbücher des Alten Testaments (WMANT 81; Neukirchen-Vluyn: Neukirchener, 1999); Reinhard G. Kratz, Die Komposition der erzählenden Bücher des Alten Testaments. Grundwissen der Bibelkritik (Göttingen: Vandenhoeck \& Ruprecht, 2000); Eckart Отто, Die Tora des Mose. Die Geschichte der literarischen Vermittlung von Recht, Religion und Politik durch die Mosegestalt (Berichte aus den Sitzungen der Joachim Jungius-Gesellschaft der Wiss. E.V., Hamburg, 19 Jg., H. 2; Göttingen: Vandenhoeck \& Ruprecht, 2001); Jan Assmann, Exodus. Die Revolution der Alten Welt (München: Beck, 2015); Christoph Dohmen, Exodus (HThK.AT; 2 Bde.; Freiburg i.Br.: Herder, 2015+2004); sowie die aktuellen Sammelbände zur Exodus-Rezeption: Matthias EdERER / Barbara Schmitz (Hg.), Exodus. Interpretation durch Rezeption (SBB 74; Stuttgart: Katholisches Bibelwerk, 2017); Judith GärTner / Barbara Schmitz (Hg.), Exodus. Rezeptionen in deuterokanonischer und frühjüdischer Literatur (Deuterocanonical and Cognate Literature Studies 32; Berlin-Boston: de Gruyter, 2016); Thomas E. Levy / Thomas Schneider / William H.C. Propp (Hg.), Israel's Exodus in Transdisciplinary Perspective. Text, Archaeology, Culture and Geoscience (Cham-Heidelberg-New York: Springer, 2015); Thomas B. Dozeman / Craig A. Evans / Joel N. Lohr (Hg.), The Book of Exodus. Composition, Reception, and Interpretation (Vetus Testamentum, Supplements 164; Leiden-Boston: Brill, 2014). 
Dieses geschichtliche Faktum lässt noch völlig offen, welcher religiöse oder nichtreligiöse Status mit der Entstehung dieser Texte verbunden wird. Sie stellen jedenfalls die bewusst konzipierte Gestalt eines kollektiven Weltbildes dar, indem sie die Vorstellung einer konkreten, gesellschaftlich und politisch relevant gewordenen Ordnung - das, was in weiterer Folge die kulturelle Identität Israels prägen wird - innerhalb eines textuellen Narrativs erkennbar werden lassen. In diesem Sinn können sie auch als der imaginäre Ausdruck einer symbolischen Ordnung bezeichnet werden.

Ich stelle hier also nicht eine theologische Bedeutung in den Mittelpunkt meiner Ausführungen, sondern vielmehr den existenziellen Aspekt einer kulturellen Identität, deren Struktur in ihrem geschichtlichen Kontext sehr sorgsam wahr- und ernstgenommen werden sollte. Somit können und dürfen die zentralen Texte der Hebräischen Bibel heute nicht mehr einfach als nachträgliche Aufzeichnung einer mündlichen, mehr oder minder mythischen Überlieferung verstanden werden. Sie sind vielmehr das Ergebnis einer geschichtlich motivierten, durchaus rational durchgeführten und mit einer noch zu bestimmenden Autorität verbundenen Intervention von Schreibern. ${ }^{11}$ Gerade dort, wo die literarische Gattung von biblischen Texten der des Mythos zu ähneln scheint, gilt es in Er-

11 Dies gilt nicht nur für die narrativen Texte, sondern auch für das Prophetencorpus: Gerade die israelitische Schriftprophetie, in der das mündliche Prophetenwort nicht nur aufgezeichnet, sondern in weiterer Folge auch über Generationen hinweg autoritativ fortgeschrieben wird, ist im Alten Orient analogielos (Schmid, Literaturgeschichte, aaO. [Anm. 10], 93). Vgl. dazu auch die Feststellung von Reinhard Kratz, die neben der Besonderheit der Schriftlichkeit auch bereits den außergewöhnlichen kritischen Gehalt hervorhebt: „Was die alttestamentlichen Propheten im besonderen auszeichnet und zur Ausnahme macht, ist zweierlei: die unbedingte Unheilsbotschaft und die Schriftlichkeit. Beides hängt miteinander zusammen. Die Unheilsbotschaft ist der Grund für die Schriftlichkeit, die Schriftlichkeit gibt der Unheilsbotschaft die ihr adäquate Form.“ (Reinhard G. Kratz, Das Neue in der Prophetie des Alten Testaments (2001), in: Ders, Prophetenstudien. Kleine Schriften II (FAT 74; Tübingen: Mohr Siebeck, 2011), 49-70, hier: 57.) - Einen aktuellen Überblick zur Bedeutung der Schriftprophetie gibt Jörg Jeremias, Das Proprium der alttestamentlichen Prophetie (1994), in: Jörg Jeremias: Hosea und Amos. Studien zu den Anfängen des Dodekapropheton (FAT 13; Tübingen: Mohr, 1996), 20-33.; sowie jüngst Jörg Jeremias : Das Rätsel der Schriftprophetie (2013), in: Studien zur Theologie des Alten Testaments (hg.v. Friedhelm Hartenstein / Jutta KrisPenz; FAT 99; Tübingen: Mohr Siebeck, 2015), 288-310. - Allgemein zur besonderen Bedeutung der Schriftlichkeit in Israel siehe: Erich Bosshard-NePustiL, Schriftwerdung der Hebräischen Bibel. Thematisierungen der Schriftlichkeit biblischer Texte im Rahmen ihrer Literaturgeschichte (AThANT 106; Zürich: TVZ, 201), sowie Hindy Najman, The Symbolic Significance of Writing in Ancient Judaism, in: Hindy Najman / Judith H. Newman (Hg.), The Idea of Biblical Interpretation. Essays in Honor of James L. Kugel (Supplements to the Journal for the Study of Judaism 83; Leiden-Boston: Brill, 2004), 139-176. 
innerung zur rufen, dass die Texte der Bibel nicht wie mythische Überlieferungen anonym geschichtlich gewachsen sondern im Kern das Produkt einer kompositorischen Tätigkeit von selbstbewussten Autoren sind, die in einem bestimmten kulturellen und politischen Kontext diese Texte genau so und nicht anders formuliert haben. Darin - so wird sich zeigen - liegt die Besonderheit und zugleich das politisch Ungeheuerliche dieser Texte. Emmanuel Levinas hat die Ambiguität einer Ausdrucksgestalt an einer entscheidenden Stelle seines Werkes (von der sein Spätwerk seinen Ausgang nimmt), im Moment der Entfaltung seines Begriffs der Spur (trace) als einer „rätselhaften Verwirrung (dérangement)“, die die herrschende Ordnung unterbricht, in ihrer Produktivität anerkannt. Diese spurhafte Störung der Ordnung ist kein Manko und sie ist auch dort nicht irrational, wo sie die Rationalität übersteigt: „Niemand ist irrational mit dem Bewusstsein, es zu sein.“12 Es kommt nicht allein auf den ausgedrückten Gehalt, sondern stets auch auf den Modus an, in dem ein Ausdruck erscheint. Darauf wird zu achten sein.

Die Tatsache, dass judäische Schreiber um die Mitte des 1. Jtsd. v. Chr. die Struktur und damit auch die zentrale Aussage der biblischen Botschaft eigenständig komponiert haben, ist durchaus bemerkenswert und in seiner Bedeutung für ihr Verständnis kaum zu überschätzen. Denn im Alten Orient war es bis dahin keineswegs der Fall und ist es vermutlich nicht einmal denkbar gewesen, dass Schreiber eine gegenüber dem herrschenden Weltbild nеuе Botschaft komponieren und somit zugleich einen neuartigen Diskurs erfinden könnten, der über das bestehende Wissen hinausführt. ${ }^{13}$ In dem in der biblischen und altorientali-

12 Emmanuel Levinas, Rätsel und Phänomen (1965), in: Emmanuel Levinas: Die Spur des Anderen. Untersuchungen zur Phänomenologie und Sozialphilosophie (Freiburg/Br.-München: Alber, 1983), 236-260, hier: 248. - Zur Bedeutung der Spur bei Levinas und ihrer Konsequenzen für das Verständnis performativer Texte siehe Peter Zeillinger, Phänomenologie des Nicht-Phänomenalen. Spur und Inversion des Seins bei Emmanuel Levinas, in: Michael Blamauer / Wolfgang Fasching / Matthias Flatscher (Hg.), Phänomenologische Aufbrüche (Reihe der Österreichischen Gesellschaft für Phänomenologie 11; Frankfurt/M. u. a.: Lang, 2005), 161-179.

13 Im Folgenden wird es eben darum gehen, inwiefern die Entstehung und Formulierung der biblischen Botschaft in ihrem historischen Kontext über das „,bestehende Wissen“ hinausführte. Damit wird keineswegs einer mythischen Inspiration das Wort geredet, sondern ein in geschichtlichen Kategorien beschreibbares Phänomen zu beschreiben versucht. In diesem Kontext ist daher das Wort „erfinden“ durchaus angemessen, wenn man damit nicht sogleich Beliebigkeit oder Willkür verbindet, sondern vielmehr das eigenständige „Benennen“ einer neuartigen (ereignishaften) Erfahrung oder Vorstellung, für die es im gegenwärtigen kulturellen Rahmen (Diskurs) noch keine Darstellung gibt. Eine solche „narrative Benennung“ verändert damit zugleich die bestehende Situation in einem durchaus politisch zu nennenden Sinn. „Inventio “wäre hier also zu verstehen im Sinne einer Intervention in der herrschenden symbolischen Ordnung. Sowohl Alain Badiou als auch Jacques Derrida haben dem Begriff der inventio eine 
schen Wissenschaft breit rezipierten Buch Scribal Culture. The Making of the Hebrew Bible ${ }^{14}$ beschreibt der niederländische Altorientalist und Alttestamentler Karel van der Toorn an zahlreichen Beispielen das Selbstverständnis und die Funktion der altorientalischen Schreiberkultur. Demnach gehörte es keinesfalls zur Aufgabe von Schreibern nеuе Aussagen zu erfinden, sondern vielmehr bestehende kulturelle Überzeugungen oder ihnen - vom Palast oder vom Tempel vorgegebene Botschaften oder Entscheidungen aufzuzeichnen, um sie auf diese Weise zu bewahren oder zu kommunizieren. Die altorientalischen Schreiber waren demnach keineswegs eigenständige Autoren im heutigen Sinn.

„An author [im Alten Orient, Anm. PZ] does not invent his text but merely arranges it; the content of a text exists first, before being laid down in writing." ${ }^{\text {.15 }}$

Schriftlichkeit und geschriebene Dokumente hatten seit ihrer Entstehung somit vor allem eine archivarische Funktion. Die Erfindung der Schrift im Mesopotamien des 4. Jtsd. v. Chr. war zunächst auch nicht darauf ausgerichtet, lesbare ${ }^{16}$ Texte zu produzieren. ${ }^{17}$ Die Schrift erfüllte vielmehr ökonomische, buchhalteri-

solche politische Bedeutung zugemessen. Vgl. dazu Peter Zeillinger, Offenbarung als Ereignis. Zeitgenössische Philosophie, die Rede von Gott und das Sprechen der Bibel, in: Salzburger Theologische Zeitschrift, 21 (2017) 1, 25-101, bes. 29 (zum Ereignisbegriff). $59 \mathrm{f} \mathrm{(zu} \mathrm{Badiou).} 72 \mathrm{f}$ (zu Derrida). 85-90 (Kap. „Die „Erfindung“ des Konzepts schriftlicher Offenbarung im Alten Orient"), sowie grundsätzlich dazu: Jacques DeRRIDA, Psyche. Erfindung des Anderen (Wien: Passagen, 2011 [fr. 1987]). - Aufgrund des interventionistischen und damit zugleich politischen Charakters unterscheidet sich das Verständnis von inventio hier auch vom rhetorischen Gebrauch des Begriffs im Sinne einer Lehre von der Argumentfindung. Die Anwendbarkeit des Verständnisses von „Erfindung“ auf die Entstehung des biblischen Exodus-Narrativs wird unten in Abschnitt 5 ausführlicher thematisiert. Zur rhetorischen inventio siehe: M. KiEnPoInTnER, Inventio, in: Historisches Wörterbuch der Rhetorik IV (hg.v. Gert Ueding; Tübingen: Niemeyer, 1998), 561-587.

14 Karel van der Toonn, Scribal Culture and the Making of the Hebrew Bible (Cambridge, Mass.: Harvard UP, 2007).

15 van der Toorn, Scribal Culture 47.

16 Der Begriff des Lesens wird hier und in weiterer Folge im heutigen Sinn als ein Zugang zu Texten verstanden, der über das Entziffern oder Decodieren einer Information hinausgeht und daher mit einer der Interpretation offenen Bedeutung und damit ihrer Mehrdeutigkeit umzugehen vermag. Schriftliche Aufzeichnungen (Dokumente, Listen, Briefe, Verträge) wurden daher in der altorientalischen Schriftkultur nicht im engeren Sinn ,gelesen“, sondern entziffert bzw. decodiert - was der Eigenart der Keilschrift, die zunächst keine Alphabetschrift war, entspricht.

17 Zur Entstehung und Entwicklung der Schrift siehe: Denise Schmandt-Besserat, How Writing Came About (Austin: University of Texas Press, 1996); Jean BotтÉRo, Mesopotamia. Writing, Reasoning, and the Gods (Transl. by Zainab Bahrani and Marc 
sche und archivarische Zwecke. Da die Vorstellung, eine Aufzeichnung interpretieren zu können, noch nicht gegeben war, muss man sagen, dass es im Alten Orient während des 3. Jtsd. v. Chr. noch keine Texte im heutigen Sinn gab, sondern lediglich dokumentarische Aufzeichnungen unterschiedlichster Art. Selbst nachdem in der ersten Hälfte des 3. Jahrtausends die Keilschrift auch phonetische Elemente und Silben zu repräsentieren vermochte, wurden die Tontafeln, in die diese Schrift eingraviert war, nicht in der heute üblichen Weise gelesen und interpretiert. Die komplexen Symbole mussten vielmehr „entziffert“ werden. Diese Decodierung beruhte auf einem von Schreibern und Lesern gemeinsam geteilten Verständnis der Bedeutung der Zeichen. Aus diesem Grund wurde den geschriebenen Dokumente im Alten Orient auch niemals eine eigenständige, vom König oder einer anderen gesellschaftlichen Autorität unabhängige Autorität zugestanden. Die Entscheidungen des Königs und die gemeinsam geteilten Überzeugungen im Rahmen eines mythischen Weltbildes blieben die maßgebliche Autorität, die durch keinen Text in Frage gestellt werden konnte. Alles prinzipiell Neue würde nicht nur die Stabilität des sozialen und politischen Bandes gestört haben, sondern auch dessen Plausibilität. Solche Aufzeichnungen repräsentieren demnach kein unabhängiges Wissen, sondern die Einstellung und das Weltbild ihrer Adressaten.

"If the author took the initiative, he made sure that he wrote under the auspices of either the palace or the temple. The gentleman author, writing for his own pleasure, did not appear on the scene until the Hellenistic period." ${ }^{\text {"18 }}$

Selbst bei prophetischen Botschaften und religiösen Befragungen der Götter (Divination) kam es niemals zu grundsätzlich neuen Erkenntnissen, sondern lediglich zu Variationen und Klärungen innerhalb der gegebenen Überzeugungen. Stets wurden die Aussagen in die vorgegebene Kommunikationssituation eingepasst. ${ }^{19}$

Van De Mieroop; Chicago-London: University of Chicago Press, 1992), bes. Kap. 5 („From Mnemonic Device to Script“); Dominique Charpin, Writing, Law, and Kingship in Old Babylonian Mesopotamia (transl. by Jane Marie Todd; Chicago-London: University of Chicago Press, 2010); Harald HaArmann, Universalgeschichte der Schrift (Frankfurt/M.-New York: Campus, ${ }^{2} 1991$ ). - Eine Zusammenfassung dieser Entwicklung gibt Thomas Vesting, Die Medien des Rechts: Schrift (Weilerswist: Velbrück, 2011). Vesting schließt in seine geschichtliche Darstellung auch die postmodernen, poststrukturalistischen und dekonstruktiven Zugänge zur Geschichte und zur Schrift(lichkeit) ein.

18 Toorn, Scribal Culture, aaO. [Anm. 14], 48.

19 Dies bedeutet nicht automatisch, dass bestehende Verhältnisse nicht auch - unter Aufrechterhaltung des bestehenden Weltbilds - kritisiert werden konnten. Ein offensichtliches Beispiel dafür sind jene Orakel-Befragungen, deren Ausgang den Intentionen der Auftraggeber nicht zu entsprechen schien. Stephan Maul hat aufgezeigt, wie im Alten Orient solche „kritischen“ Ergebnisse innerhalb der gegebenen Situation produktiv 
Repräsentation einer Leerstelle, oder: Auszug ins Reale

„In Babylonia, as elsewhere in the ancient Near East, ,people who recorded an orally delivered statement did not feel obligated to register it in the precise form $\mid$ in which they heard it. As it reached different ears, the statement was shaped to suit the perspective of the hearer." (Jack M. Sasson)“20

Schriftlichkeit war damit eingebettet in das altorientalische System kultureller und gesellschaftlicher Stabilität, das durch die jeweiligen religiösen Vorstellungen gestützt und geschützt wurde. Ganz generell lässt sich sagen, dass Religion im Alten Orient - wie überall in der Antike und im Abendland zum Teil noch bis heute - neben der Vermittlung und Bewahrung des überlieferten (mythischen) Weltbildes vor allem die Funktion besaß, die herrschende politische und gesellschaftliche Ordnung zu legitimieren, zu stützen und aufrecht zu erhalten. In diesem strukturell konservativ-bewahrenden und stabilisierenden Kontext wird es verständlich, wieso altorientalische Schreiber niemals die Funktion von Schöpfern einer neuen Botschaft innehaben konnten. Eine solche wäre insbesondere dann unangemessen und unverständlich gewesen, wenn das Neue den bereits bekannten Traditionen und geteilten Überzeugungen widersprochen hätte. - Allerdings ist genau das der Fall mit der zentralen Botschaft der biblischen Texte. Sie unterwandern und kritisieren die überlieferten Überzeugungen, insbesondere in Bezug auf das Verständnis und die Legitimation identifizierbarer

gewendet werden konnten, indem sie z. B. zu einer nochmaligen Überprüfung und Korrektur der geplanten Absichten führten, die dann eine neuerliche Befragung der Götter möglich machten. Auf diese Weise wird auch verständlich, wieso die verschiedenen, uns heute oft befremdlich und irrational anmutenden Formen der Divination (z. B die Leberschau) überhaupt über einen so langen Zeitraum hinweg „,funktionieren“, das heißt Entscheidungen beeinflussen und Stabilität bewirken konnten. Ebenso wird deutlich, dass es in diesem Kontext nie zu einer prinzipiellen Hinterfragung der herrschenden Autoritäten kommen konnte. - Zur ausführlichen Darstellung der Produktivität dieser religiösen Praktiken siehe Stefan M. Maul, Die Wahrsagekunst im Alten Orient. Zeichen des Himmels und der Erde (München: Beck, 2013), bes. 317-323 („Vom Sinn und Unsinn der Prognostik“); sowie Stefan M. Maul: Die Wissenschaft von der Zukunft. Überlegungen zur Bedeutung der Divination im Alten Orient, in: Eva CANCIKKirschbaum / Margarete van Ess / Joachim Mahrzahn (Hg.), Babylon. Wissenskultur in Orient und Okzident (Berlin-New York: de Gruyter, 2011), 135-151, bes. die zusammengefassten Gründe des „Funktionierens“ der divinatorischen Praktiken: ebd. 148 ff.

20 Karel van der Toorn, From the Oral to the Written. The Case of Old Babylonian Prophecy, in: Ehud Ben Zvi / Michael H. Floyd (Hg.), Writings and Speech in Israelite and Ancient Near Eastern Prophecy (SBL Symposium Series 10; Atlanta: Society of Biblical Literature, 2000), 219-234, hier: 232. Van der Toorn zitiert hier aus: Jack M. SAsson, Water beneath Straw. Adventures of a Prophetic Phrase in the Mari Archives, in: S. Gitin, M. Sokoloff, Z. Zevit (Hg.), Solving Riddles and Untying Knots. Biblical, Epigraphic, and Semitic Studies in Honor of Jonas C. Greenfield (Winona Lake, IN: Eisenbrauns, 1995), 599-608, hier: 607. 
Souveränität - sowohl im Feld des Politischen (Königs- und Herrschaftskritik) als auch des Religiösen (Kritik des antiken Religionsverständnisses). Dieser Bruch mit den kulturellen und politischen Überzeugungen des Alten Orients verlangt nach einer aufmerksamen Wahrnehmung und Erläuterung des geschichtlichen Kontextes wie auch der Mittel, in und mit denen diese Veränderungen erkennbar werden.

Die Exodus-Erzählung ist für diese Entwicklung, die ihren Ausdruck keineswegs zufällig in der Entstehung des biblischen Verständnisses von Schriftlichkeit und Textualität gefunden hat, gewissermaßen paradigmatisch. Neben den bekannten Motiven der Befreiung eines Volkes aus einer Zwangsherrschaft, des Einzugs in ein verheißenes Land und der zwischenzeitlichen Etablierung einer neuen religiösen und sozialen Ordnung sind es vor allem die Aspekte einer „politischen Emanzipation“, der „Überwindung des Ausschlusscharakters von Souveränität" sowie die Etablierung der Vorstellung einer „Gemeinschaft-ohneSouveränität“"21 , die bei der geschichtlich und politisch zu verortenden Entstehung des Exodus-Narrativs im Zentrum stehen. Auf sie soll im Folgenden die Aufmerksamkeit gerichtet werden. Um eine solche Lektüre aber nicht von Anfang an mit möglichen Missverständnissen zu belasten, sollen zunächst drei mögliche Fehlschlüsse identifiziert werden.

Man könnte (1.) der Meinung sein, dass es sich beim Exodus-Narrativ entweder um eine religiöse Erzählung handeln würde, die auch nur innerhalb eines gläubigen Vorverständnisses von Bedeutung wäre, - oder aber dass dabei alle religiösen Konnotationen von vornherein zu negieren wären. Dabei handelt es sich jedoch um eine falsche Alternative. Sie greift zu kurz, weil sie ein mythisches Verständnis von Religion voraussetzt, das jedoch seinerseits bereits von der Struktur der Exodus-Erzählung überwunden wird und daher die Bedeutung jenes Begriffs von Religion, den die biblischen Texte selbst entwerfen, an dieser Stelle noch völlig unbestimmt ist.

Man könnte (2.) etwas ängstlich darauf insistieren, dass die Exodus-Erzählung entweder auf eine tatsächlich geschehene und nachträglich beschriebene historische Erfahrung einer politischen und gesellschaftlichen Befreiung zurückgehen muss, oder aber die gesamte Erzählung nichts weiter sei als eine literarische Erfindung, die ein bloßes Wunschdenken zum Ausdruck bringt. Tatsächlich wird man sagen müssen, dass der Exodus als die beschriebene kollektive Befreiungserfahrung

21 Diese ungewöhnliche, bewusst mit Bindestrichen zu einer Einheit verbundene Formulierung zielt nicht auf ein Gemeinschaftsverständnis, das (gewissermaßen nachträglich) den Aspekt souveräner Herrschaft eliminieren würde oder könnte, sondern das sich vielmehr von Anfang an vom Aspekt eines „ohne Souveränität" her inszeniert. Inwiefern eine solche Vorstellung mit dem Exodus-Narrativ zu verbinden ist und darüber hinaus politisch relevant werden kann, müssen die folgenden Beobachtungen und Überlegungen erst sichtbar werden lassen. 
historisch nicht stattgefunden hat. ${ }^{22}$ Dennoch ist ebendiese Erzählung schon zur Zeit ihrer Entstehung zur Grundlage der Identität eines Volkes geworden sowie zur Basis von drei Weltreligionen, die bis heute über geographische und kulturelle Grenzen hinweg von Bedeutung sind. Insofern jedenfalls deutlich gemacht werden kann, dass die Struktur der Erzählung eine eminent politische Bedeutung besitzt, die auch für die gegenwärtigen politischen Herausforderungen von Relevanz ist, wird sich auch diese Alternative (- entweder reale geschichtliche Erfahrung oder literarisches Wunschdenken -) als eine falsche oder zumindest zu kurz greifende Opposition herausgestellt haben.

Der dritte (3.) mögliche Fehlschluss ist vermutlich der schwerwiegendste, da er zugleich eine strukturelle Kritik des Narrativs selbst beinhaltet: Man könnte nämlich meinen, dass die Erzählung zwar auf den ersten Blick eine Erfahrung von Befreiung und Emanzipation vermittelt (unabhängig davon, ob sie geschichtlicher oder anderer Art ist) und damit zugleich die Hoffnung auf eine verheißungsvolle Zukunft eröffnet. Am Ende jedoch läuft der gesamte Prozess des Auszugs erneut auf die Etablierung einer juridischen und politischen Ordnung hinaus, der sich jeder einzelne bedingungslos unterzuordnen hat: dem Gesetz vom Berg Sinai, an das Israel von nun an gebunden ist. Damit stellt sich die durchaus berechtigte Frage: Kann eine politische und emanzipatorische Lektüre der Exoduserzählung von diesem Narrativ all jene Aspekte negieren oder entwerten, die neuerlich auf die Einrichtung eines hierarchisch verordneten Gesetzes hinauslaufen? Im Kern ist hier jene Schwierigkeit benannt, die von vielen der zeitgenössischen politischphilosophischen Bezugnahmen auf den Exodus formuliert und kritisiert wird ${ }^{23}$ und die dazu führt, dass die biblische Erzählung lediglich als zumeist unbestimmt bleibendes „Motiv“ rezipiert wird. Wird es also möglich sein, das Exodus-Narrativ auf eine andere Weise zu lesen?

22 Es gibt heute keine ernstzunehmenden Versuche mehr der Rekonstruktion einer solchen Auszugs- und Wanderungsbewegung einer soziologischen oder politischen Größe, die mit dem historisch fassbaren Israel zu identifizieren wäre. Die wenigen historischen Anhaltspunkte aus frühen Erfahrungen, die sich in der israelitischen Kultur erhalten haben und in die Exoduserzählung integriert wurden (z. B. die auffällige ägyptische Herkunft des Mosenamens) stehen in keinem unmittelbaren zeitlichen oder inhaltlichen Zusammenhang mit den zentralen Aussagen des Geschehens, das vom Exodus-Narrativ vermittelt wird - weder zum Zeitpunkt seiner historischen Entstehung noch in der Gestalt seiner späteren Kanonisierung. Vgl. dazu die zeitgenössischen Rekonstruktionen und Diskussionen der Exoduserzählung in der in Anm. 10 genannten Literatur.

23 Vgl. dazu die oben (Anm. 9) zitierten Ansätze insbesondere von Chantal Mouffe, Isabell Lorey und Paolo Virno. 
Peter Zeillinger

\section{Der historische Kontext der Entstehung des Exodus-Narrativs}

Die exegetische Diskussion zur Entstehung, Schichtung und Redaktion der biblischen Texte ist keineswegs abgeschlossen. Sie ist in den Details der Textinterpretation immer noch von zahlreichen divergierenden Thesen geprägt und damit immer wieder auch Wandlungen unterworfen. In den letzten beiden Jahrzehnten sind allerdings zahlreiche historische Untersuchungen und kulturgeschichtliche Studien erschienen, die den geschichtlichen Rahmen wie auch den sozialen und politischen Kontext der Entstehung der monotheistischen Traditionen, ihrer religiösen Institutionen sowie die Entwicklung ihrer zentralen Schriften doch in einer wachsenden Übereinstimmung deutlich erkennbar werden lassen. ${ }^{24}$ Es sind vor allem die geschichtlichen Eckdaten zur Entstehung und zum Kontext von Schriftlichkeit im Alten Israel, an die sich eine Deutung der vorliegenden, kanonisch gewordenen und damit sowohl für die innerreligiöse wie auch für die breitere kulturelle Rezeption relevanten Textgestalt rückbinden muss und auch ihren Ausgang nehmen kann.

Alttestamentler stimmen heute darin überein, dass es vor dem Fall des Nordreichs Israel Ende des 8. Jh. v. Chr. keine eigenständige Mose- oder ExodusErzählung gegeben hat. ${ }^{25}$ Die Eroberung durch das neuassyrische Königreich im Jahr 722 v. Chr. spielt für die zentrale Thematik des später komponierten und redigierten Narrativs sogar eine zentrale Rolle. Weitere historische Eckdaten, die die Entstehung, die Gestalt und die Grundaussagen der biblischen Botschaft entscheidend geprägt haben sind die Eroberung Jerusalems durch die Babylonier

24 Einen aktuellen historischen Überblick aus unterschiedlichen Blickwinkeln geben Israel Finkelstein / Neil A. Silberman, The Bible Unearthed. Archaeology's New Vision of Ancient Israel and the Origin of Its Sacred Texts (New York: The Free Press, 2001); Barbara Schmitz, Geschichte Israels (Paderborn: Schöningh, ${ }^{2} 2015$ ); Christian Frevel, Geschichte Israels (Stuttgart: Kohlhammer, 2016); Schmid, Literaturgeschichte, aaO. [Anm. 10]; Otto KAISER, Glaube und Geschichte im Alten Testament. Das neue Bild der Vor- und Frühgeschichte Israels und das Problem der Heilsgeschichte (Biblisch-Theologische Studien 150; Neukirchen-Vluyn: Neukirchener, 2014); sowie die umfangreiche, vor allem aufgrund ihrer zahlreichen archäologischen Bezüge bemerkenswerte Darstellung in Othmar KeEL, Die Geschichte Jerusalems und die Entstehung des Monotheismus (2 Bde.; Orte und Landschaften der Bibel IV,1+2; Göttingen: Vandenhoeck \& Ruprecht, 2007). - Einen vergleichbaren Zugang zur Entstehung der koranischen Botschaft in ihrem geschichtlichen Kontext verfolgt Angelika Neuwirth, Der Koran als Text der Spätantike. Ein europäischer Zugang (Berlin: Verlag der Weltreligionen, 2010); DiEs., Die koranische Verzauberung der Welt und ihre Entzauberung in der Geschichte (Freiburg i.Br.: Herder, 2017); Dies., Koranforschung - eine Politische Philologie? Bibel, Koran und Islamentstehung im Spiegel spätantiker Textpolitik und moderner Philologie (Litterae et Theologia 4; Berlin-Boston: de Gruyter, 2014); Dies., Der Koran 1: Frühmekkanische Suren. Poetische Prophetie (Berlin: Verlag der Weltreligionen, 2011).

25 Siehe dazu die Literaturangaben zum Exodus in Anm. 10. 
587/6 v. Chr., die damit einhergehende Zerstörung des Ersten Tempels, die Deportation ins Exil nach Babylon, sowie schließlich die Ermöglichung der Rückkehr ins Land nach dem Sieg des Perserkönigs Kyros II. über die Babylonier. Diese historisch unerwartbare Rückkehr und die Möglichkeit - unter persischer Oberherrschaft - die kulturelle Eigenständigkeit zurückzugewinnen führte zum Wiederaufbau des Zweiten Tempels und zur Ausgestaltung jener spezifisch jüdischen Identität auf der Basis der zunehmend zu einem Abschluss gebrachten biblischen Überlieferung, die bis heute die Grundlage der jüdischen Religion und Kultur bildet und sowohl die Entstehung des Christentums wie auch die koranische Botschaft und damit die islamische Religion und Kultur entscheidend mitprägte. Für die Entfaltung des Exodus-Narrativs sind dabei insbesondere die negativen Erfahrungen der assyrischen Krise bis zur Zerstörung Jerusalems und die damit verbundene Reflexion über den Verlust der eigenen Identität von Bedeutung. Die Erfahrungen der kulturellen Hegemonie, des Exils und der erstaunlichen Möglichkeit der Rückkehr haben dieser Frage nach Identität nochmals entscheidende Impulse gegeben.

Für die weiteren Überlegungen zentral ist zunächst der Umstand, dass es vor dem 8. Jh. v. Chr. in Israel weder biblische Schriften gab noch jene zusammenhängenden Erzähltraditionen, die die Hebräische Bibel heute prägen. Vor dieser Zeit gab es noch gar keine entwickelte Schriftkultur in Israel $^{26}$ und auch die Anfänge der Schrift im 9./8. Jh. v. Chr. dienten nicht einer literarischen Tätigkeit sondern erfüllten vor allem administrative Zwecke. ${ }^{27}$ Mit der Entstehung der Grundzüge der zunächst noch separaten Mose- und Exodus-Erzählungen ${ }^{28}$ in dieser Zeit und dem Umstand, dass diese Traditionen später zu einem zentralen Motiv der biblischen Botschaft werden sollten, haben wir es also durchaus mit dem geschichtlichen Kontext des „Beginns“ der biblischen Geschichte Israels zu tun - auch wenn die narrative Gestaltung dieses Beginns einer oberflächlichen Lektüre nicht genau jene geschichtliche Erfahrung vermittelt, die ihr historisch zugrunde liegt. Doch dies darf nicht als Problem der Texte selbst verstanden werden. Es ist vielmehr das Problem jener Art von Lektüre, die es niemals gelernt hat - oder aus bestimmten Gründen wieder verlernt hat -, in Texten nicht bloß

26 „Only in the ninth century was a script devised that was used for the production of texts in Hebrew, Moabite and Ammonite, followed by the emergence of a distinctly Hebrew script towards the end of the ninth century." (Schaper, Literary history, 110) Vgl. dazu auch Johannes Renz, Die vor- und ausserliterarische Texttradition. Ein Beitrag der palästinischen Epigraphik zur Vorgeschichte des Kanons, in: Joachim ScHAPER (Hg.), Die Textualisierung der Religion (FAT 62; Tübingen: Mohr Siebeck, 2009), 53-81, sowie Seth L. SANDERs, The Invention of Hebrew (Urbana-Chicago: University of Illinois Press, 2009).

27 „Ancient Hebrew text production started, as in so many other ancient cultures, in the administrative and economic realms." (Schaper, Literary history, 110)

28 Schmid, Literaturgeschichte, $86 \mathrm{f}$. 
ihre oberflächliche Aussage zu entziffern, sondern sie daraufhin zu lesen, was in ihnen zum Ausdruck kommt. ${ }^{29}$

Mit dieser geschichtlichen Eingrenzung des Beginns der biblischen Texttraditionen wird deutlich, dass es wenig Sinn macht, ein so breit entfaltetes Narrativ wie das der Exodus-Überlieferung mit einem historischen Ereignis in Verbindung zu bringen, das nachträglich in seinen Grundzügen aufgezeichnet und danach bloß redaktionell überarbeitet worden wäre. Es ist vielmehr überhaupt danach zu fragen, wovon das Exodus-Narrativ eigentlich spricht. Die immer wieder gegebenen Hinweise auf ,alte“ Motive, die in diese Überlieferung eingearbeitet wurden, dürfen nicht darüber hinwegtäuschen, dass aus ihnen nicht der Gesamtduktus des in der abendländischen Rezeptionsgeschichte so breit rezipierten Motivs abzuleiten ist. Es wurde bereits betont, dass dies nicht bedeutet, dass dieser Tradition keinerlei geschichtliche Erfahrung zugrunde läge. Doch worin diese besteht, muss eine genauere Lektüre des Textes selbst ergeben.

In diesem Sinn möchte ich eine erste These bzw. eine erste Schlussfolgerung formulieren: Für ein angemessenes Verständnis der politischen Dimension des Exodus-Narrativs ist es von größter Bedeutung, dass es sich nicht auf eine reale Migrationsbewegung von Punkt A nach Punkt B bezieht, also auf keine historische Wanderungsbewegung rückblickt aus einem geographisch zu verortenden Land Ägypten in das Land Kanaan/Israel. Diese Art von „Nicht-Historizität“ des Gründungsnarrativs der biblischen Tradition ist von größter Bedeutung - und zwar nicht in kritischer, sondern in höchst produktiver Hinsicht. Erst jetzt, erst unter der Voraussetzung dieser Art von fiktionaler Erzählung eröffnet sich für den/die LeserIn oder VermittlerIn des Textes die Frage, wovon der Exodus eigentlich spricht. Erst jetzt wird der Text frei vom Balast nachträglich eine mehr oder minder nachvollziehbare Gestalt der Aufzeichnung eines einmaligen historischen Geschehens zu präsentieren. Nun wird die Lektüre vielmehr frei, um nach jenem geschichtlichen Kontext zu fragen, der seiner Entfaltung und Gestaltung zugrunde liegt und den dieser gerade nicht unmittelbar präsentiert, sondern vielmehr auf eine zur aufmerksamen Lektüre auffordernde Weise repräsentiert.

29 Zum Verständnis des Lesens dessen, was in einem Text performativ „zum Ausdruck kommt“ im Kontext der Entstehung von Textualität im Alten Orient siehe: Peter ZEILlinger," “. (52) Leerstellen, die gelesen werden müssen, in: Matthias SchmidT (Hg.), Rücksendungen zu Jacques Derridas „Die Postkarte“. Ein essayistisches Glossar (Wien-Berlin: Turia+Kant, 2015), 13-38, sowie Zeillinger, Offenbarung als Ereignis, aaO. [Anm. 13] . - Für eine Hinführung zu einer Phänomenologie des Lesens im Kontext jener zeitgenössischen Philosophien, die auch für die vorliegende Studie von Interesse sind vgl. Peter Zeillinger, Über das Lesen. Heidegger und die Vermeidung des Aussagesatzes, in: Patrick Baur / Bernd Bösel / Dieter Mersch (Hg.), Die Stile Martin Heideggers (Freiburg/Br.-München: Alber, 2013), 243-264. 
Dieser Zugang zur Textualität und textuellen Autorität eines Textes über den im altorientalischen Kontext bereits bekannten Charakter einer schriftlichen Aufzeichnung hinaus, ist keineswegs eine moderne Attitüde. Wie der Altorientalist und Alttestamentler Eckart Otto an zahlreichen Textbeispielen aufgezeigt hat, war es den LeserInnen und HörerInnen im Alten Israel sehr wohl bewusst, dass die Exoduserzählung (wie auch die gesamte Tora) sie nicht einfach über eine vergangene kollektive und danach verschriftlichte Erfahrung informierte, sondern eine sehr zeitgenössische politische und religiöse Botschaft entfaltete, die auf Israels gegenwärtige und zukünftige Identität zielte.

„Die Autoren der Mosebücher fügen an zahlreichen Stellen Hinweise darauf ein, dass sie in einer späteren als der erzählten Zeit schreiben, was die Erzählung der Mosebücher transparent für die Erzählzeit macht. Dieses literarische Verfahren der Autoren, Hinweise auf ihren Standort jenseits der Mosezeit als erzählter Zeit in den Text einzufügen und so ihre Adressaten auf die hermeneutische Mehrschichtigkeit der Erzählungen hinzuweisen, setzt voraus, dass die Autoren und ihre Adressaten davon ausgingen, dass nicht Mose diese Erzählungen verschriftete, sondern postmosaische Schreiber. [...] Wird nun postkanonisch Mose mit den Autoren der Mosebücher unter Einschluss der Erzählungen der Urgeschichte identifiziert, so geht die von den Autoren der Mosebücher intendierte hermeneutische Mehrdimensionalität der Erzählungen, die zwischen Erzählzeit und erzählter Zeit differenzieren, verloren und eine Fülle von narrativen Inkonsistenzen belastet nun die Lektüre der Mosebücher“30

In seinem Opus magnum hebt Otto diese Hermeneutik der Zeitebenen schließlich sogar als auch gegenwärtig zu beachtenden Lektüreschlüssel der Endgestalt der biblischen Texte hervor:

„Widersprüche und Spannungen im Pentateuch sollten weder synchron fortinterpretiert werden noch der diachronen Analyse nur als Einstieg in die Rekonstruktion von Texten hinter den Texten dienen, sondern als gezielt für den Leser stehen gelassene oder gezielt eingefügte Marker begriffen werden, die den Leser in die Lage versetzen sollen zu erkennen, dass die Erzählungen nicht in der erzählten Zeit allein ihren Horizont haben, sondern eine hermeneutische Strategie der Applikabilität auf die Erzählzeit als die des Lesers verfolgen, also ein tua res agitur zum Ausdruck bringen wollen, wenn sie von der Mosezeit erzählen. "31 (Kursiv i.O.)

Damit wird auf eine gänzlich andere Art erneut der Blick auf die Geschichtlichkeit der biblischen Erzählungen gelenkt. Geschichtlichkeit und geschichtliche Autorität werden in den biblischen Überlieferungen nicht mittels des Charakters

30 Eckart Отто, Das Gesetz des Mose (Darmstadt: WBG, 2007), hier: 99 f. Siehe dazu auch die zahlreichen Textbeispiele in diesem Werk.

31 Eckart Отто, Deuteronomium (4 Bde.; HThK.AT; Freiburg i.Br.: Herder, 20122017), hier: 260 (Kursiv i.O.). 
einer Aufzeichnung geschehener Tatsachen oder tradierter Überzeugungen vermittelt, sondern über eine narrative Darstellung, die in einer erkennbaren Spannung steht zu den gewohnten Erwartungen und der herrschenden symbolischen Ordnung. Diese Spannung wird jedoch von den LeserInnen in ihrer Gegenwart nicht als Manko erlebt, sondern vielmehr als Anspruch, dem es in der eigenen gesellschaftlichen und politischen Realität in irgendeiner Form zu entsprechen gilt. Der Bereich des Religiösen - zumindest soweit es die Autorität der biblischen Texte betrifft - hat hier den üblichen, in den antiken Kulturen letztlich unhinterfragten Charakter von Religion als Legitimierung und Bewahrung der herrschenden Ordnung gewissermaßen in ihr Gegenteil verkehrt. Vor diesem Hintergrund wird es nochmals interessanter danach $\mathrm{zu}$ fragen, worin eigentlich die politische Botschaft der Exodus-Erzählung besteht - und in welchem geschichtlichen Kontext sie diese Botschaft formuliert.

Die Struktur der Exodus-Erzählung lässt diesbezüglich einiges erwarten, denn in ihr geht es offensichtlich nicht nur um einen „Auszug aus ...“ einer Unterdrückungssituation, sondern zugleich um einen „Einzug in ...“ eine verheißene Zukunft. Welche Rolle aber der breit entfaltete dritte Abschnitt dabei spielt, der als „Zwischenzeit“ zwischen dem bereits vollzogenen Auszug und dem noch ausstehenden Einzug gewissermaßen in einem Niemandsland und daher als Wüstenwanderung beschrieben und gestaltet wird, ist noch völlig unbestimmt. Offensichtlich ist aber mit dem gelungenen Auszug das verheißene Ziel noch keineswegs erreicht. Das wurde und wird in der Rezeptionsgeschichte des Exodus oftmals übersehen. Es ist auffällig, dass sich die meisten politischen Bezugnahmen auf das Exodus-Motiv in der Vergangenheit und in der Gegenwart - hier sei nochmals auf Paolo Virno, der sich u. a. auf ein Exodus-Verständnis bei Karl Marx bezieht, auf Chantal Mouffe und Isabell Lorey verwiesen ${ }^{32}$ - vor allem auf den Aspekt des Auszugs beziehen und die daraus entstehende Situation aber weitgehend unbestimmt lassen, so als ob eine berechtigte „Befreiung“ bereits genüge, um ein künftiges Zusammenleben zu sichern und die Wiederkehr der Unterdrückungsmentalität abzuwehren. ${ }^{33}$ Damit sei nochmals betont, dass die sich aufdrängende Aufmerksamkeit auf die Struktur des Exodus-Narrativs letztlich seine Brisanz erst von der Erkenntnis bekommt, dass der Exodus von keiner historischen Migrationsbewegung berichtet und dennoch vor einem konkreten geschichtlichen Hintergrund eine eminent politische Botschaft entfaltet.

\section{S. o. Anm. 9.}

33 In manchen Ansätzen, z. B. bei Hardt und Negri bzw. den Proponenten einer „constituent power“ von unten als Gegenbegriff zur souveränen Macht von oben wird daher alle Hoffnung in eine Art permanentem Exodus oder permanenter Revolution gelegt. Siehe dazu Michael Hardt, Three Keys to Understanding Constituent Power, in: Antonio Negri, Insurgencies. Constituent Power and the Modern State (MinneapolisLondon: Univ. of Minnesota Press, 2009), vi-xii; sowie Andreas Kalyvas, Popular Sovereignty, Democracy, and the Constituent Power, in: Constellations 12 (2005) 2, 223-244. 


\section{Der politische Hintergrund der Exoduserzählung: die altorientalische Königs- und Herrschaftsideologie}

Inwiefern ist es unhintergehbar, die bekannte Exodus-Erzählung als politisches Programm zu lesen, wenn die erzählte Befreiung offensichtlich nicht auf eine reale historische Erfahrung zurückgeht? Der Münchner Alttestamentler und Altorientalist Eckart Otto hat in mehreren Studien die politische Dimension insbesondere der Mose-Figur und ihrer zentralen Stellung in der Tora des Judentums - und damit fast identisch auch für das Christentum sowie motivlich auch für die koranische Botschaft ${ }^{34}$ - aufgezeigt. ${ }^{35}$ Auf sie und den darin verarbeiteten aktuellen Forschungsstand zur altorientalischen Kultur- und Rechtsgeschichte werden sich die folgenden Ausführungen stützen. ${ }^{36}$

Als Ausgangspunkt der politischen Bedeutung der Mose-Exodus-Erzählung erweist sich bereits die Einführung der Mose-Figur ${ }^{37}$ im Rahmen der Geschichte

34 Ich spreche hier bei der islamischen Mose-Rezeption von einer motivlichen Entsprechung (Angelika Neuwirth würde in dem Zusammenhang wohl spezifischer von einem typologischen Aufgreifen sprechen), da die Entstehung der koranischen Botschaft in der altarabischen Kultur zu einer Zeit erfolgte, in der die arabische Schrift noch nicht voll entwickelt war. Aus diesem Grund gab es auch noch keine schriftliche arabische narrative Literatur und somit auch keine arabischen Übersetzungen der biblischen Texte. Dennoch spielen die biblischen Überlieferungen der jüdischen wie christlichen Kultur der Spätantike - der Hebräischen Bibel, der Botschaft der christlichen Evangelien sowie der nach- wie auch außerbiblischen Fortschreibungen im jüdischen Talmud und in der sowohl jüdischen wie christlichen apokryphen Literatur - eine zentrale Rolle in und für die Entfaltung der koranischen Botschaft. Insbesondere die Mose-Figur und das ExodusMotiv werden (unabhängig von konkreten geschichtlichen Bezügen, auf die die spätantike Kultur keinen historisch-reflektierten Zugriff hatte, sondern auf die Erzählungen und ihre Tradierung angewiesen war) aufgegriffen und in die koranische Botschaft integriert. Vgl. dazu Angelika Neuwirth, Der Koran als Text der Spätantike. Ein europäischer Zugang (Berlin: Verlag der Weltreligionen, 2010), bes. 653-671 („Mose - seine koranische Entwicklung"); Dies., Die koranische Verzauberung der Welt und ihre Entzauberung in der Geschichte (Freiburg i.Br.: Herder, 2017), bes. 153-180 („Ein Mosevermächtnis an die koranische Gemeinde: Der Dekalog“); sowie Karl-Josef Kuschel, Die Bibel im Koran. Grundlagen für das interreligiöse Gespräch (Ostfildern: Patmos, 2017), bes. 359-442 (zu Mose und Exodus im Koran).

35 Ein erster Gesamtüberblick findet sich in Otto, Tora des Mose, aaO. [Anm. 10]. 36 Einen hervorragenden und noch dazu äußerst knapp gehaltenen Überblick über das Verhältnis von Religion, Politik, Recht und Gesellschaft in den Kulturen der Antike - in Mesopotamien, Ägypten, Israel und Griechenland - mit dem Fokus auf die Entwicklung von Recht und Ethik in Israel und Griechenland um die Mitte des 1. Jahrtausends v. Chr. bietet Eckart Отто, Law and Ethics, in: Sarah Iles Johnston (Hg.), Ancient Religions (Cambridge-London: Harvard UP, 2007), 84-97.

37 Zum komplexen Faktum, dass die Mosegestalt zum einen den Autoren der Mose- 
seiner Geburt in Ex $2 *:^{38}$ seine Aussetzung im Schilf, seine Auffindung und Adoption durch die Tochter des ägyptischen Pharao und schließlich sein Aufwachsen am Hof. ${ }^{39}$ Die Exegese ist sich heute weitgehend einig, dass dieses historisch recht früh - allerdings nicht vor der Eroberung des Nordreichs Israel durch die Assyrer (722 v. Chr.) - entstandene Detail der Exoduserzählung eine unmittelbare Aufnahme und subversive Unterwanderung der zeitgenössischen neuassyrischen Sargon-Legende darstellte. ${ }^{40}$ Den politischen Kontext der SargonLegende bildete das Grundproblem der Königsnachfolge bei den Sargoniden, die keinen ihrer jeweiligen Erstgeborenen in legitimer Thronfolge auf den Thron brachten und nun mit der Legende, dass selbst Sargon von Akkade (um 2300 v. Chr.), der als das große geschichtliche Vorbild der assyrischen Könige galt, von politisch illegitimer Herkunft gewesen sei. Dennoch wurde er aber von der Göttin Ischtar geliebt und war politisch erfolgreich. ${ }^{41}$ Mit dieser Parallelisierung der Geburtserzählung des Mose mit der neuassyrischen Legende zur Legitimierung der königlichen Herrschaft könnte zunächst der Eindruck entstehen, dass nun im biblischen Narrativ Mose selbst zum König stilisiert und legitimiert werden sollte. Doch genau das Gegenteil ist der Fall, denn an entscheidenden Stellen der MoseErzählung wird diese Parallele unterlaufen: Während Sargon von edler Geburt war-seine Mutter war Prinzessin und Hohepriesterin - ist Mose in der Erzählung von niederer Herkunft. Er stammt von zur damaligen Zeit wenig geachteten und bedürftigen landlosen Leviten ab. Vor allem aber läuft Moses weitere Lebensgeschichte gerade nicht auf den Aufstieg am pharaonischen Hof hinaus. Mose wird kein König. Er wird sich stattdessen sogar vom Pharao lösen und sich mit seinem gesamten Volk erfolgreich dessen Herrschaftsbereich entziehen. ${ }^{42}$

Erzählung bereits vorgelegen war, diese aber zugleich in einen völlig neuen Kontext gestellt wurde, vgl. Otto, Tora des Mose, aaO. [Anm. 10], 32, Anm. 85.

38 Eckart Отто, Die Geburt des Mose. Die Mose-Figur als Gegenentwurf zur neuassyrischen Königsideologie im 7. Jh. v. Chr. (2000), in: Ders, Die Tora. Studien zum Pentateuch (BZAR 9; Wiesbaden: Harrassowitz, 2009), 9-45.

39 Bisher vertretene Theorien des Vergleichs der Geburtserzählung mit der ägyptischen Erzählung der Geburt des Horus oder der von Herodot berichteten Erzählung von der Geburt des Perserkönigs Kyrus scheitern zum einen an fehlenden Parallelen im Detail, sowie - bei der ägyptischen Erzählung - daran, dass diese zur fraglichen Zeit noch gar nicht existierte. Siehe dazu Otto, Tora des Mose, aaO. [Anm. 37], 15 Anm. 35.

40 Otto, Tora des Mose, aaO. [Anm. 37], 11-17.

41 Otto, Tora des Mose, aaO. [Anm. 37], 14. Siehe dort auch die Auflistung der auffälligen Gemeinsamkeiten der beiden Erzählungen. Vgl. dazu auch Otto, Gesetz des Mose, aaO. [Anm. 30], bes. 182-187 („Die Mose-Exodus-Erzählung und der historische Mose").

42 Otto, Tora des Mose, aaO. [Anm. 10], 16; zu den subversiven politischen Konsequenzen siehe auch ebd. 31 f. Vgl. auch Otto, Gesetz des Mose, aaO. [Anm. 30], 185; sowie zusammenfassend mit einigen weiterführenden Anmerkungen zur jeweiligen literarischen Gestalt der Sargon- und der Mose-Erzählung, ihrer intertextuellen Bezüge 
Repräsentation einer Leerstelle, oder: Auszug ins Reale

Letztlich geht es hier aber nicht bloß um eine literarische Auseinandersetzung mit der Erzähltradition einer anderen Kultur. Im Zentrum steht vielmehr der Bezug auf die Thematik der altorientalischen Herrschaftslegitimation selbst. Dieses politische Motiv wird auch die gesamte weitere Entwicklung des ExodusNarrativs hindurch aufrechterhalten und mit Blick auf eine grundlegende Neufundierung entfaltet. ${ }^{43}$ Diese Thematik stellte im Alten Orient keineswegs ein nebensächliches oder bloß abstrakt-theoretisches Motiv dar. Die Frage der Herrscherlegitimation war so zentral für die Aufrechterhaltung des Selbstverständnisses von Politik und Gesellschaft, dass sie den Kern nicht nur der Schöpfungsmythen bildete, sondern auch zum Zentrum einer regelmäßigen Aktualisierung der politischen Repräsentation dieser Ordnung in Gestalt eines religiösen Rituals wurde. Stefan Maul hat dieses Ritual der aktualisierenden Erinnerung des kosmischen Chaoskampfs, von dem die mesopotamischen Schöpfungsmythen berichten, gemeinsam mit seinen realen politischen Konsequenzen zusammengefasst: ${ }^{44}$ Im gesamten Alten Orient war das gesellschaftliche und politische Selbstverständnis nicht an einer heilvollen Zukunft ausgerichtet, sondern an der Wiederherstellung der Verhältnisse aus ,den Tagen der Ewigkeit “45. Legitimation und Stabilität wurden daher durch Rückgriff auf eine als ursprünglich vorgestellte Ordnung erreicht. Im babylonischen Weltschöpfungsepos Enuma elisch ${ }^{46}$ findet sich nun mit der Beschreibung der Überwindung der Kräfte des (bewegungslosen) Chaos zugleich auch die Etablierung und Übertragung eines Königtums. Marduk,

und der daraus sich ergebenden Konsequenzen für eine angemessene Lektüre: Klaus Bieberstein, Sargon und Mose im Binsenkörbchen. Geschichten schreiben und lesen, in: Konstantin Lindner / Andrea Kabus / Ralph Bergold / Harald Schwillus (Hg.), Erinnern und Erzählen. Theologische, geistes-, human- und kulturwissenschaftliche Perspektiven (Münster: Lit, 2013), 125-136.

43 Ich vermeide es, an dieser Stelle von einer „religiösen“ Entfaltung zu sprechen, da sich in weiterer Folge zeigen wird, dass gerade das im Alten Orient und in der gesamten Antike vorausgesetzte Religionsverständnis mit Hilfe des Exodus-Narrativs selbst unterwandert wird. Wenn im antiken polytheistischen Kontext die Götter und damit die Religion „the function of maintaining the world order" (Otto, Law and Ethics, 85), also eine herrschaftsstabilisierende politische Position innehaben und ebendieses Religionsverständnis nun aber grundsätzlich verworfen - und nicht bloß durch eine bloße Alternative ersetzt - wird, dann besteht das gleichermaßen politische wie „religiöse“ Resultat einer solchen Veränderung darin, dass das bisherige Verständnis von Religion und religiöser Funktion preisgegeben werden muss. Was schließlich an die Stelle der bisherigen Position von "Religion“ tritt und auf welche Weise in weiterer Folge der Bereich des Politischen „legitimiert“ wird, wird zu zeigen sein.

44 Stefan M. Maul, Altorientalische Schöpfungsmythen, in: Reinhard BRAndt / Steffen Schmidt (Hg.), Mythos und Mythologie (Berlin: Akademie, 2004), 43-54.

45 Maul, Schöpfungsmythen, 44.

46 Wilfred G. Lambert, Enuma Elisch, in: Otto Kaiser u.a. (Hg.), TUAT III, Lfg. 4 (1994), 565-604. 
der das Chaos in Gestalt der großen Urmutter Tiamat besiegen konnte, erschafft aus ihr den Himmel und die Erde und beginnt damit jene Ordnung herzustellen, die für den antiken Menschen erfahrbar war.

„Er [Marduk; PZ] erschafft Gestirne, Flüsse und Berge und erwählt inmitten der Erde Babylon zu seinem Wohnort. Dort wird nach seiner Weisung der Mensch erschaffen, um die anderen Göttern von ihren Arbeiten zu entlasten. Diese nun erkennen Marduk auf ewig als ihren König an und errichten ihm zum Dank seinen Wohnsitz, den MardukTempel Esagil und die Stadt Babylon, die als wahre Heimstatt aller Götter gilt.“" ${ }^{47}$

Dass es in diesem Mythos nicht bloß um eine Ursprungslegende ging, wird in den öffentlichen Ritualen des jährlichen Neujahrsfestes erkennbar, in denen der Kampf des Marduk gegen die Kräfte des Chaos nachgelebt wurde. Dazu „reisten“ die Kultbilder aller Götter in feierlichen Prozessionen aus verschiedenen Städten Babyloniens an. ${ }^{48}$ Auf diese Weise wurde die Anerkennung des siegreichen Marduk durch alle anderen Götter und die Übertragung des Königtums auf ihn nachgestellt. An dieser Zeremonie hatte nun aber auch der babylonische König maßgeblich teil. Die Errichtung eines Götter-Königtums in der mythischen Erzählung stellte also keineswegs bloß eine literarisch-poetische Vorstellung dar, sondern formulierte eine Überzeugung und ein Weltbild, das zugleich die reale politische und gesellschaftliche Situation nicht bloß prägte, sondern auch unmittelbar und für jeden sichtbar legitimierte. Die legitimierende Kraft bestand dabei darin, dass sich die gegenwärtige Königsherrschaft aus der mythischen Vergangenheit abzuleiten vermochte.

„So wie im Mythos Marduk zum Götterkönig erhoben wurde und das Schicksal der Welt bestimmte, indem er die Schöpfung einrichtete, so wurde im Neujahrsfest der amtierende König von Marduk und den Göttern in seinem Amt bestätigt und sein Schicksal für das kommende Jahr bestimmt." ${ }^{49}$

Diese Legitimationsstrategie galt jedoch nicht bloß in der babylonischen Kultur, sondern findet sich strukturell in allen Kulturen des Alten Orients. Ein entscheidendes Detail dieser Struktur ist dabei die prinzipielle Differenz zwischen der einen Person des Königs und den vielen Menschen, die in seinem Einflussbereich leben. Eckart Otto ruft diesbezüglich den assyrischen Mythos über die Erschaffung des Menschen und des Königs ${ }^{50}$ aus der ersten Hälfte des 1. Jahr-

\footnotetext{
47 Maul, Schöpfungsmythen, 46.

48 Maul, Schöpfungsmythen, 48.

49 Maul, Schöpfungsmythen, 48.

50 W. R. MAYER, Ein Mythos von der Erschaffung des Menschen und des Königs, in: Orientalia 56 (1987), 55-68; vgl. dazu auch: dazu H.-P. MüLLER, Eine neue babylonische Menschenschöpfungserzählung im Licht keilschriftlicher und biblischer Parallelen. Zur
} 
tausends v. Chr. in Erinnerung, also jener Zeit, in die auch der Beginn der Entfaltung der Mose- und Exodus-Erzählungen fällt. Dieser Mythos ...

„[...] makes a distinction between the creation of human beings, who are supposed to relieve gods of the toil of cultivating the land, and the creation of the king as a „human being who by virtue of his superiority makes decision". To the king is granted rule over people and the power to wage war following the gods' instructions. “51

In einem solchen Weltbild wird es verständlich, dass der Einzelne nur dann ein erfülltes Leben leben kann, wenn er seinen Platz in dieser Herrschaftsordnung findet:

„In this system, a person could lead a successful life only by following Marduk, god of the empire, who conquered chaos and was represented on earth by the king of Babylon. For a fulfilled life, it was therefore necessary to obey the laws of the Babylonian state or, in the Assyrian version, to obey the laws of the Assyrian ruler, who represented the god of that empire, Assur. “52

Geordnete gesellschaftliche Verhältnisse und die Möglichkeit, ein gutes Leben zu führen, konnten somit nur von einer starken und mächtigen Herrschaft gesichert werden. Sie waren das Resultat der politischen, wirtschaftlichen und militärischen Erfolge des jeweiligen Königs, der im Sinne dieser Königsideologie seine Erfolge aber auch nur deshalb erfahren konnte, weil er stets im Sinn und im Namen des Reichsgottes gehandelt hatte. ${ }^{53}$ Im Falle einer Unterwerfung fremder Völker lag

Wirklichkeitsauffassung im Mythos, in: Orientalia 58 (1989) 69-85. - Vgl. dazu auch Otto, Tora des Mose, aaO. [Anm. 10], 28 (mit Übersetzung).

51 Otto, Law and Ethics, 87. - Zur besonderen Stellung des Königs im mesopotamischen Weltbild anhand des zum Modell für das antike Königsverständnis gewordenen assyrischen Königs siehe Stefan M. Maul, Der assyrische König - Hüter der Weltordnung, in: Jan Assmann / Bernd JAnOwski / Michael Welker (Hg.), Gerechtigkeit. Richten und Retten in der abendländischen Tradition und ihren altorientalischen Ursprüngen (München: Fink, 1998), 65-78, zum Mythos der Erschaffung des Königs: ebd. $71 \mathrm{f}$.

52 Otto, Law and Ethics, 87.

53 Das politische Scheitern eines Königs stellte zwar naturgemäß auch für die gesamte Bevölkerung eine leidvolle Erfahrung dar, brachte aber dieses Legitimitationssystem nicht grundsätzlich ins Wanken. Das Scheitern konnte als Fehlleistung des Königs in Bezug auf den göttlichen Auftrag interpretiert und zugleich die Wirksamkeit des siegreichen Herrschers und seiner Beziehung zu den Göttern anerkannt werden. Auf diese Weise stellte auch der Wechsel von Reichsgottheiten im Normalfall kein prinzipielles Problem für das antike Weltbild dar. - Siehe dazu nochmals das ähnlich gelagerte „Funktionieren“ der altorientalischen Praktiken der Divination in: Maul, Wahrsagekunst, aaO. [Anm. 19]. 
es daher allein an ihm - als Repräsentanten des Reichsgottes - zu entscheiden, was mit den Besiegten geschehen solle. Der König ist im Alten Orient derjenige, der den Menschen das Land zuteilt. Von diesen altorientalischen Königsideologien her gibt es keine Ethik jenseits des Kriteriums von Erfolg und Aufrechterhaltung der sozialen Ordnung. Der Wertekanon, der vom dritten bis zum ersten Jahrtausend im Alten Orient stabil blieb, war dementsprechend konservativ-bewahrend.

„Thus, the good [-] as that which is just [-] is what has always been realized in human action, not an „ought“ or obligation, separated from what is, but rather the realized ethical substance of society since time immemorial. [...] The values intended to guide moral action [...] are correspondingly traditional. They demand [...] the values of an average bourgeois morality in the modern sense. ${ }^{654}$

Es ist notwendig, diese politischen und gesellschaftlichen Konsequenzen der altorientalischen Königsideologie in Erinnerung zu rufen, da sie vom biblischen Exodus-Narrativ, auf das nun zurückzukommen ist, gerade am Punkt ihrer Begründung verworfen werden. Das Exodus-Narrativ stellt in diesem Sinn sogar eine ausdrückliche Gegen-Erzählung ${ }^{55}$ dar zum mythischen Entwurf der Stabilisierung des sozialen und politischen Zusammenhalts. Die biblische Erfindung im oben bereits genannten Verständnis ${ }^{56}$-, das heißt der spezifisch biblische Zugang zum Feld des Politischen und Sozialen, den es nun zu entfalten gilt, markiert einen entscheidenden und im antiken Kontext bislang undenkbaren Wandel im Verständnis politischer Legitimation und politischen Handelns. ${ }^{57}$ Die altorientalische Königsideologie lief letztlich auf die Anerkennung der faktisch und unhinterfragbar herrschenden politischen Macht hinaus. ${ }^{58}$ Der König war unmittelbarer Repräsentant des Reichsgottes. ${ }^{59}$ Aufgrund dieser Unmittelbarkeit

54 Otto, Law and Ethics, 86.

55 Vgl. Otto, Tora des Mose, aaO. [Anm. 10], 31: „Im Streit um die Überlieferungen werden der assyrischen Macht zentrale Texte ihrer Legitimität genommen und zu Gegentexten umfunktioniert."

56 S. o. Anm. 13.

57 Siehe dazu aus einem anderen Blickwinkel: Eckart Oтто, Staat-Gemeinde-Sekte. Soziallehren des antiken Judentums, in: Zeitschrift für altorientalische und biblische Rechtsgeschichte 12 (2006), 312-343.

58 Otto, Tora des Mose, aaO. [Anm. 10], 27: „Der König als Verkörperung des göttlichen Auftrags, das Chaos in der Welt zurückzudrängen und in die Schranken zu weisen, war um jeden Preis vor Rebellion und Aufstand als Ausdruck schöpfungswidrigen Chaos zu schützen.“ Vgl. zur „herausragenden“ Rolle des Königs auch ebd. 24 f, sowie: Karen RADNER, Assyrian and Non-Assyrian Kingship in the First Millenium BC, in: Giovanni B. LANFranchi / Robert Rollinger (Hg.), Concepts of Kingship in Antiquity (Winona Lake, IN: Eisenbrauns, 2010), 25-34.

59 Vgl. dazu den neuassyrischen Krönungshymnus Assurbanipals (686-626 v. Chr.), 
war in diesem Weltbild die Struktur des Ausschlusses, die Inkompatibilität mit allem Fremden und Neuen, mit jeder Form von prinzipieller Veränderung, letztlich unvermeidbar. Die autoritativen Entscheidungen der herrschenden Macht etablierten von sich aus eine gesellschaftliche, politische und juridische Trennung in jenem Sinn, den Carl Schmitt als Freund-Feind-Unterscheidung bezeichnet hat und der von Giorgio Agamben in seinen Homo-sacer-Studien als Struktur der Souveränität ausführlich beschrieben wurde. ${ }^{60}$ Diese Struktur der Souveränität - wie überhaupt das abendländische Verständnis von souveräner Herrschaft - hat in den Herrschaftslegitimationen des Alten Orients, ${ }^{61}$ insbesondere in der neuassyrischen Königsideologie des 7. Jh. v. Chr. ihre geschichtlichen Wurzeln. Dieses Modell war in der gesamten Antike als Vorbild bekannt und prägt so das Verständnis des Begriffs „Herrschaft“ bis heute. Über die Vermittlung der Perser und Makedonier konnte es so auch in die Politik des Römischen Reiches einfließen. Die mittelalterlichen Entfaltungen souveräner Herrschaft und die neuzeitlichen Versuche politischer Theorien, die monarchischen

der zum Vor- bzw. Gegenbild für eine subversive Rezeption der assyrischen Politischen Theologie in Juda wurde: Otto, Tora des Mose, aaO. [Anm. 10], 22ff (mit Übersetzung). Zur gesamten Auseinandersetzung siehe Eckart Отто, Political Theology in Judah and Assyria. The Beginning of the Hebrew Bible as Literature, in: Svensk Exegetisk Arsbok (SEA), 65 (2000), 59-76; Eckart Отто: Politische Theologie in den Königspsalmen zwischen Ägypten und Assyrien. Herrscherlegitimation in den Psalmen 2 und 18 in ihren altorientalischen Kontexten, in: Eckart Otтo / Erich Zenger (Hg.), , Mein Sohn bist du“ (Ps 2,7). Studien zu den Königspsalmen (SBS 192; Stuttgart: Katholisches Bibelwerk, 2002), 33-65. - Deutliche und affirmative Worte der Differenz zwischen altorientalischer Herrschaftslegitimation und der Politischen Theologie des biblischen Monotheismus finden sich auch bei Jan Assmann, der damit seine Kritik am Monotheismus (zumindest in der geschichtlichen Gestalt der Entstehung der biblischen Botschaft) deutlich korrigiert. Assmann sieht den fruchtbaren politischen Aspekt vor allem im Idolatrieverbot des biblischen Bilderverbots begründet: „Der Gott Israels [...] lässt sich nicht repräsentieren. Jede Repräsentation wird als Idolatrie verboten. Das Idolatrieverbot richtet sich gegen alles, was den Anspruch erhebt, Gott zu repräsentieren. Auch der Sinn des Bilderverbots ist daher im Kern politisch." in: Jan Assmann, Monotheismus als Politische Theologie, in: Jürgen Brokoff / Jürgen Fohrmann (Hg.), Politische Theologie. Formen und Funktionen im 20. Jahrhundert (Paderborn-München-Wien-Zürich: Schöningh, 2003), 13-27, hier: 25 (mit ausdrücklichem Verweis auf den Kontext der Neuen Politischen Theologie von Johann Baptist Metz).

60 Giorgio Agamben, Homo sacer. Die souveräne Macht und das nackte Leben (Frankfurt/M.: Suhrkamp, 2002 [ital. 1995]).

$61 \mathrm{Zu}$ ihren frühesten Entfaltungen siehe Gebhard J. SELz, Über mesopotamische Herrschaftskonzepte. $\mathrm{Zu}$ den Ursprüngen mesopotamischer Herrscherideologie im 3. Jahrtausend, in: Manfried Dietrich / Oswald Loretz (Hg.), dubsar anta-men. Studien zur Altorientalistik (Münster: Ugarit-Verlag, 1998), 281-344. 
Vorstellungen zu überwinden, arbeiten sich - zumeist ohne sich dessen bewusst zu sein - daher immer noch an diesem altorientalischen Modell ab. ${ }^{62}$

An eben diesem Punkt wird das biblische Exodus-Narrativ jedoch mit dem im Alten Orient scheinbar unhinterfragbaren Verständnis von Souveränität bzw. königlich-göttlicher Letztinstanz brechen und in der Auseinandersetzung mit ihrer neuassyrischen, neubabylonischen und persischen politischen Gestalt ${ }^{63}$ nicht bloß einen Auszug aus der bestehenden politischen Ordnung vollziehen, sondern zugleich auch den Einzug in eine andere Art des Denkens des Politischen. Auf diese Weise wird auch eine andere Art kollektiver Identität etabliert einer „Identität“, die sich nicht aus der Dichotomie von Inklusion und Exklusion heraus entfaltet. Identität wird im Rahmen der sich nun etablierenden monotheistischen Struktur ${ }^{64}$ nicht von einem Gegenüber im Sinn einer identifizierba-

62 Simo Parpola hat die Modellhaftigkeit der neuassyrischen Königsideologie für die Antike herausgearbeitet: Simo PARPOLA, Neo-Assyrian Concepts of Kingship and Their Heritage in Mediterranean Antiquity, in: Giovanni B. LANFRANCHI / Robert Rollinger (Hg.), Concepts of Kingship in Antiquity (Winona Lake, IN: Eisenbrauns, 2010), 35-44: „Contemporaries did not make a big distinction between the Assyrian Empire and its successors. In their eyes, the „monarchy“ or „universal hegemony“ first held by the Assyrians had simply passed to or been usurped by other nations. We know for certain that the Neo-Babylonian and Persian kings, and no doubt the Median ones as well, saw themselves as successors of the Assyrian kings. Nabonidus and Cyrus refer to them as their „royal predecessors“, while Greek and Jewish sources refer to several Neo-Babylonian, Persian and Seleucid kings as „kings of Assyria“. The Neo-Babylonian, Median and Persian kings not only considered themselves successors of the Assyrian kings; they also adopted the Assyrian kingship in essentially unchanged form. [...] It is of course well known that the Achaemenid model of kingship and administrative methods were perpetuated virtually unchanged by the Macedonian rulers of Mesopotamia, and that the Macedonian system was in its turn taken over by imperial Rome." (ebd. $39 \mathrm{f}$ )

63 Schmid, Literaturgeschichte, aaO. [Anm. 10], 88: „Vor allem aber zeigt der neuassyrische Überlieferungshintergrund die [...] kritische, antiassyrische Ausrichtung der Mose-Exodus-Erzählung: An die Stelle des assyrischen Großkönigs tritt die nichtkönigliche Gestalt Mose als Objekt göttlicher Erwählung, die Israel von der imperialen Fron befreit."

64 Mit dem Begriff einer „monotheistischen Struktur“ wird hier nicht auf theologische Inhalte des sich erst entfaltenden monotheistischen Gottesverständnisses angespielt, sondern auf jene Struktur, die in weiterer Folge insbesondere den Text-Traditionen von Judentum, Christentum und Islam zugrundeliegt und diese - ungeachtet der Formen, in denen sich die geschichtliche Entfaltung dieser Religionen vollzogen hat - bis heute prägt. Diese Struktur lässt sich fürs erste durch die beiden Aspekte der „Abwesenheit einer identifizierbaren souveränen Letztinstanz“ einerseits und der „Hervorhebung textueller Autorität“ andererseits beschreiben. Mit „Textualität“ ist hier - ganz im Sinne des Verständnisses bei Jacques Derrida - erneut keine Eindeutigkeit der Bedeutung von Texten verbunden, sondern vielmehr die Notwendigkeit, dem Text mit dem Wagnis einer 
ren (und damit ausgrenzbaren) Gruppe abgesetzt. Im Kontext der Exodus-Erzählung oszilliert die Identität Israels vielmehr auf mannigfaltige Weise zwischen einem Innen und einem Außen, zwischen einem Sowohl-Als auch und einem Weder-Noch. Dies wird bereits im Gründungsnarrativ der Exoduserzählung an der symbolträchtigen Verortung der Entstehung der Identität Israels im Niemandsland einer Wüste erkennbar. ${ }^{65}$

„Wie ist die Mose-Exodus-Erzählung literaturgeschichtlich zu charakterisieren? Die elementarsten Hinweise ergeben sich zunächst dadurch, dass sie eine allochthone Begründung der Existenz Israels formuliert - Israel ist Israel von Ägypten her und wurzelt nicht seit jeher in Palästina. “66

deutenden Lektüre zu entsprechen (siehe dazu das Motto dieser Studie) Gerade dort, wo die geschichtliche Entfaltung dieser Traditionen in den monotheistischen Religionen immer wieder einen Rückfall aus dieser monotheistischen Struktur erkennen lässt, war und ist es aber stets möglich mit Rückgriff auf die Text-Traditionen den entstandenen performativen Widerspruch aus ihnen selbst heraus kritisch aufzuzeigen. Zur näheren Ausführung dazu siehe: Peter Zeillinger, Dekonstruktive Bibellektüre. Aufmerksamkeiten für die Textualität monotheistischer Schriften, in: Ursula Roth / Jörg SEIP (Hg.), Schriftinszenierungen. Bibelhermeneutische und texttheoretische Zugänge zur Predigt (Ökumenische Studien zur Predigt 10; München: Don Bosco, 2016), 143-164; Peter Zeillinger: Geschichtliche Erinnerung und textuelle Autorität. Beantwortung der Frage „Was ist gute Theologie?“, in: Martin Kirschner (Hg.), Dialog und Konflikt. Erkundungen zu Orten theologischer Erkenntnis (Stuttgart: Grünewald, 2017), 149-173.

65 Zur spezifischen Bedeutung des Wüsten-Motivs im Rahmen der Exoduserzählung siehe: Christoph Dohmen, Exodus 1-18 (HThK.AT; Freiburg i.Br.: Herder, 2015), 145 f (Exkurs „Wüste“): „In diesem Sinne erhält die Wüste im Horizont der Erzählung von Israels Wüstenwanderung auf dem Weg zum Verheißenen Land schließlich eine RaumZeit-Signatur als Übergang im Sinn einer prägenden Zeit. [...] Die Extraterritorialität, auf der nach J. Assmann die Ursprungsbilder Israels beruhen, stehen in engem Zusammenhang mit dem „Ort“ der „Wüste“.“(ebd. 146)

66 Schmid, Literaturgeschichte, aaO. [Anm. 10], 89. - Es wird stets leicht sein, diese Aussage angesichts der herrschenden Spannungen um den zeitgenössischen Staat Israel als anti-israelischen Gestus misszuverstehen. Doch wenn man sich in Erinnerung ruft, dass es - wie bereits ausgeführt - keinen Sinn macht, das Exodus-Narrativ auf eine historische Migrationsbewegung zurückzuführen, wird erkennbar, dass das biblische Motiv einer allochthonen Verortung der „Identität Israels“ in einem viel grundsätzlicheren Sinn politisch ist als die gegenwärtigen Debatten. Der politische Entwurf des biblischen Narrativs kreist unverkennbar um die Frage der Bestimmung kollektiver Identität durch die Beziehung zu demjenigen, was sich in keinem Identitätsverständnis unmittelbar oder mittelbar „,präsentieren“ lässt. 


\section{Was genau wurde im Exodus-Narrativ ,erfunden ${ }^{667}$ ?}

Für eine strukturelle Beschreibung der an dieser Stelle in seinen Grundzügen als bekannt vorausgesetzten Exoduserzählung sind im Kontext dieser Studie vor allem zwei zentrale Themen hervorzuheben: Zum einen die Frage, in welcher Form mit der in der altorientalischen Herrschaftslegitimation wirksamen Gestalt der königlichen Repräsentation einer (mythisch begründeten) souveränen Letztinstanz gebrochen wird; und zum anderen gilt es zu fragen, wodurch die offensichtliche Wirkmächtigkeit dieser königlichen Repräsentation ersetzt wird. Erst die Beantwortung dieser zweiten Frage lässt entscheiden, inwiefern das biblische Exodus-Narrativ tatsächlich einen seinerseits politisch und juridisch wirksamen Bruch mit der Vorstellung souveräner Repräsentation darstellt.

\section{a) Die leere Stelle der Souveränität}

1. Mit der literarischen Konstruktion des Exodus-Narrativs und ihrer innerbiblischen Fortschreibung wurde das mythische Verständnis von Souveränität und politischer Macht (Herrschaft) einer radikalen Transformation unterworfen. Im biblischen Zugang zum Bereich des Politischen ist es nicht mehr die konkrete Instanz eines Königs oder einer anderen sichtbaren Instituierung der Macht, der die Position einer politischen oder juridischen Letztinstanz zukommt. Im Gegenteil werden die Institutionen einer (weltlichen) politischen Macht, Gesetzgebung und letztgültigen Rechtsprechung vom Bereich der Souveränität getrennt. Sie werden nun ihrerseits unter ein Kriterium gestellt, das sie nicht selbst begründet haben und daher auch nicht einfach negieren oder in ihrem eigenen Sinn verändern können.

Dass es dabei auch nicht um die Präsentation einer Art Naturrecht gehen wird, ergibt sich zum einen schon aus dem prozessualen Gehalt des Narrativs, das offensichtlich einem innerweltlichen Geschehen nachempfunden ist (und so auch das oberflächliche Verständnis des Bezugs auf ein historisches Befreiungsge-

67 Ganz im Sinne des bereits erwähnten und hier näher zu entfaltenden Verständnisses von inventio als „Intervention in der herrschenden Ordnung“ (s.o. Anm. 13) liest die jüdische Literaturwissenschaftlerin Regina M. Schwartz das Exodus-Narrativ, das sie auch als „Sinai-Ereignis“ bezeichnet, sehr konsequent mit Alain Badious Verständnis der „Treue zu einem Ereignis“ und Emmanuel Levinas' Lektüren zum revolutionären Aspekt des biblischen „Gesetzes“ zusammen. Siehe dazu Regina M. SchwARTz, Revelation and Revolution. Law, Justice, and Politics in the Hebrew Bible, in: Roberta Sterman Sabbath (Hg.), Sacred Tropes. Tanakh, New Testament, and Qur'an as Literature and Culture (Biblical Interpretation Series 98; Leiden-Boston: Brill, 2009), 485-792. Zum Kontext der Begrifflichkeit bei diesen Autoren siehe: Zeillinger, Offenbarung als Ereignis, aaO. [Anm. 13]. 
schehen begünstigt hat) und zum anderen aus dem in einem ganz anderen Sinn geschichtlichen Bezug zur altorientalischen Königsideologie, zu der das Narrativ einen Gegenentwurf formuliert. Jedenfalls wird in der biblischen Erzählung (die schließlich zu einem Gründungsnarrativ nicht nur des Selbstverständnisses und der Identität des Alten Israel sondern auch der sich darauf beziehenden monotheistischen Traditionen des späteren Judentums, Christentums wie auch des Islam ${ }^{68}$ und der mit ihnen verbundenen kulturellen Konkretisierungen geworden ist) die Instanz der Souveränität von der Position der politischen Macht und der juridischen Entscheidung abgezogen.$^{69}$ Der Text legitimiert keine innerweltliche Instanz souveräner Autorität.

Das Exodus-Narrativ verwirft damit allerdings keineswegs jeglichen Bezug auf eine legitimierende Souveränität. Doch Souveränität wird nun als Instanz verstanden, die als solche nicht unmittelbar identifiziert werden kann und daher weder präsentierbar noch re-präsentierbar ist. Dabei ist es allerdings entscheidend zu erkennen, inwiefern die monotheistische Struktur ${ }^{70}$ der biblischen Traditionen nicht bloß jegliche Form einer unmittelbaren Präsentation von Souveränität verwirft, sondern ebenso die Möglichkeit ihrer Re-präsentation, wenn mit der Identifizierung des Repräsentanten erneut die Vorstellung einer Art Sicherheit verknüpft wird, das Abwesende (das Repräsentierte) im Repräsentierenden selbst gewissermaßen , verortet" zu haben. ${ }^{71}$ Eine so verstandene Funktion der

68 Zur differenzierten, gleichwohl unhintergehbaren Bezugnahme der koranischen Botschaft auf die Exodus-Überlieferung siehe oben die Hinweise in Anm. 34.

69 Dass dieses entscheidende Faktum in den verschiedenen kulturellen und politischen Konkretisierungen, die sich auf die hier erörterten monotheistischen Traditionen beziehen, nicht immer erkennbar war und ist, ist das Drama der kritisch zu hinterfragenden Rezeptionsgeschichte des Exodus-Narrativs. Doch diese nach-kanonische Rezeption nimmt der Entfaltung des Narrativs in seinem ursprünglichen historischen Kontext und seiner weiteren innerbiblischen Fortschreibung, die überhaupt erst zu seiner Kanonisierung führte, nichts an ihrer politischen Kraft und Brisanz. In kritischer Weise lässt sich das geschichtlich kontextualisierte Narrativ vielmehr als entscheidender Ausgangs- und Bezugspunkt für jede inner- oder außer-religiöse Hinterfragung der weltlichen Identifizierung ,souveräner“ Instanzen des Politischen verstehen. - Michel Foucault hat in seinem berühmten Vortrag „Was ist Kritik?“ das Potential philosophischer Kritik in einer ebensolchen Struktur der biblischen Text-Traditionen grundgelegt gesehen: Michel Foucault, Was ist Kritik? [27. Mai 1978] (Berlin: Merve, 1992). Vgl. zu einer textnahen Rekonstruktion von Foucaults Bezugnahmen auf souveränitätskritische frühchristliche Gemeinschaftspraktiken: Peter Zeillinger, Das christliche „Pastorat“. Elemente einer Relecture der politischen Kultur des Abendlandes im Spätwerk Michel Foucaults, in: Geist und Leben, 86 (2013) 4, 351-373.

70 S. o. Anm. 64.

71 Dies ist eines der großen Probleme der späteren Entfaltung christlicher Theologie insbesondere in der römisch-katholischen Tradition. Das dortige, sachlich berechtigte Hervorheben und Festhalten einer sakramentalen Präsenz und ihrer theologischen 
Repräsentation hatte vielmehr bereits der altorientalische König innegehabt. Gerade sie ist es aber, der die Kritik der Mose-Exodus-Erzählung gilt. Auf diese Art des Repräsentationsverständnisses treffen letztlich auch die zeitgenössischen Analysen der einleitend zitierten „Krise der Repräsentation“ zu. Es wird im Folgenden also darum gehen müssen zu verstehen, ob und inwiefern im ExodusNarrativ nicht nur eine Kritik der (identifizierbaren) weltlichen Repräsentation einer souveränen Letztinstanz in Gestalt einer politischen und juridischen Autorität formuliert wird, sondern zugleich ein davon deutlich zu unterscheidendes positives Verständnis einer wirksamen (politischen und juridischen) Gestaltung des Zusammenlebens.

Mit der biblisch-monotheistischen Betonung der Nicht-Identifizierbarkeit und Nicht-Darstellbarkeit eines keineswegs geleugneten oder verworfenen Bezugs auf Souveränität ist der symbolische Ort dieser Souveränität aber jedenfalls leer, zu einer leeren Stelle geworden. Das biblische und auch koranische Bilderverbot ist dafür ein durchaus angemessener symbolischer Ausdruck. Es meint allerdings im Kern nicht einfach die Kritik dessen, was man im Englischen als picture im Sinne der materiellen Gestalt eines Bildes bezeichnet, sondern vielmehr die Kritik der Identifizierung eines image, also jeglichen Versuchs einer imaginären Vorstellung. ${ }^{72}$ Die vorliegende Studie ist damit an jenem Punkt angelangt, der in

Entfaltung wird aber erst dann mit der biblischen Überlieferung vereinbar, wenn das Wissen darum, dass alles theologische Sprechen den Charakter eines gewagten Bekenntnisses und einer gelebten Haltung besitzt, weder mehr oder minder strategisch verschwiegen noch in den jeweiligen theologischen Ausdrucksgestalten vergessen oder verdrängt wird. In einem berühmt gewordenen Vortrag hat Karl Rahner dieses Problem kurz vor seinem Tod unter Rückgriff auf die mittelalterliche Lehre von der analogia entis angesprochen: „Aber man müsste eben doch in der Theologie deutlicher merken, dass man bei den einzelnen Aussagen nicht immer wieder vergessen hat, was man irgendwo allgemein und abstrakt behauptet von der Analogheit aller theologischen Begriffe.“ (Karl Rahner, Von der Unbegreiflichkeit Gottes. Erfahrungen eines katholischen Theo-

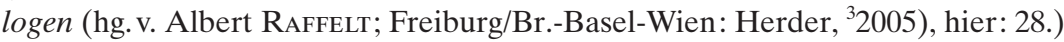

72 Siehe dazu nochmals J. Assmann, Monotheismus als Politische Theologie, aaO. [Anm. 59], 25. - Allerdings ist auch diese Differenzierung zwischen picture und image möglicherweise missverständlich: Das Problem des biblischen Bilderverbots ist weder die „Materialität“ des Bildes bzw. der Skulptur als solche noch die künstlerische Imagination im engeren Sinn. Christoph Dohmen betont daher ausdrücklich, dass das Bilderverbot kein „Kunstverbot“ darstellt (Christoph DoHmEn, Exodus 19-40 (HThK.AT; Freiburg i.Br.: Herder, 2004), 107; vgl. auch Christoph Dohmen, Das Bilderverbot. Seine Entstehung und seine Entwicklung im Alten Testament (BBB 62; Königstein/Ts.-Bonn: P. Hanstein Verlag, 1985), 277. Das Problem des biblischen Verbots liegt vielmehr im altorientalischen Verständnis von Kultbildern, deren Herstellung vom jeweiligen Herrscher „im Namen der Götter“ in Auftrag gegeben wurde und die im Bilderkult daher die Königsideologie und das religionspolitische Programm des jeweiligen Königs repräsentierten. Siehe dazu ausführlich: Angelika Berlejung, Die Theologie der Bilder. Her- 
der Vorbemerkung bereits durch einen Hinweis Jacques Derridas aufgezeigt wurde, den ich hier nochmals wiedergeben möchte:

„Die Grenze der Repräsentation zu denken heißt, das Nichtrepräsentierte oder das Nichtrepräsentierbare zu denken [...] über die Repräsentation hinaus zu denken, um die Repräsentation von ihrer Grenze her zu denken [...]. | Ich nenne hier das riesige Problem des Verbots bezüglich der Darstellung (représentation), bezüglich dessen, was man von einer jüdischen oder islamischen Welt ausgehend mehr oder weniger legitim (ein anderes unerhörtes Problem) mit „représentation/Darstellung“ übersetzen könnte.“73

Tatsächlich spielt das sog. „Bilderverbot“ im narrativen Konzept sowohl der Exodus-Erzählung ${ }^{74}$ als auch der Position, die die Figur des Mose in ihr einnimmt, eine zentrale Rolle.

stellung und Einweihung von Kultbildern in Mesopotamien und die alttestamentliche Bilderpolemik (OBO 612; Göttingen: Vandenhoeck \& Ruprecht, 1998), 94-112, 402, 419 u. ö. - Das biblische Verbot richtet sich also weder gegen künstlerische Darstellungen im modernen Sinn, noch gegen religiöse Offenbarungen (anderer Kulturen) als solche, sondern gegen die politische Identifizierung „göttlicher“ und menschlicher Macht in einer objektivierten „Repräsentationsgestalt“ (Kultbild). Es geht also um eine Kritik der antiken Politischen Theologie bzw. des klassischen antiken Religionsverständnisses (auch noch der Griechen und Römer!), von dem sich die monotheistischen Traditionen im Folgenden deutlich zu unterscheiden begannen. Eine moderne Differenzierung zwischen picture (sichtbarer, künstlerischer „Gegenstand“) und image (machtvolle „Vorstellung/Repräsentation“) kann den Sinn des biblischen Verbotes zumindest erhellen helfen und vor einer neuerlichen Ideologisierung - nun im Namen der Bilderlosigkeit - warnen. Das im Bilderverbot kritisierte Verständnis von „Kultbild“ bezeichnet „nicht eine bestimmte Art von Bildträgern, sondern ist ein „funktionaler Begriff“. (Otto, Deuteronomium. Bd. 1, aaO. [Anm. 31], 564.)

73 Derrida, Sendung, aaO. [Anm. 6], $137 \mathrm{f}$.

74 Vgl. dazu neben der bekannten Formulierung des Bilderverbots innerhalb der biblischen Dekalog-Entwürfe (Ex 20; Dtn 5) vor allem die besondere Stellung von Dtn 4 in der Konzeption des Buches Deuteronomium, der E. Otto große Aufmerksamkeit geschenkt hat. Diese späte (nachexilische) Passage ist dem Dekalog in Dtn 5 und der gesamten weiteren Gesetzespromulgation, die Mose im Narrativ der Gesamterzählung am letzten Tag seines Lebens vornimmt, auf auffällige Weise vorangestellt. Sie schlägt in ihren dichten und sorgsam komponierten Formulierungen einen Bogen von den Ereignissen der erzählten Zeit innerhalb der Fabel des Exodus hin zur Zeit der späteren Leser - und damit letztlich bis in die Gegenwart. Das Exodus-Narrativ wird damit in einen größeren politischen Kontext gestellt. Dtn 4 erweist sich als Schlüssel für das Verständnis der beiden keineswegs identischen Darstellungen der Ereignisse am Sinai und somit auch für das Exodus-Narrativ in seiner heute vorliegenden Gestalt. Das Bilderverbot und ebenso der Bruch desselben werden in dieser Passage zum sichtbaren Kriterium dafür, ob die neue Ordnung, die mit den Erfahrungen der Wüstenzeit und mit den nun als Konsequenz daraus formulierten Regelungen verbunden ist, das politische und soziale Leben 
Peter Zeillinger

2. Allerdings sollte an dieser Stelle noch einmal innegehalten und ein Schritt zurückgetreten werden. Stimmen diese Andeutungen überhaupt mit der literarischen Gestalt und dem narrativen Gehalt der Exodus-Erzählung überein? Inwiefern genau wird darin nicht nur eine Kritik, sondern auch ein wirksamer Bruch

tatsächlich bestimmen oder nicht. Das Bilderverbot und die Autorität der formulierten Gesetze haben demnach nicht den Charakter von „Vorschriften“, sondern vielmehr von Konsequenzen. Der Rückfall in die alten religiösen Vorstellungen und das Nicht-wahrnehmen der „neuen Ordnung“, haben in Dtn 4 stets auch den Rückfall in die alten Herrschaftspraktiken zur Folge. Damit wird das eigentlich in die Frühzeit Israels rückblickende Exodus-Narrativ zu einer Botschaft, die nicht nur in die jeweilige Gegenwart hinein spricht, sondern - in Form der juridischen Regelungen, die das „mosaische Gesetz“ prägen, - auch einen anderen Weg „,in ein neues Land“ weist. Die „zweite Generation“ derer, die aus „Ägypten“ ausgezogen sind und zu denen Mose vor dem Einzug ins Verheißene Land spricht, wird in Dtn 4 parallelisiert sowohl mit der nachexilischen Generation der Schreiber und LeserInnen/HörerInnen, die - so die Deutung der Ereignisse, die zum Exil geführt haben, - erneut in alte politische Modelle zurückgefallen waren und nochmals, ereignishaft, daraus befreit wurden (Rückkehr aus dem Babylonischen Exil) als auch mit denen, die in späterer Zeit (,heute“, Dtn 4,8.40; 11,32; s. u. Markl, Gottes Volk) in diesem Narrativ alle Analysen, Kriterien und Konsequenzen vorfinden, um ihre jeweilige Gegenwart kritisch zu hinterfragen und eine mögliche andere Zukunft ins Werk zu setzen. - Zur Analyse dieses auf mehreren narrativen und zeitlichen Ebenen agierenden Textes siehe: Eckart Отто, Tora für eine neue Generation in Dtn 4. Die hermeneutische Theologie des Numeruswechsels in Deuteronomium 4,140, in: Georg Fischer / Dominik Markl / Simone Paganini (Hg.), Deuteronomium. Tora für eine neue Generation (BZAR 17; Wiesbaden: Harrassowitz, 2011), 105-122, sowie weiterführend mit mehreren Exkursen zum Kontext: Otto, Deuteronomium. Bd. 1, aaO. [Anm. 31], 508-592, bes. 588-592. - Dass das Bilderverbot einen politisch revolutionären Gestus umfasst, der nicht auf die Durchsetzung einer juridischen Regel, sondern im Gegenteil auf eine Universalisierung zielt, die den anderen Menschen ernst nimmt, zeigt Emmanuel Levinas in einer seiner Hinführungen zum „Phänomen“ des Anderen als Unterbrechung herrschender Vorstellungen: Emmanuel LevinAs, Bilderverbot und „Menschenrechte“ (1984), in: Verletzlichkeit und Frieden. Schriften über die Politik und das Politische (Hgg. u.m.e. Vorw. v. Pascal Delnom u. Alfred Hirsch; Zürich: Diaphanes, 2007), 115-123. - Zum Bilderverbot allgemein siehe Dohmen, Exodus 19-40, aaO. [Anm. 72], sowie Ders., Studien zu Bilderverbot und Bildtheologie des Alten Testaments (SBAB 51; Stuttgart: Katholisches Bibelwerk, 2012). Vgl. im Kontext von Dtn 4 und der beginnenden Entgrenzung des biblischen Gottesverständnisses auch: Sven Petry, Das Gottesbild des Bilderverbots, in: Brigitte Groneberg / Hermann Spieckermann (Hg.), Die Welt der Götterbilder (BZaW 376; Berlin-New York: de Gruyter, 2007), 257-271; Ders., Die Entgrenzung JHWHs. Monolatrie, Bilderverbot und Monotheismus im Deuteronomium, in Deuterojesaja und im Ezechielbuch (FAT II.27; Tübingen: Mohr Siebeck, 2007). Zur besonderen Stellung des „Heute“ im Deuteronomium siehe: Dominik MARKL, Gottes Volk im Deuteronomium (BZAR 18; Wiesbaden: Harrassowitz, 2012), bes. 70-79. 
mit den überlieferten Vorstellungen mythischer Herrschaftslegitimation zum Ausdruck gebracht? Wir haben bereits gesehen: Würde diese Erzählung von politischer Befreiung und Emanzipation als nachträglicher Versuch der interpretierenden Aufzeichnung der Erfahrung einer historischen Migrationsbewegung verstanden, dann wäre nicht von der Hand zu weisen, dass Mose über weite Strecken der Erzählung die Position eines politischen Führers innehat, sowie als Vermittler eines neuerlich mythisch fundierten religiösen Gesetzes - der Tora vom Sinai - erscheint, dem unbedingt Folge zu leisten ist. Eine solche historisierende Interpretation der politischen Struktur des Exodus-Narrativs würde aber das entscheidende schöpferische Potential der literarischen Komposition verfehlen. Daher ist es immer noch von zentraler Bedeutung, darauf hinweisen zu können, dass die - nun in ihrer literarischen Struktur gelesene - Erzählung Mose gar nicht als Modell für einen künftigen König präsentiert. ${ }^{75}$ Stattdessen bleibt Mose, wie auch die weitere Rezeptionsgeschichte zeigt, eine singuläre Gestalt in der Hebräischen Bibel. Mose hat in diesem Narrativ keinen Nachfolger, der seinen Platz und seine Stellung einnehmen wird (Num 12,6-8; Dtn 34,10-12) ${ }^{76}$.

75 Eckart Otto betont gerade dort, wo Mose als Lehrer des Gesetzes auftritt, das Paradox, dass eine „antikönigliche Gestalt mit königlicher Funktion versehen wird“ (Otto, Deuteronomium. Bd. 1, aaO. [Anm. 31], 554) und zeigt, wie dieses Paradox gerade mit einer „kulturhistorisch entscheidenden Weichenstellung, der Lösung des Rechts vom Staat, verbunden ist." (ebd.) Vor allem die Konsequenzen sind hier politisch entscheidend: „Das judäische Gerechtigkeitsverständnis [...] kann mit der Emanzipation vom Staat auch seinen traditionalen Charakter im Sinne der Sicherung des Bestehenden verlieren und $[. .$.$] programmatisch dem Bestehenden im Dienste einer besseren Ge-$ sellschaft entgegentreten." (ebd.)

76 Zur zentralen Bedeutung der Einzigartigkeit des Mose für den späteren Umgang mit dem Exodus-Narrativ siehe: Dominik MarkL, Moses Prophetenrolle in Dtn 5; 18; 34. Strukturelle Wendepunkte von rechtshermeneutischem Gewicht, in: G. FischER / Dominik Markl / Simone Paganini (Hg.), Deuteronomium - Tora für eine neue Generation (BZAR 17; 2011), 51-68, bes: 58-61 („Moses Einmaligkeit am Abschluss des Deuteronomiums und des Pentateuch“); Günter Stemberger, Mose in der rabbinischen Tradition (Freiburg i.Br.: Herder, 2016), bes. 236-241 („Nachfolger des Mose“); Theresia Heither, Biblische Gestalten bei den Kirchenvätern. Mose (Münster: Aschendorff, 2010), bes. 300-304 („Schluß: Keiner war wie Mose“). - Stemberger hebt hervor, dass durch den Umstand, dass mit Mose keine Dynastie begründet wurde, zugleich gesichert war, dass nun ,,jeder direkten Zugang zur Tora“ hatte und damit ,jeder Rabbi sich in der Nachfolge Moses sehen kann“ (ebd. 236). Diese Nachfolge besteht demnach aber gerade nicht in der Unmittelbarkeit einer weiteren Gottesbegegnung, sondern in der Aufgabe, die Toraim Kern also die kanonische Gestalt des Exodus-Narrativs - auszulegen und für die Gegenwart hin zu kommentieren. Zur „Zusammenfügung“ der biblischen Traditionen zu einem Kanon und der dabei erkennbaren „Mosaisierung Davids“, die die Einmaligkeit Mose wahrt, siehe: Georg Steins, Zwei Konzepte - ein Kanon. Neue Theorien zur Entstehung und Eigenart der Hebräischen Bibel, in: Ders. / Johannes TAschner (Hg.), 
Doch welche Position weist ihm die literarische Komposition zu? Jedenfalls nicht das Modell eines politischen Führers. Mose wird, wie oben bereits angezeigt wurde, im Zuge der Parallelisierung der Geschichte seiner Geburt mit der neuassyrischen Sargon-Legende nicht einfach als eine bessere Alternative zum assyrischen König dargestellt, sondern zunächst viel grundlegender als GegenEntwurf zur Position des Königs. In der weiteren Entfaltung der literarischen Erzählung gehört Mose nun aber zudem zu jener Generation von Israeliten, die nicht in das Gelobte Land hineingeführt werden. Es ist erneut ein zentraler Punkt für das Verständnis des Exodus-Narrativs, dass jene, die in der literarischen Fiktion in das Gelobte Land einziehen, nicht mehr dieselben sind, die „Ägypten“ verlassen haben. ${ }^{77}$ Die Identität der „zweiten Generation“ derer, die aus der bisherigen Zwangsherrschaft befreit wurden, ist vielmehr vollständig von jenem politischen und juridischen Rahmen geprägt, der in der Zwischenzeit - im wüstenhaften Niemandsland ${ }^{78}$ zwischen der Situation des Auszugs aus ... und des Einzugs in ... ${ }^{79}$ - durch die Ereignisse am Berg Sinai etabliert wurde. ${ }^{80}$ Mit diesem

Kanonisierung - die Hebräische Bibel im Werden (Biblisch-Theologische Studien 110; Neukirchen-Vluyn: Neukirchener Verlag, 2010), 8-45, bes. 34, 41. - Zu Dtn 34,10-12 als „Epitaph der Tora“ siehe: Otto, Deuteronomium. Bd. 4, aaO. [Anm. 31], 2284ff: „Mit dem Tod des Erzpropheten Mose endet die Zeit mosaischer Offenbarungsmittlerschaft der Tora. Von da an ist die Toraoffenbarung nur noch in der von Mose verschrifteten Gestalt zugänglich und Prophetie an die Auslegung der Tora gebunden." (ebd. 2284) 77 Aus der Sicht der Gesamtkomposition des Exodus-Narrativs erweist sich „die Erste Generation [...] mit dem Bruch des Ersten Gebots noch am Gottesberg und dann auf der Wanderung in der Kundschaftererzählung als verstockt“ und „erst die Zweite Generation [erkennt] mit dem Moabbund, dass JHWH ihr Gott ist. So kann die Zweite Generation [...] das Verheißene Land jenseits des Jordans in Besitz nehmen.“ (Otto, Deuteronomium. Bd. 1, aaO. [Anm. 31], 247.)

78 S. o. Anm. 65.

79 Dass das Motiv des Auszugs aus ... in der Konzeption des biblischen ExodusNarrativs nicht von der Vorstellung und der Verheißung eines Einzugs in ... getrennt werden kann - und damit die Beschreibung des „Auszugs aus Ägypten“ noch keineswegs jene „Befreiung“ darstellt, die mit dem Exodus-Narrativ verbunden ist, - macht Christoph Dohmen anhand von Ex 3,8 deutlich. Darin bilden die drei Abschnitte - Auszug, Identitätsfindung in der Wüste und Einzug ins Gelobte Land - eine untrennbare Einheit für alle, die die Exoduserzählung in ihrer literarischen und kanonisch gewordenen Gestalt ernstnehmen. Siehe dazu Dohmen, Exodus 1-18, aaO. [Anm. 65], $152 \mathrm{f}$.

80 „Für die Moabredaktion lerne die Zweite Generation, und das sind alle Generationen der Adressaten des Deuteronomiums auch in der Erzählzeit, mit dem Deuteronomium nicht nur ein vom Horebdekalog abgeleitetes Gesetz kennen, sondern die Bundesverpflichtung des Moabbundes, das zu befolgen Voraussetzung für ein erfolgreiches Leben im Verheißenen Land ist, wie es Mose formuliert: „So beachtet die Gebote dieses Bundes und handelt ihnen gemäß, damit ihr Erfolg habt in allem, was ihr tut" (Dtn 29, 8).“(Otto, Deuteronomium. Bd. 1, aaO. [Anm. 31], 247.) 
neuen Rahmen, dieser Etablierung einer neuen gesellschaftlichen und juridischen Ordnung, wurde das Volk Israel in all den Episoden, Erfahrungen und Entscheidungen vertraut gemacht, von denen das Exodus-Narrativ im Rahmen der keineswegs geradlinigen Durchquerung des Niemandslands der Wüste episodenhaft berichtet. ${ }^{81}$

In diesem Sinn ist es keineswegs zufällig, dass der Übergang ins Gelobte Land dadurch eingeleitet wird, dass die Figur des Mose am letzten Tag seines Lebens und noch knapp außerhalb des Landes, in das das Volk einziehen wird, in mehreren großen Reden, die heute das Buch Deuteronomium ausmachen, ${ }^{82}$ die gesamte Auszugserfahrung, die Ereignisse am Berg Sinai und die Etablierung der neuen Ordnung, die von nun an die politisch-juridische, soziale und (in einem völlig neuen Sinn) auch „religiöse“ Grundlage des Lebens im Land sein wird, nochmals zusammenfasst und damit die bereits vorliegende Darstellung dieser Ereignisse kommentiert und interpretiert. Das biblische Exodus-Narrativ, wie es in der später als kanonisch geltenden Fassung nun vorliegt, enthält die Darstellung des Gesamtgeschehens demnach zweimal - allerdings nicht im Sinne von zwei unabhängig voneinander zu lesenden Varianten. Die in der Chronologie des Narrativs ,zweite“ Darstellung im Buch Deuteronomium stellt in ihrer literarischen Gestaltung vielmehr zugleich einen interpretierenden Kommentar der früheren dar. ${ }^{83}$ Eine der Besonderheiten des kanonisch gewordenen Narrativs be-

81 Zur 40-jährigen Wüstenwanderung Israels vom Gottesberg am Sinai zum Gelobten Land und den zahlreichen Klagen und Rebellionen des Volkes auf diesem Weg siehe: Otto, Gesetz des Mose, aaO. [Anm. 30], 73-84. - Christoph Dohmen und Matthias Ederer haben die Vielzahl der „Aufbrüche“, die die Erzählungen von der Wüstenwanderung beinhalten, herausgearbeitet und kommen zu dem Schluß: „Der „Exodus“ - oder genauer das „Ausziehen“ - [avanciert] zu der zentralen theologischen Deutekategorie für die (,ganze“) Gründungsgeschichte Israels. (Christoph Dohmen / Matthias Ederer, Wie Exodus zum Exodus wurde. Ein Buch und sein Thema, in: Judith GärTnER / Barbara Schmitz (Hg.), Exodus. Rezeptionen in deuterokanonischer und frühüdischer Literatur (Deuterocanonical and Cognate Literature Studies 32; Berlin-Boston: de Gruyter, 2016), 1-16, hier: 14.)

82 Johannes TASChNer, Die Mosereden im Deuteronomium. Eine kanonorientierte Untersuchung (FAT 59; Tübingen: Mohr Siebeck, 2008). - Vgl. dazu auch Otto, Deuteronomium. Bd. 1, aaO. [Anm. 31], 217-219.

83 Dies ist ein durchaus erstaunliches Faktum, da es eine solche Form von deutender Kommentierung, die Spannungen und Brüche in der Erzählung nicht harmonisiert (s. o. Anm. 30), sondern stehenlässt bzw. bewusst einfügt, in der Schriftkultur des Alten Orients bis dahin nicht gab. Diese Brüche haben die performative Funktion, die späteren LeserInnen bzw. HörerInnen zu zwingen, ihrerseits interpretierend damit umzugehen (s. o. Anm. 31). Die Konsequenzen daraus werden im Folgenden eigens zu bedenken sein. Ein vergleichbares Phänomen findet sich jedenfalls in der griechischen Kultur nicht, da die Motivation und das Ziel der dortigen Entwicklung einer Kommentarkultur im Gegenteil darin bestand, Brüche aufzulösen und nicht mehr Verständliches durch Erklä- 
steht demnach darin, dass die Gesamterzählung zugleich ein Modell der Kommentierung der Exoduserzählung beinhaltet - ein Modell, das in weiterer Folge natürlich auch auf die Gesamterzählung selbst anwendbar wird. ${ }^{84}$

Auch hier gilt es, die performative Struktur des Narrativs in ihren Konsequenzen ernstzunehmen. Die Integration eines Modells von Interpretation und Kommentierung in die Erzählung selbst läuft keineswegs auf eine unendliche Kette von Iterationen im Stil von ,ein Kommentar des Kommentars des Kommentars ..." hinaus, sondern lediglich auf die allgemeine Eröffnung und Etablierung des Konzepts einer notwendigen Kommentierung und Aktualisierung. Dies wurde oben bereits durch Eckart Ottos Hinweise auf die Spannungen im Text zwischen erzählter Zeit und Erzählzeit angedeutet. Das Exodus-Narrativ ist in seiner literarischen Gestalt demnach nicht im Sinne der bisherigen altorien-

rungen „verstehbar“ zu machen. Vgl. zur griechischen Entwicklung des Kommentars: Han Baltussen, From Polemic to Exegesis. The Ancient Philosophical Commentary, in: Poetics Today 28.2 (2007), 247-281. - Das biblische Exodus-Narrativ stellt dagegen eine Hinführung zu dem dar, was zwar am Text festzumachen ist, aber über die Formulierung des Textes hinaus weist. An dieser Stelle sei lediglich ein für die entstehende jüdische Auslegungskultur zentrales Beispiel genannt - die notwendige Identifizierung der LeserGeneration mit der Situation innerhalb der Exoduserzählung: „Dass die Adressaten des Buches Deuteronomium in der nachexilischen Zeit, die durch die „Zweite Generation“ in der erzählten Zeit des Mose repräsentiert werden, sich unmittelbar in Dtn 4,1-40 angesprochen wissen sollen, wird durch eine Inkongruenz in der Fabel des Deuteronomium in Dtn 4,3-4 dadurch angezeigt, dass die Zweite Generation in Ba'al Pe'or den Dekalog in der erzählten Zeit noch gar nicht kennen konnte." (Otto, Tora für eine neue Generation. Dtn 4, aaO. [Anm. 74], 118.) - Zur Bedeutung von Dtn 4 als Schlüsseltext für Hermeneutik des Deuteronomiums siehe oben Anm. 74.

84 Bereits am Beginn der deuteronomischen Exodus-Erzählung, in dem Moment, an dem die Mosereden an seinem letzten Tag eingeführt werden, spricht die Rahmenerzählung davon, dass Mose „,begann die Tora auszulegen (verdeutlichen, erläutern, erklären)“ (Dtn 1,5). Dass der Wortsinn des verwendeten Begriffs auch den damaligen LeserInnen bekannt war, lässt sich anhand von antiken Übersetzungen und jüdischen Targumim zeigen. Vgl. dazu ausführlich: Eckart Отто, Mose, der erste Schriftgelehrte. Deuteronomium 1,5 im Narrativ des Pentateuch (2005), in: Die Tora. Studien zum Pentateuch. Gesammelte Schriften (BZAR 9; Wiesbaden: Harrassowitz, 2009), 480-489. Da am Ende mit der Auslegung des Mose nunmehr zwei Formulierungen der ExodusEreignisse innerhalb derselben Gesamtkomposition vorliegen, stellt sich unweigerlich die Frage nach ihrem Verhältnis zueinander. „Alles kommt im Narrativ des Pentateuch darauf an, daß die von Mose [gegebene, sic!] Toraauslegung (Dtn 1,5) identisch ist mit der von Gott gegebenen Tora. [...] Ausgelegte, d. h. von Gott offenbarte, und auslegende, d.h. von Mose mitgeteilte Tora (Dtn 4,44 ff.) sind identisch. Das Volk aber hat die Tora nicht anders als in ausgelegter Gestalt. [...] Nur in Gestalt der mosaischen Auslegung und der an sie anknüpfenden schriftgelehrten Auslegung ist die Tora in Israel. Die auslegende Tora ist die Tora Gottes als ausgelegte Tora.“ (ebd. 488f) 
talischen Schrifttraditionen als Aufzeichnung eines bereits bekannten Wissens bzw. als nachträgliche Ausgestaltung eines gemeinsam geteilten Weltbilds lesbar. ${ }^{85}$ Wie nun künftig mit einer solchen Kommentierung umzugehen wäre, ist damit noch nicht bestimmt. Es ist lediglich die Unausweichlichkeit angezeigt, mit der Differenz zwischen Kommentar und Kommentiertem aktiv und produktiv umgehen zu müssen.

Solche sich zunächst scheinbar allein im Rahmen der geschichtlichen Entwicklung eines reflektierten Verständnisses von Textualität und Literatur abspielenden Beobachtungen bekommen schließlich unweigerlich dann eine politische Bedeutung, wenn ein Gründungsnarrativ zugleich eine im eben geschilderten Sinn performative Struktur aufweist, die den Leser und die Leserin nötigt, in eben jene Haltung des interpretierenden Kommentierens und Aktualisierens einzutreten, die von/in dem Text gewissermaßen gerade erst „erfunden“ wird bzw. die in eine solche Grundlegungs-Erzählung bewusst integriert wurde. Dort, wo das Exodus-Narrativ tatsächlich als Gründungserzählung einer gemeinsamen Identität verstanden wird, ist die Struktur der altorientalischen Herrschaftslegitimationen bleibend und unhintergehbar unterwandert und depotenziert. Der narrative Gehalt der Exoduserzählung - das vielschichtige Befreiungsgeschehen sowie die Gestaltung des Mose als Gegen-Modell zu einem König sowie als Modell eines „ersten Kommentators“" - befreit ihre Rezipienten vom Korsett der Identifizierung und Anerkennung eines politisch und juridisch wirksamen Repräsentanten einer souveränen Letztinstanz. Er nötigt die LeserInnen vielmehr dazu, diese Gründungserzählung selbst daraufhin zu befragen, was in ihr zum Ausdruck kommt - und genau darin den ersten Schritt der neuen Grundlegung politischer und gesellschaftlicher Ordnung zu erkennen. Auf diese Weise wird der Bezug auf eine Souveränität, die das individuelle Handeln und die gemeinschaftliche Ordnung bestimmt, weder geleugnet noch auf eine identifizierbare Weise präsentiert oder re-präsentiert. Die in diesem Sinn symbolisch leer bleibende Stelle der Souveränität wird lediglich von dem Narrativ selbst markiert. Aber auch dieses stellt keine identifizierbare Re-präsentation im alten Stil dar, da es von seiner performativen Struktur her den kommentierenden und interpretierenden Umgang mit dem Gegebenen beinhaltet.

85 Siehe dazu nochmals die zusammenfassende Darstellung der altorientalischen Schrift- und Schreiberkultur in: Toorn, Scribal culture, aaO. [Anm. 14], sowie ihre Einbettung in die Veränderung bzw. Wahrnehmung des Verständnisses von „Textualität“im Sinne der Notwendigkeit, eine Schrift nicht bloß in einem gegebenen Kontext zu „entziffern“, sondern einen Text daraufhin zu „lesen“, was in ihm (über das Gegebene hinaus) zum Ausdruck kommt - im Alten Israel im Zuge der Entstehung der biblischen Texte in: Zeillinger, Offenbarung als Ereignis, aaO. [Anm. 13], bes. 84-96. 
Peter Zeillinger

\section{b) Die Textualisierung der Macht}

Im Folgenden wird eine für die politischen Konsequenzen des Exodus-Narrativs zentrale Passage, nämlich der Erhalt bzw. die Einführung eines neuen Gesetzes in der literarischen Darstellung der Szene der Gottesbegegnung des Mose am Berg Sinai, in ihrer doppelten Bedeutung zu lesen versucht: zum einen im Kontext ihrer Stellung innerhalb des Narrativs selbst und zum anderen in ihrer politischen Bedeutung im Sinne der Etablierung eines nicht-souveränen Legitimationsdiskurses. Die am Beginn dieses Kapitels gestellte Frage ist an dieser Stelle ja noch immer offen: Wodurch genau wird die Wirkmächtigkeit der altorientalischen Königsideologie, deren Struktur die gesamte abendländische politische Tradition hindurch rezipiert wird ${ }^{86}$, ersetzt?

Das zentrale und letztlich auch namengebende Thema der jüdischen Tora (,Weisung“), in deren Mitte das Exodus-Narrativ steht, findet sich in der sorgfältig entwickelten Darstellung des Empfangs des Gesetzes JHWHs am Berg Sinai (Ex 19-34). JHWH, der nicht-darstellbare Gott Israels, dessen Name in der jüdischen Kultur nicht ausgesprochen wird und dessen Namensbedeutung keine inhaltliche Identifizierung zulässt, sondern den Charakter eines ,schon jetzt wirksamen Versprechens“ besitzt - ,Ich bin (schon jetzt erfahrbar als) der, der ich (letztlich) sein werde“ (Ex 3,14) $)^{87}$, hat in der Hebräischen Bibel, insbesondere

86 Siehe dazu nochmals die Hinweise von Simo Parpola in Anm. 62.

87 In der innerbiblischen Deutung des Gottesnamens JHWH in der Szene von Moses Begegnung mit Gott im brennenden Dornbusch (Ex 3) ist bereits eine wesentlicher Grundzug des gesamten Exodus-Narrativs verpackt. Das hebräische Verb HJH, ,sein, werden, geschehen“, das zur deutenden Erklärung der Identität Gottes herangezogen wird, „hat im biblischen Hebräisch vor allem die Funktion, den Aspekt der „Zeit“ zu bezeichnen." (Georg FISCHER, Jahwe unser Gott. Sprache, Aufbau und Erzähltechnik in der Berufung des Mose (Ex 3-4) (OBO 91; Göttingen: Vandenhoeck \& Ruprecht, 1989), hier: 148.) Die Verbform, die in Ex 3,14 vorliegt, „dient dabei überwiegend für die Kennzeichnung eines zukünftigen Seins“ (ebd.), sodass ein Vergleich mit ähnlichen Formulierungen im Hebräischen zu dem Schluss führt, „Ex 3,14a will also verstärkt das zukünftige Sein Gottes aussagen, dabei aber offenlassen, wie dieses sein wird." Wichtig für alle weiteren Überlegungen ist, so hat bereits der Rabbiner Benno Jacob in seinem berühmten Exodus-Kommentar betont, dass ,alle Deutung eines Seins in abstrakt metaphysischem Sinn fehlgehen: Ich bin, der ich bin, d. h. durch Notwendigkeit Existierende (Maimonides).“ (Benno JACOB, Das Buch Exodus (hgg. im Auftrag des Leo Baeck Instituts von Shlomo Mayer; Stuttgart: Calwer, 1997 [1943]), hier: 65.) „Mit dem Präsens darf es nur in dem Sinne eines immer wiederkehrenden, in seiner Natur begründeten und gewohnheitsmäßigen Verhaltens wiedergegeben werden.“ (ebd. 66) Benno Jacob fasst daher die Bedeutung der Selbstvorstellung Gottes im Kontext der mosaischen Frage von Ex 3,13 („Wenn sie zu mir sagen: Was ist sein Name? Was soll ich zu ihnen sagen?") wie folgt zusammen: „Du Mensch brauchst nur zu wissen, $d a \beta$, nicht wie ich helfen und mich erweisen werde. Es ist eine Lektion im Gottvertrauen, die Mose erhält. [...] Sage ihnen: 
im Narrativ des Exodus, ganz offensichtlich die Position der letzten unhinterfragbaren Souveränität inne. Doch was wird hiermit genauerhin zum Ausdruck gebracht? Worin unterscheidet sich der biblische Diskurs vom JHWH-Souverän von den anderen offensichtlich mythischen Traditionen der Antike? An dieser Stelle kann es, wenn man die Frage eines für die Gegenwart auch außerhalb religiöser Überzeugungen relevanten politischen und juridischen Grundlegungsdiskurses nicht aus den Augen verlieren will, offensichtlich nicht darum gehen, theologische Formulierungen und Überzeugungen der späteren Rezeption der biblischen Tradition vorauszusetzen oder einfachhin zu übernehmen. Zugleich aber kann es auch nicht darum gehen, diese Rezeption außeracht zu lassen, zu negieren oder zu verwerfen. Es stellt sich vielmehr die bereits aus mehreren

Der Gott, der so von sich sprechen kann „Ich werde es sein, Ich komme“ hat mich zu euch gesandt." (ebd. 66 f; kursiv i.O.) Es handelt sich hier also nicht um ein Rätselspiel, sondern um die Vermittlung einer Hoffnung und eines Vertrauens, die nicht als Behauptung inszeniert werden, sondern verknüpft sind mit eben jener Erfahrung, in die hinein diese Namensdeutung erfolgt: in die Erfahrung einer politischen und gesellschaftlichen Befreiung. Die Öffnung auf Zukunft hin, auf die später noch ausführlicher einzugehen sein wird, kann hier nicht als Konstativum erfolgen („Ich bin „der und der““), sondern nur durch den aktiven Vollzug eines Sich-Ausrichtens-an-der-Zukunft. Daher wird Gott nicht mit einem Namen ,identifiziert“, sondern mit ihm wird eine gegenwartsverändernde Zukunft verbunden. Keine Vertröstung auf ein „später einmal“, sondern: Hierund-jetzt bin ich schon der, der am Ende die Situation verändert haben wird. (Siehe dazu unten den Abschnitt 5 c „Repräsentation der Zukunft“). - Franz Rosenzweig kommt zu einem vergleichbaren Schluss: „So ist aus dem erzählerischen Zusammenhang nur eine Übersetzung gerechtfertigt, die nicht das Ewigsein in den Vordergrund rückt, sondern das Gegenwärtigsein, das Für-euch- und Bei-euch-dasein und -daseinwerden." (zit. n. Dohmen, Exodus 1-18, aaO. [Anm. 65], 164.) Wie noch öfters im Exodus-Narrativ werden hier also mehrere Zeitebenen miteinander verknüpft: (1.) Die Gegenwart derer, die sichim Rahmen der Erzählung - in Ägypten bzw. später am Sinai befinden. (2.) Die Vergangenheit, in der bereits mit diesem Gott eine Erfahrung gemacht wurde. Damit sind neben den in Ex 3,13 genannten „Vätern“ („Der Gott eurer Väter hat mich zu euch gesandt.") aber auch (außerhalb der Fabel auf der Ebene der LeserInnen) die Rezipienten des Exodus-Narrativs angesprochen, die sich auf die gesamte Exoduserzählung bereits als Gründungsdokument zurückbeziehen. Beide Zeitebenen, Gegenwart und Vergangenheit, werden nun aber - sowohl im Narrativ als auch in der Rezeption - mit der Deutung des JHWH-Namens (3.) zur Zukunft in Beziehung gesetzt. Dieser dritte Zeitbezug ist dabei der Entscheidende: Die Vergangenheit liefert das Vertrauen, die Gegenwart auf die Zukunft hin zu verändern, d. h. die Zukunft schon jetzt am Werk zu sehen. Im Exodus-Narrativ ist es stets die verheißene Zukunft, die bereits hier-und-jetzt die Situation wirksam zu verändern beginnt. Damit wird die Ebene der Fabel strukturell bereits auf konkrete geschichtliche Veränderungen hin überschritten. Es geht um reale politische Orientierungen. - Vgl. zur exegetischen Diskussion mit ausführlichen Literaturangaben: Dohmen, ebd. 160-164 („Exkurs: Namensoffenbarung in Ex 3,14?“). 
Blickwinkeln heraus formulierte Rückfrage, worum genau es im Kontext der geschichtlichen Entstehung dieses Narrativs eigentlich geht. Es gilt daher, das Narrativ in eben jener Bedeutung in den Blick zu bekommen, die es zu einem Grundlegungsdiskurs nicht nur in seinem geschichtlichen Kontext werden ließ sondern auch - so die These dieser Studie - seine politische Relevanz bis heute begründet. Diese Bedeutung „offenbart“ sich in jener Episode am Berg Sinai, die innerhalb der Exoduserzählung zugleich performativ die Offenbarung thematisiert, mit der das Narrativ schließlich selbst identifiziert wird. ${ }^{88}$

Moses Gottesbegegnung am Berg Sinai erzählt von jenem Moment, an dem der unsichtbare Gott, dem kein Mensch direkt zu begegnen und auch kein Mensch ins Antlitz zu sehen vermag, dennoch mit Mose in der Abgeschiedenheit des Berges in Kontakt tritt (Ex 19,20-25; 24,12-18). Mose wird damit als Vermittler eingeführt zwischen der Position des unsichtbaren ${ }^{89}$ Souveräns und dem Volk, das Mose

88 Die multiple Bedeutung und Verwendung des hebräischen Terminus „Tora“ ist dafür bereits ein bemerkenswerter Hinweis: Tora meint zum einen jenes Gesetz, das Mose am Sinai offenbart wird und mit dem Inhalt der Dekalog-Tafeln identifiziert wird (Dohmen, Exodus 19-40, aaO. [Anm. 72], 211-214 „Exkurs: Die Tafeln“). Darüber hinaus meint Tora jedoch auch die Auslegung der Sinai-Offenbarung durch Mose und damit das Narrativ der Exoduserzählung selbst, die in ihrer Gesamtheit die Tora des Mose vermittelt (vgl. Dtn 1,5: „Mose begann die Tora auszulegen“, diese Auslegung ist aber zugleich selbst die Tora; s. o. Anm. 84). Schließlich meint Tora aber auch die als kanonisch aufgefasste Textsammlung - die „Fünf Bücher des Mose“ -, in der dieses Narrativ geschichtlich überliefert wird. Es ist auffällig, dass das Narrativ, das als Tora gilt, zugleich selbst performativ das Wesen und die Bedeutung der Tora reflektiert. In der Erzählung von der Auffindung eines „Buches der Tora“ im Jerusalemer Tempel in 2 Kön $22+23$ wird diese performative Verschränkung des Textes mit der Reflexion der Bedeutung ebendieses Textes offensichtlich: Man erfährt in dieser Erzählung nichts vom Inhalt des aufgefundenen Buches, sondern lediglich von seiner Bedeutung, da der König und das gesamte Volk sich verpflichten sich an seine Gesetze zu halten. Zugleich ist das aufgefundene Buch aber letztlich genau jene Tora, in deren kanonisierter Gestalt die Erzählung seiner Auffindung nun integriert ist. Die Erzählung 2 Kön $22+23$ berichtet also von der Autorität eines Textes, der sie letztlich selbst ist. Siehe dazu Hindy NaJman, The Symbolic Significance of Writing in Ancient Judaism, in: Hindy NaJman / Judith H. Newman (Hg.), The Idea of Biblical Interpretation. Essays in Honor of James L. Kugel (Supplements to the Journal for the Study of Judaism 83; Leiden-Boston: Brill, 2004), 139-176; sowie Joachim Schaper, A Theology of Writing. The Oral and the Written, God as Scribe, and the Book of Deuteronomy, in: Louise Joy Lawrence / Mario I. Aguilar (Hg.), Anthropology and Biblical Studies. Avenues of Approach (Leiden: Deo Publishing, 2004), 97-119.

89 Auch von Mose wird Gott nicht „gesehen“, sondern nur seine Stimme „gehört“. Vom Volk wird in einer paradoxen Formulierung gesagt: „Ihr habt selbst gesehen, dass ich [JHWH] vom Himmel her mit euch geredet habe." (Ex 20,22) Israel kann also „sehen“, dass Gott spricht, im Unterschied zu Mose aber nicht verstehen, was gesagt 
im Auftrag JHWHs aus Ägypten geführt hat. Wie bereits erwähnt, wird diese Mittlergestalt des Mose, der das Land, in das das Volk schließlich einziehen wird und von dem her es bis heute seine Identität bestimmt, niemals betreten hat, im Exodus-Narrativ keinen Nachfolger erhalten, der diese Mittlerfunktion übernimmt. ${ }^{90}$ Sowohl die Position JHWHs als auch die Mittlerposition des Mose bleiben demnach in der Exoduserzählung singulär. Dies ist erneut eine nicht zu unterschätzende Differenz zur Königsideologie des Alten Orients. Es wird im Kontext der hier begründeten neuen Ordnung nicht möglich sein, die Position des Mose je neu zu besetzen während es stets möglich war und ist, einen neuen Repräsentanten (König) im Rahmen des gegebenen politischen Weltbildes einzusetzen. Auch aus diesem Grund darf man die Positionen des altorientalischen Königs und des Mose im Exodus-Narrativ nicht aufeinander beziehen. Wer oder was tritt dort aber dann an die Stelle des Königs?

Die biblische Erzählung berichtet davon, dass Mose, der Mittler, in einem ersten Anlauf am Gipfel des Berges aus den Händen JHWHs zwei Steintafeln ${ }^{91}$ erhält, die den Text des Bundes Gottes mit seinem Volk enthalten. Die neuassyrische Praxis, einen Bund zwischen dem König eines Reiches und den von ihm besiegten Völkern, die nun unter seiner Herrschaft leben, zu errichten, wird im Exodus-Narrativ in die Idee eines Bundes zwischen Gott selbst und seinem Volk transformiert. ${ }^{92}$ Der König als politische Autorität, dem die Treue gehalten wer-

wird. Siehe zur sublimen Differenzierung der Medialitäten der Sichtbarkeit, der Stimme und der Schrift im Buch Exodus: Joachim Schaper, Anthropologie des Schreibens als Theologie des Schreibens. Ein medienarchäologischer Gang durch das Buch Exodus, in: Friedrich-Emanuel FocKen / Michael R. Oтт (Hg.), Metatexte. Erzählungen von schrifttragenden Artefakten in der alttestamentlichen und mittelalterlichen Literatur (Materiale Textkulturen 15; Berlin-Boston: de Gruyter, 2016), 281-296, zur Sinai-Theophanie bes. $286 \mathrm{f}$.

90 Siehe oben Anm. 76.

91 Zur Bedeutung der Steintafeln in der Hebräischen Bibel und ihrer späteren Rezeption siehe: Hermut LöHR, Steintafeln. Tora-Traditionen in 2Kor 3, in: Dieter SäNGER (Hg.), Der zweite Korintherbrief. Literarische Gestalt, historische Situation, theologische Argumentation (FS Dietrich-Alex Koch; Göttingen: Vandenhoeck \& Ruprecht, 2012), 175-187.

92 Siehe zu dieser Differenz zwischen biblischem und altorientalischem Bundesdenken: Eckart Отто, Die Ursprünge der Bundestheologie im Alten Testament und im Alten Orient, in: Zeitschrift für altorientalische und biblische Rechtsgeschichte 4 (1998), 1-84. $\mathrm{Zu}$ den politischen und rechtlichen Konsequenzen, die die Bundestheologie des Deuteronomiums als frühe Form der im Abendland erst viel später etablierten Menschenrechte ausweist, siehe: Eckart Отто, Gottes Recht als Menschenrecht. Rechts- und literaturhistorische Studien zum Deuteronomium (BZAR 2; Wiesbaden: Harrassowitz, 2002), bes. 128-166 („Ursprung der Bundestheologie in Assyrien und Juda“) und 167194 („Die Politische Theologie des Deuteronomiums als Wiege der Menschenrechte“). - $\mathrm{Zu}$ einer aktuellen Würdigung des befreienden Charakters des biblisch-mono- 
den muss, fällt damit als eigenständige oder notwendige Instanz weg. Dieser neuartige Gottesbund sollte nun in weiterer Folge von Mose, der die von Gott selbst geschriebenen Tafeln mit dem Bundestext (der Tora Gottes) aus dessen Hand empfangen hat (Ex 31,18), dem Volk vermittelt werden. In dieser ersten Begegnung vermittelt das Exodus-Narrative also den Eindruck als hätte es zu diesem Zeitpunkt tatsächlich ein Autograph Gottes gegeben, einen Text, ein Wort Gottes, das unmittelbar von der Hand des Souveräns geschrieben worden war. ${ }^{93}$ Als Mose jedoch vom Berg herabsteigt und zu seinem Volk zurückkehrt (Ex 32), muss er erkennen, dass diese begonnen hatten, sich wieder an der traditionellen religiösen Ordnung und Politischen Theologie mit ihren gewohnten Ritualen auszurichten und sich offensichtlich zwischenzeitlich vom Interesse an der ganz anderen Ordnung, unter deren Namen sie den bisherigen Verhältnissen entronnen sind, wieder abgewendet haben. In seinem Zorn zerstört Mose daraufhin die Tafeln mit dem einzigen Autograph JHWHs (Ex 32,19). Doch damit ist die Erzählung nicht zu Ende. Mose darf schließlich noch einmal den Berg besteigen und begegnet dort JHWH ein zweites Mal. Und wiederum wird ihm das gesamte Gesetz Gottes vermittelt (Ex 34). Diesmal allerdings wird Mose die Tafeln selber beschreiben - und zwar nachdem das Gesetz ihm von Gott zuvor vollständig vorgetragen worden war (Ex 34,27-29). Das Resultat dieser zweiten Begegnung sind zwar erneut zwei Steintafeln, diese sind diesmal aber nicht mehr von JHWH selbst geschrieben. Sie stellen auch keine Mitschrift im Sinne einer Aufzeichnung dar, die während des Vortrags Gottes gewissermaßen parallel dazu erstellt worden wäre, sondern es handelt sich um eine nachträgliche Niederschrift des Gehörten, diesmal aus der Hand des Mose. Zurückgekehrt zu seinem Volk wird diese schriftliche Gestalt des Gottesbundes von Mose dem Volk vorgelesen.

Die Differenz zwischen den beiden Gottesbegegnungen ist im Kontext des kanonisch gewordenen Narrativs der Exoduserzählung, das am Ende in Gestalt des Buches Deuteronomium schließlich auch das innerbiblische Modell eines Kommentars seiner selbst enthalten wird, durchaus von Bedeutung. Die Möglichkeit einer kommentierenden und interpretierenden Auslegung ist ja stets nur dort gegeben, wo ein Diskurs nicht einfach mit seiner vorliegenden Gestalt un-

theistischen Verständnis von Gottesrecht als Bundesrecht siehe Jan Assmann, Die sakralstaatliche Rechtskultur des Alten Orients und die frühjüdische Theologisierung des Rechts, in: Markus Graulich / Ralph Weimann (Hg.), Ewige Ordnung in sich verändernder Gesellschaft? Das göttliche Recht im theologischen Diskurs (QD 287; Freiburg i.Br.: Herder, 2018), 11-30, bes. 26ff (mit starkem Bezug auf das Exodus-Narrativ); sowie in demselben Band: Dominik MarkL, Gottes Gesetz und die Entstehung des Monotheismus, ebd. 49-67, und Thomas SöDING, Das Gesetz der Freiheit. Neutestamentliche Impulse in der Debatte um das ius divinium, ebd. 68-115.

93 Zur sublimen Bedeutung von Medialität in der Sinai-Perikope und letztlich im gesamten Exodus-Narrativ, siehe nochmals: Schaper, Theologie des Schreibens, aaO. [Anm. 89]. 
terschiedslos identifiziert wird, ${ }^{94}$ sondern vielmehr - um diese Formulierung hier erneut zu verwenden - daraufhin gelesen werden muss, was in ihm zum Ausdruck gebracht worden ist. ${ }^{95}$ Genau dies ist hier aber der Fall. Der gegenüber dem Alten Orient neuartige Bundestext Israels, das Gesetz bzw. die Tora Gottes stellt in ihrer textuellen Gestalt gerade kein unmittelbares Wort Gottes dar, sondern wird vom Exodus-Narrativ als nachträgliche Aufzeichnung eines von der Person des Mose gehörten Gotteswortes eingeführt.

In der weiteren Darstellung von der Zeit der Wüstenwanderung fungiert Mose dann immer wieder als authentischer Interpret dieses Gottesbundes, der damit offensichtlich nicht als ,selbsterklärend“ charakterisiert wird. In der Situation der Wüstenzeit, also noch vor dem Einzug in das Verheißene Land, besitzt die neue Gemeinschaft demnach nicht nur eine Aufzeichnung des Gesetzes Gottes, sondern auch die Möglichkeit über Mose als Schreiber dieses Textes, dem die niedergeschriebene Botschaft zunächst persönlich vermittelt worden war und der weiterhin als Mittler zwischen Gott und dem Volk fungierte, nähere Auskunft über dessen Bedeutung und seine Konsequenzen $\mathrm{zu}$ erhalten. In diesem $\mathrm{Zu}$ sammenhang wird es nun für die Gesamtdarstellung dieses Narrativs in besonderer Weise relevant, dass die singuläre menschliche Figur des Mose nicht in das Verheißene Land mit einziehen wird. Dieser Gottesbund, der zur juridischen Grundlage eines politischen Gemeinwesens und einer sozialen Ordnung werden sollte, ist - im Unterschied zu den Herrschaftslegitimationen des Alten Orients nicht nur durch keinen menschlichen Repräsentanten vermittelt, sondern im neuen Land wird es auch keine unmittelbare Begegnung mehr mit der Mittlergestalt des Mose als göttlich legitimiertem Kommentator und Interpreten geben. Das einzige, was Israel gemäß dem Narrativ des Exodus im Verheißenen Land dann noch in Händen halten wird, ist jener Text, der die nachträgliche Verschriftlichung des souveränen Wortes Gottes beinhaltet. ${ }^{96}$

Politisch interessant werden die Konsequenzen dieses Narrativs aus dem Blickwinkel derer, für die das Exodus-Narrativ bzw. der Tora-Diskurs schließlich eine Gründungserzählung darstellt. Dies sind zum einen zunächst diejenigen, in

94 Genau diese Differenz zwischen Kommentar und Kommentiertem, sowie zwischen Schriftlichkeit und dem, was in ihr zum Ausdruck kommt, spielt im Exodus-Narrativ sowohl beim Empfang der Sinai-Tora im Tafel-Motiv eine zentrale Rolle als auch beim Verständnis der Autorität der ausgelegten Mosa-Tora im Buch Deuteronomium. Siehe dazu oben Anm. 84, sowie Schaper, Theologie des Schreibens, aaO. [Anm. 89].

95 Zum spezifischen Verständnis von „lesen“ in diesem Zusammenhang siehe oben Anm. 16.

96 „Mose muß vor dem Betreten des verheißenen Landes sterben, so daß statt seiner die von ihm verschrifteten Gesetze mit dem Volk über den Jordan ziehen. Die verschriftete Tora übernimmt die mosaische Funktion der Offenbarungsmittlerschaft. [...] Der Tod des Mose wurde so zur Geburtsstunde der Tora. Von jetzt an war nur noch rechtsgültig, was mosaisch war.“(Otto, Tora des Mose, aaO. [Anm. 10], 57.) 
deren ursprünglichem geschichtlichem Kontext das Exodus-Narrativ einen durchaus realpolitischen Gegenentwurf zur altorientalischen Königsideologie darstellte, und zum anderen aber auch diejenigen, die in einer späteren Rezeption auf dem Boden dieses Narrativs und in ihrem jeweils eigenen geschichtlichen Kontext daraus politische oder religiöse Konsequenzen zu ziehen beabsichtigen. $\mathrm{Zu}$ dieser zweiten Gruppe gehören natürlich zunächst einmal die sich daraus entwickelnden monotheistischen ${ }^{97}$ religiösen Traditionen, deren Verständnis von Religion nun aber deutlich abweicht von jenem antiken Religionsverständnis, das letztlich der Aufrechterhaltung der herrschenden Ordnung verpflichtet ist und somit mit der altorientalischen Königsideologie strukturell vereinbar war bzw. diese legitimiert hat. Letztlich würden aber auch all jene Bezugnahmen auf eine Exodus-Politik hier subsumiert werden können, die sich am Exodus-Motiv auch in der Gegenwart noch affirmativ oder kritisch abarbeiten. ${ }^{9}$ Sie müssten nun allerdings daraufhin befragt werden, ob oder inwiefern sie dem biblischen Exodus-Narrativ, auf das sie sich beziehen, tatsächlich gerecht werden.

Was also bleibt am Ende vom biblischen Exodus-Narrativ und seiner politischen Relevanz nicht nur innerhalb des ursprünglichen geschichtlichen Kontextes sondern auch für seine Relevanz in den politischen Herausforderungen der Gegenwart? Auf der Ebene des literarischen Narrativs, also innerhalb der Exoduserzählung selbst, ist das, was am Ende bleibt, nur mehr ein Text, nämlich jenes Gesetz des Mose, von dem die Erzählung spricht und das zudem in der Erzählung

97 Auch hier wird - wie schon zuvor im Begriff der „monotheistischen Struktur“ (s. o. Anm. 64) - der Begriff „monotheistisch“ nicht bereits auf konkrete religiöse Praktiken und Überzeugungen bezogen, sondern zunächst allein auf die in dieser Studie beschriebene, sich in der Struktur ihrer Gründungserzählungen von der antiken (mythischen) Religiosität und Politischen Theologie aber deutlich unterscheidende Gestalt der Einführung und des Bezugs auf eine nicht-fassbare, nicht-darstellbare und auch nicht unmittelbar benennbare, sondern nur in Gestalt einer symbolischen Leere repräsentierbare autoritative Struktur. In diese Bestimmung fallen die faktischen Entfaltungen der sogenannten „monotheistischen Religionen“ mit ihrem neuartigen Gottesverständnis und ihren dementsprechend ausdifferenzierten Lehren ebenso hinein wie auch andere politische Diskurse, an denen diese Struktur erkennbar wird. Mit diesem, der gewöhnlichen Bezeichnung „monotheistische Religionen“ entlehnten Begriff ist also keineswegs automatisch auch ein religiöser Gehalt verbunden (- im Gegenteil muss sich ein formulierter religiöser Gehalt stets darüber verantworten, ob er tatsächlich „monotheistisch“ ist-), sondern er markiert eine Struktur, die sich grundlegend von der des Mythos und der damit zumindest strukturell vergleichbaren Metaphysik (Onto-Theologie) unterscheidet. Dass vor dem Hintergrund dieser Unterscheidung zahlreiche Phänomene und Diskurse der abendländischen Geistes-, Kultur- und Religionsgeschichte in einer neuen Weise differenziert und unvoreingenommen in den Blick zu nehmen wären, ist eine der Konsequenzen der hier in einem konkreten geschichtlichen Kontext verorteten Überlegungen.

98 Auf einige solche Diskurse wurden oben bereits hingewiesen. Siehe dazu Anm. 9. 
selbst - in den Mosereden des Buches Deuteronomium - eine Kommentierung und Interpretation erfahren hatte. Auf der Ebene der politischen Realität, in die hinein das Exodus-Narrativ entworfen wurde, ist dieser allein verbliebene Text das Exodus-Narrativ selbst. Es wird nun der altorientalischen Königsideologie entgegengehalten und diese damit in ihrer mythischen, herrschaftslegitimierenden Struktur entlarvt und dekonstruiert. Eine grundsätzliche kritische Frage bleibt aber noch zu beantworten: Ist damit am Ende nun aber nicht doch eine mythische Erzählung durch eine andere, alternative, aber ebenso mythische oder mythenähnliche Erzählung ersetzt worden? Abgesehen davon, dass sich in einer bestehenden Kultur ein mythisches Narrativ nicht einfach willentlich durch ein ganz anders gelagertes ersetzen lässt, wird durch das Exodus-Narrativ aber gerade auf der Ebene seiner politischen Relevanz die Struktur des Mythos unwiederholbar unterlaufen. ${ }^{99}$ Sowohl seine Funktion der Legitimation und Aufrechterhaltung des Bestehenden wie auch die damit verbundene Legitimation einer Institution, in der die letztinstanzliche Souveränität autoritativ repräsentiert und verkörpert ist, sind damit dekonstruierbar geworden. ${ }^{100}$

Wie lässt sich nun das politische Potential, das das Exodus-Narrativ auf literarische Weise entfaltet, näher umschreiben? Inwiefern wird der Mythos unterlaufen und wodurch wird die Instanz der königlichen Repräsentation der Souveränität und damit der wirksamen politischen Macht ersetzt? Die Antwort kann an dieser Stelle sehr knapp ausfallen: Die Position des Königs wird im ExodusNarrativ ersetzt durch die Position des Textes. Man kann in diesem Sinn durchaus von einer Textualisierung der Macht sprechen. Die politische Autorität liegt nicht in der Position einer politischen Institution, sondern in der Wahrnehmung der

99 Diese Unwiederholbarkeit besteht nicht darin, dass es keinen Rückfall in eine mythische Legitimationsstruktur mehr geben könne. Die abendländische Kultur- und Geistesgeschichte lässt gerade im Feld des Verständnisses und der Konkretisierung politischer Macht zahlreiche Formen eines solchen Rückfalls erkennen. Diese sind keineswegs auf ihre religiösen Ausdrucksgestalten beschränkt, sondern lassen sich - im Sinne der strukturellen Kriterien, denen das Mythische folgt - in allen politischen und auch revolutionären oder anti-politischen Denkrichtungen finden. Für eine Differenzierung wäre es hilfreich zu erkennen, dass die mythische Struktur (ebenso wie die „monotheistische“ Struktur) nicht an bestimmten Inhalten oder Gattungen festzumachen ist, sondern gewissermaßen an ihrer Performance, das heißt am performativen Modus, in dem ein bestimmter Gehalt vermittelt wird. Unwiederholbar ist die Struktur des Mythos jedoch dadurch, dass sie von nun an durch das Exodus-Narrativ - wie auch jedes andere Narrativ, das dessen performativen Gestus entfaltet - stets identifizierbar und dekonstruierbar geworden ist und von daher jene (in einem bestimmten Rahmen durchaus „funktionierende“) Stabilität und Sicherheit nun nicht mehr plausibel zu gewährleisten vermag. Darin liegt die historische Singularität des „Ereignisses“ des biblischen Exodus.

100 Vielleicht ist eben das die heute politisch durchaus positiv einzuschätzende Bedeutung der „Krise der Repräsentation“. 
Position eines Textes bzw. der politischen Wahrnehmung der Bedeutung von Textualität. ${ }^{101}$ Doch was kann man hier im gegebenen Kontext unter dem Begriff Text verstehen ohne dazu lediglich auf etymologische Erklärungen oder auf voraussetzungsreiche Schriftverständnisse zu verweisen, durch die letztlich für die Fragestellung dieser Studie nichts geklärt würde? Und schließlich: Welche politischen Konsequenzen ergeben sich aus all dem?

Zum ersten: Glücklicherweise entwirft das Exodus-Narrativ auf performative Weise selbst ein Verständnis von Textualität, das seine Relevanz durchaus auch gegenüber gegenwärtigen Fragestellungen behaupten kann: Als Text (im Unterschied zum altorientalischen Verständnis von Schrift als Aufzeichnungsmedium) könnte man ganz allgemein genau jene Position bezeichnen, die das ExodusNarrativ im Bild der Gesetzestafeln vermittelt. Drei Charakteristika zeichnen dieses literarische Bild aus: Diese Tafeln haben (1.) keinen unmittelbaren Autor, präsentieren am Ende also gerade kein Autograph. Sie haben vielmehr lediglich einen nachträglichen Schreiber, der eine Botschaft, die ihm vorgegeben war, festgehalten hat. - Sie sind (2.) nicht unmittelbar verständlich, sondern bedürften eigentlich einer Vermittlung, die ihre schriftliche Gestalt immer wieder auf die ursprünglich mit ihnen verbundene Botschaft hin zu erläutern vermag. Dies war die Funktion des Mose als Kommentator und Interpret zur Zeit der Wüstenwanderung, sowie in den Reden am Ende seines Lebens. - Entscheidend ist aber (3.), dass es diesen mit der ursprünglichen Botschaft direkt verbundenen und gewissermaßen göttlich legitimierten Kommentator und Interpreten in der realen geschichtlichen Situation der Leserinnen und Leser nun ebenfalls nicht mehr gab und gibt. Übrig geblieben sind für das Volk „,im Land“ am Ende lediglich die Tafeln als Text, der diesem Text zugesprochene Anspruch, die Notwendigkeit der Interpretation und nicht zuletzt: die Erfahrung des Modells einer solchen Interpretation durch Mose. In der realen Situation der LeserInnen finden sich alle vier Aspekte nun gebündelt versammelt im verschriftlichten Text des Exodus-Narrativs, der Tora des Mose.

Zum zweiten: Tritt man nun aus der Erzählung heraus und fragt nach der politischen Bedeutung des Narrativs, so ließe sich diese wie folgt zusammenfassen: Das Fundament einer Gesellschaft bzw. einer politischen oder juridischen Ordnung besteht hier nicht einfach in einer gemeinsam geteilten gegebenen Überzeugung, deren Wirksamkeit von einer politischen Institution repräsentiert würde. Dies wäre das Modell der altorientalischen Königsideologien und ihrer späteren abendländischen Fortschreibungsgeschichte. Das politische und gesellschaftliche Band, von dem das Exodus-Narrativ spricht, hat vielmehr den Charakter eines Textes im genannten Sinn, dessen juridische und politische Autorität dadurch markiert ist, dass (1.) die abwesende Position eines Souveräns

101 Siehe dazu ausführlicher: Zeillinger, Dekonstruktive Bibellektüre, aaO. [Anm. 64], 143-164; Zeillinger, Geschichtliche Erinnerung und textuelle Autorität, aaO. [Anm. 64], $149-173$. 
nicht identifiziert oder mit einer identifizierbaren Repräsentation verbunden wird sondern stattdessen mit der symbolischen Repräsentation einer leeren Stelle; dass (2.) die Notwendigkeit sichtbar wird, die konkrete Textgestalt auf die unsichtbare Souveränität hin zu interpretieren; und dass (3.) die notwendige Interpretation die Aufgabe hat, anhand des Textes jene Autorität zu entfalten und zu konkretisieren, deren symbolische Repräsentation der Text auf performative Weise ist. Der Text nötigt also aus sich selbst heraus zu einer politischen Konkretisierung dessen, was er nur in der literarischen Gestalt einer symbolischen Leere als abwesende und daher nicht unmittelbar wirksame souveräne Instanz zu repräsentieren vermag.

Diese drei Punkte sind letztlich nichts anderes als eine strukturelle Beschreibung dessen, was das Exodus-Narrativ (neben vielen anderen Aspekten) der altorientalischen Königsideologie politisch entgegenhält und sich dadurch als Grundlegungsdiskurs im strukturell „monotheistischen“ Sinn ${ }^{102}$ empfiehlt:

1. Das Exodus-Narrativ entwirft nirgends eine unmittelbare Repräsentation der abwesenden Souveränität: Der biblische Gott JHWH ist nicht darstellbar, nicht repräsentierbar, sein Name wird nicht ausgesprochen und seine Benennung stellt keine Identifizierung dar, sondern besitzt eher den Charakter eines Versprechens. ${ }^{103}$ Auch Mose ist nicht das Pendant zum altorientalischen König und seine Mittler-Position ist singulär. Nicht erst die rabbinische Tradition, sondern bereits der Text selbst sind hier sehr deutlich (Num 12,6-8; Dtn 34,10.12). Seine Stellung kann von niemandem nach ihm im selben Sinn eingenommen werden. Zudem ist Mose im Moment der Rezeption - also in der Situation der Rezipienten „im Land“ -, selbst bereits abwesend. ${ }^{104}$ Damit bleibt die Position des Souveräns im Sinn des bisherigen Verständnisses von Repräsentation, insofern es die altorientalische Königsideologie und ihre

102 S.o. Anm. 97.

103 Siehe dazu oben Anm. 97.

104 Hier findet ein bemerkenswerter Übergang statt von der Autorität des Mose im Rahmen der Exodus-Fabel hin zur Autorität des Exodus-Narrativs in der geschichtlichen Wirklichkeit. Die „Abwesenheit“ des Mose im Gelobten Land stellt innerhalb der Erzählung kein Problem dar, da seine Autorität in die Autorität seiner Auslegung übergegangen ist und von dieser Auslegung gesagt wird, dass sie mit der Offenbarung Gottes übereinstimmt (siehe oben Anm. 84). Damit stellen aber auch in der geschichtlichen Realität der Rezipienten bis heute weder die Abwesenheit des Mose noch das Wissen um den Exodus als Fabel ein Manko dar. Die Autorität des Narrativs ist - aufgrund der besonderen Performativität des Textes - identisch mit der Autorität, von der es erzählt. Der Anspruch des Narrativs ist ja nicht der, dass es historische Abläufe korrekt vermittelt, sondern der, dass seine Botschaft eine grundlegende, politisch und ethisch relevante Alternative zur herrschenden Ordnung der politischen Repräsentation von Souveränität formuliert und lebbar macht. In dieser performativen Veränderung des Weltbilds und des daraus resultierenden Handelns liegt die Realität der Exodus-Befreiung, die sehr konkret in eine neue gesellschaftliche Ordnung hineinführt. 
weitere Geschichte bis in die Gegenwart prägt, un-repräsentiert und unrepräsentierbar. Die kulturellen Praktiken der Aufrichtung symbolischer Repräsentationen in der biblischen Tradition tragen vielmehr alle den Charakter einer Leerstelle (Bilderverbot, Nicht-Aussprechen des Namens Gottes, leeres Allerheiligstes im Tempel, leeres Grab, etc.).

2. Das Exodus-Narrativ entwirft eine Vorstellung eines autoritativen Textes (als der es sich letztlich selbst erweist), der allerdings kein Autograph ist und der für seine Aktualisierung stets eines interpretierenden Kommentars bedarf. Das Narrativ entwirft sich trotz des Bezugs auf eine textuelle Autorität letztlich selbst nur als nachträgliches Ergebnis aber zugleich auch als Vollzug eines solchen Kommentars.

3. Die Funktion der Interpretation bzw. des Kommentars wird mit der Figur des Mose so eingeführt, dass der Interpret im Namen jener Instanz zu sprechen hat, die er mit dem Text verbindet. Der Kommentar muss sich auf das Narrativ einlassen, er kann nicht über es hinweg kommentieren. Damit ist ein Kriterium gegeben, das nicht nur Willkür in der Kommentierung sondern auch willkürliche Kritik als inadäquat zu entlarven vermag. Auf diese Weise wird die singuläre Figur des Mose zum Modell für alle späteren Kommentatoren und Interpreten im Sinn der biblischen Schriftgelehrten, also jener mit der Schrift vertrauten Schreiber, die den Text von diesem selbst her, das heißt von dem, woraufhin er performativ zielt, und nicht von einer an ihn herangetragenen Intention her zu interpretieren versuchen.

\section{c) Die Repräsentation der Zukunft}

Es ist gerade der zuletzt genannte Aspekt, der über eine Dekonstruktion und Delegitimation des Modells der souveränen Repräsentation hinausgeht und die Struktur eines politisch wirkmächtigen Gegenmodells zur altorientalischen Königsideologie bzw. überhaupt zur Repräsentation souveräner Macht erkennen lässt. Während das mythische Weltbild alle politischen und ethischen Entscheidungen am Rückgriff auf ein bereits (Vor-)Gegebenes orientiert ${ }^{105}$ und damit

105 Es ist auffällig, dass sowohl die abendländische metaphysische Tradition als auch der klassische phänomenologische Ansatz trotz der Einführung des neuzeitlichen Subjektverständnisses diese Orientierung am (Vor-)Gegebenen erkennen lassen und damit in struktureller Hinsicht mit dem mythischen Denken kompatibel sind bzw. in ihrem Denken mit der Struktur der Mythos, dessen Grundüberzeugung die einer trotz aller Spannungen einheitlichen Ordnung ist, in die der Mensch gestellt ist, offensichtlich nicht gebrochen haben. Erst jene sogenannten „nachmetaphysischen“, post-strukturalistischen und postphänomenologischen Denkrichtungen, in denen nicht nur die Unmöglichkeit, einen letzten identifizierbaren Grund zu benennen, konstatiert wird, sondern in denen diese Unmöglichkeit darüber hinaus auch als Unterbrechung der eigenen Dis- 
strukturell an der Temporalität der Vergangenheit oder ihrer Repräsentation in der Gegenwart, ${ }^{106}$ ist das biblische Modell der Auslegung und des Kommentars an einer anderen temporalen Struktur orientiert, in der der Blick auf die Zukunft kulturgeschichtlich erstmals eine positive gegenwartsverändernde Bedeutung erhält. Diese Zukunftsorientierung lässt sich strukturell am besten mit der Zeitform des Futur II zum Ausdruck bringen. Israel wird auf das Leben im Gelobten Land nicht als einem zukünftigen Ereignis ,vertröstet“, sondern an dieser - Vergangenheit und Gegenwart transformierenden - Zukunft ist das gesamte Geschehen schon jetzt (d. h. schon vom Auszug aus der alten Ordnung an) ausgerichtet. Eine aufmerksame Lektüre aber zeigt, dass die befreite Gegenwart auch tatsächlich bereits von der Ordnung der Zukunft geprägt sein muss (auch wenn ihre ,Vollendung" noch aussteht), um die Wüstenwanderung zu beenden und den Einzug ins Gelobte Land zu vollziehen. - Doch was hat die Form des interpretierenden Kommentars bzw. der Auslegung mit dieser Zukunft-schon-jetzt zu tun?

Das im Exodus-Narrativ repräsentierte Modell der Auslegung und Fortschreibung eines Textes unterscheidet sich grundlegend von der ungefähr zeitgleich eigenständig entstehenden Praxis der Kommentierung und Interpretation in der griechisch-römischen Kultur. Dort war die Kommentarkultur vor allem durch die Einführung der Kulturtechnik der Schrift sowie der Eigenart der Alphabetschrift angestoßen worden. ${ }^{107}$ Am Beginn dieser Entwicklung stand vor allem die Intention der Klärung von Widersprüchen sowie von nicht mehr verstandenen Begriffen und Zusammenhängen im Zentrum, nicht aber der Gestus eines konkretisierenden Umgangs mit dem Nichtdarstellbaren. Dagegen kommentiert bzw. interpretiert die Figur des Mose im Exodus-Narrativ nicht um Widersprüche aufzulösen, sondern um - anhand eines in der Erzählung eigentlich bereits vorliegenden (Gesetzes-)Textes - eine zukunftseröffnende Lektüre zu präsentieren, auf welche Weise das, was in diesem Text nicht einfach konstatiert sondern auf eine zu deutende Weise repräsentiert wird, zu verstehen sei, um damit die verheißene künftige Ordnung bereits hier-und-jetzt in der jeweils aktuellen Situation sichtbar zu machen. Das Modell der Auslegung, das das Exodus-Narrativ entwirft, stellt also eine Aktualisierung und Konkretisierung dar, die über die gegebene Ordnung und das aus ihr Deduzierbare hinausweist auf eine durch und in dem Text verheißene geschichtliche Zukunft. Die Einleitung und Fortführung der Deuteronomiumsfassung des Dekalogs, der im Bild der Exoduserzählung mit den beiden Tafeln, die Mose erhalten hat, identifiziert wird, aber

kursgestalt mitreflektiert wird, sodass diese Unterbrechung zu einem im Diskurs eigens zu „repräsentierenden“ Ausgangspunkt geworden ist, - erst diese Diskurse lassen sich mit der „monotheistischen Struktur“ (s. o. Anm. 97) des Exodus-Narrativs und der daran anschließenden Traditionen strukturell vergleichen.

106 Siehe dazu Maul, Altorientalische Schöpfungsmythen, aaO. [Anm. 44].

107 Vgl. dazu Han Baltussen, From Polemic to Exegesis. The Ancient Philosophical Commentary, in: Poetics Today 28.2 (2007), 247-281. 
zugleich auch das gesamte Gesetz vom Sinai und damit die Tora repräsentiert ${ }^{108}$, lässt diese Struktur einer zukunftseröffnenden Auslegung in kaum zu überbietender Klarheit erkennen.

„5 $5^{1}$ Und Mose rief ganz Israel zusammen und sprach zu ihnen: Höre Israel die Gebote und Gesetze, die ich euch heute zu Gehör bringe; ihr aber sollt sie lernen und achten, sie zu befolgen. ${ }^{2}$ JHWH, unser Gott, hat mit uns einen Bund am Horeb geschlossen. ${ }^{3}$ Nicht mit unsern Vätern hat JHWH diesen Bund geschlossen, sondern mit uns, die wir hier heute alle am Leben sind. ${ }^{4}$ Von Angesicht zu Angesicht sprach JHWH mit euch auf dem Berg mitten aus dem Feuer. ${ }^{5}$ Ich aber stand zu jener Zeit zwischen JHWH und euch, um euch die Worte JHWHs kundzutun. [...]

$6^{17} \mathrm{Ihr}$ sollt die Satzungen JHWHs, eures Gottes, beachten und seine Weisungen und Gebote, auf die er dich verpflichtet. ${ }^{18}$ Und du sollst das in den Augen JHWHs Rechte und Gute tun, damit es dir gut geht und du in das gute Land, das JHWH deinen Vätern zugeschworen hat, kommst und es in Besitz nimmst. “"109

Hier sind zunächst die drei Zeitebenen erkennbar, die das Exodus-Narrativ umfasst - 1. die ,ursprüngliche“ Erfahrung am Berg Sinai, 2. Die „gegenwärtige“ Situation von Moses Zusammenfassung der Gesetze, die einer endgültigen Promulgation gleichkommt, kurz vor seinem Tod und dem Einzug des Volkes ins Land, und 3. die künftige Situation, in der dieses Gesetz bestimmend sein soll und die zugleich die Situation derer ist, für die dieser Text ein Gründungsnarrativ darstellt. Darüber hinaus wird aber auch deutlich, dass das gute Leben in dem guten Land (v. 18) letztlich von der Anerkennung und zumindest anfanghaften Realisierung der mit der „Tora vom Sinai“ verbundenen Ordnung abhängt. Damit verknüpft das Narrativ selbst, wie wir bereits mehrfach gesehen haben, die Situation der späteren Rezipienten mit derjenigen in der Erzählung. Auf diese Weise wird eine historisch letztlich nie abschließbare Zukunftsorientierung eröffnet. Sie läuft darauf hinaus, dass das gute (künftige oder aber jeweils gegenwärtige) Leben in dem „Verheißenen Land“ im kollektiven Verhalten hier-undjetzt zur Realisierung gelangt und nicht von der Historizität einer geographischen Wanderungsbewegung in der Vergangenheit abhängt.

Das Exodus-Narrativ liefert mehrere performative Hinweise darauf, dass es auf diese Weise nicht einfach eine mythische oder poetische Erzählung als Gesetz promulgiert, ${ }^{110}$ sondern vielmehr als narrative Einführung einer notwendigen, an

108 „Die Tafeln konnten als so bestimmtes und geprägtes Symbol für die Offenbarung am Sinai nicht nur ins Zentrum aller möglichen bildlichen Darstellungen des Sinaiereignisses gerückt werden, sondern sogar zum Inbegriff der Tora und so letztlich auch zu dem bedeutendsten Symbol für das Judentum werden." (Dohmen, Exodus 19-40, aaO. [Anm. 72], 214.)

109 Übers. nach Otto, Deuteronomium. Bd. 2, aaO. [Anm. 31], 667. 778.

110 Einen deutlichen Hinweis auf den Anspruch der Realisierbarkeit der neu etablierten Ordnung gibt Mose in der Erzählung selbst, wenn er die „Nähe“ des Gesetzes 
der Zukunft orientierten Haltung anzusehen ist. Diese Haltung würde demnach darin bestehen, je neu eine interpretierende Konkretisierung (Auslegung) dessen zu formulieren, was sich künftig als ein Leben im Gelobten Land herausgestellt haben soll, und die je gegenwärtige soziale und politische Ordnung daran auszurichten. Es handelt sich also um keine Zukunftsvertröstung, sondern um eine schon jetzt wirksame und praktizierte Veränderung. Das entscheidende Kriterium, das bei all dem im Zentrum steht, wäre - so die Spitze der gesamten Erzählung -, einer Souveränität konkreten Ausdruck zu verleihen, die als solche nicht präsentierbar und auch nicht repräsentierbar ist. Das Narrativ stellt sich schließlich selbst als eine solche aktualisierende Konkretisierung dar, wie an der doppelten und miteinander verknüpften Einführung des Gesetzes vom Sinai erkennbar wird. Dass es sich bei der „zweiten“ Darstellung der Ereignisse im Zwischenbereich der Wüste ${ }^{111}$ - zwischen alter Herrschaft und neuer Ordnung -, der zugleich als Ort einer neuen, zukunftsorientierten Art der Gesetzgebung inszeniert wird, um eine solche aktualisierende Auslegung handelt, wird schon dadurch erkennbar, dass Mose auf der Ebene der literarischen Erzählung etwas zusammenfasst, das den späteren LeserInnen des kanonisierten Pentateuch aus der Sinai-Theophanie (Ex 19-34) bereits bekannt ist, die bereits geschilderten Ereignisse aber nun leicht verändert präsentiert werden. Dass diese Darstellung aber auch in der realen Rezeptionsgeschichte zu einer aktualisierenden Auslegung nötigt, erschließt sich - wie wir gesehen haben ${ }^{112}$ - aus der Tatsache, dass die Brüche zwischen Moses Zusammenfassung und der früheren Darstellung der Ereignisse von den biblischen Redaktoren durchaus bewusst und nicht aus Mangel an Überblick oder konzeptioneller Kraft stehengelassen wurden und von einer aufmerksamen Lektüre in ihrem Anspruch an die jeweilige Gegenwart erhellt werden können. Letztlich ist es genau diese Gestalt des Narrativs - in der die Brüche, Wiederholungen und temporalen Spannungen eine konzeptionelle Rolle spielen ${ }^{113}$-, die die Aufgabe der Grundlegung einer zukunftseröffnenden Ordnung erfüllt und damit - im Bild des Narrativs - den Einzug in das ,VerheiBene Land" ermöglicht.

Die am Exodus-Narrativ sichtbar werdende spezifische Temporalität ist nicht einfach die des Vorblicks auf eine Zukunft im Sinne einer vorwegnehmenden

zum Menschen und damit seine Verstehbarkeit für jeden betont. Dieser Hinweis wäre wohl als selbstkritisches Kriterium für jede Form der Rezeption und Konkretisierung des Exodus-Motivs ernstzunehmen: „30 $3{ }^{11}$ Fürwahr, diese Satzung, auf die ich dich heute verpflichte, ist nicht zu wundersam für dich und zu fern. ${ }^{12}$ Nicht im Himmel ist sie, sodass man sagen müsste, wer kann uns für uns zum Himmel hinaufsteigen sie zu uns holen und sie für uns hörbar machen, sodass wir sie erfüllen können?" (Übers. nach Otto, Deuteronomium. Bd. 4, aaO. [Anm. 31], 2033, zur Deutung siehe ebd. 2071-2073.)

111 Otto, Deuteronomium. Bd. 4, aaO. [Anm. 31], 2050.

112 Siehe oben Anm. 74 und Anm. 83.

113 Siehe oben Anm. 30 und Anm. 31. 
Antizipation (die sich der herrschenden Ordnung einfügen lässt), sondern lässt sich als Verzahnung von Zukunft und Gegenwart verstehen (und damit als Störung, Unterbrechung und Öffnung der Gegenwart) - im Unterschied zur Verzahnung von Gegenwart und Vergangenheit in den Modellen einer identifizierbaren Repräsentation von Souveränität. Die Funktion dieser Temporalität besteht dabei darin, der prinzipiell nicht-darstellbaren Souveränität einen gleichwohl vermittelbaren Ausdruck zu verleihen und damit nicht nur eine neue Ordnung zu etablieren, sondern die damit angezeigten Veränderungen bereits in der Gegenwart wirksam werden zu lassen. Diese Form politikrelevanter Temporalität entspricht jenem Zeitverständnis, das in zahlreichen zeitgenössischen philosophischen Diskursen gerade dort, wo die Etablierung einer politischen Orientierung ohne Möglichkeit des Rückgriffs auf ein letztes Fundament thematisiert wird, als Modus des futur antérieur bezeichnet wird. Damit ist stets der Gestus verbunden, bereits in der Gegenwart hier-und-jetzt eine Zukunft zu antizipieren, deren Veränderungen die herrschende Ordnung schon jetzt stören. Ein solcher Gestus lässt sich - trotz mancher möglicher Missverständnisse - in der grammatischen Form des Futur II durchaus angemessen zum Ausdruck bringen. Diese Temporalität des futur antérieur, die sich ausdrücklich reflektiert zumindest in den Arbeiten von Jean-François Lyotard ${ }^{114}$, Jacques Derrida ${ }^{115}$, Emmanuel Levinas, ${ }^{116}$ Alain Badiou ${ }^{117}$, Jean-Luc Nancy ${ }^{118}$ Judith Butler ${ }^{119}$ und Giorgio Ag-

114 Vgl. etwa Lyotards „Definition“ der Postmoderne: „Ein postmoderner Künstler oder Schriftsteller ist in derselben Situation wie ein Philosoph: [...] sie arbeiten, um die Regel dessen zu erstellen, was gemacht worden sein wird. [...] Postmodern wäre also das Paradox der Vorzukunft (post-modo) zu denken.“, in: Jean-François Lyotard, Beantwortung der Frage: Was ist postmodern?, in: Postmoderne für Kinder. Briefe aus den Jahren 1982-1985 (Wien: Passagen, 1987), 11-31, hier: 29 f.

115 Vgl. zur Temporalität des futur antérieur bei Derrida im Kontext von Theologie und einem politischen Verständnis von „Postmoderne“ im Sinne Lyotards (siehe vorige Anm.): Peter Zeillinger, Jacques Derrida: Gott im-Kommen, in: Peter Hardt / Klaus von Sтоsch (Hg.), Für eine schwache Vernunft? Beiträge zu einer Theologie nach der Postmoderne (Ostfildern: Grünewald, 2007), 66-83.

116 Zur spezifischen Temporalität des Alteritätsdenkens bei Levinas vgl. zusammenfassend Zeillinger, Offenbarung als Ereignis, aaO. [Anm. 13], bes. 41-54 (zu Levinas). 117 Zur zentralen Bedeutung des Ereignisses und der Temporalität des futur antérieur bei Badiou vgl. Peter ZeILlinger, Dem Ereignis nach-denken. Hat Badious Philosophie eine Zukunft?, in: Jens Knipp / Frank MeIEr (Hg.), Treue zur Wahrheit. Die Begründung der Philosophie Alain Badious (Münster: Unrast, 2010), 221-237, sowie Zeillinger, Offenbarung als Ereignis, aaO. [Anm. 13], 55-62 (zu Badiou).

118 Jean-Luc Nancy, Dekonstruktion des Christentums (Zürich-Berlin: Diaphanes, 2009 [fr. 2005]). Vgl. dazu Friederike D. Rass / Anita Sophia Horn / Michael U. Braunschweig (Hg.), Entzug des Göttlichen. Interdisziplinäre Beiträge zu Jean-Luc Nancys Projekt einer „Dekonstruktion des Christentums“ (Freiburg-München: Alber, 2017), sowie den theologischen Zugang in: Fana Schiefen, Öffnung des Christentums? 
amben ${ }^{120}$ findet und dort zumeist auch den Kern ihrer politischen Entwürfe prägt, wird zudem mit dem Begriff des Ereignisses in Verbindung gebracht, das sich strukturell und temporal mit jenem Verständnis von Offenbarung deckt, das in den monotheistischen Text-Traditionen entfaltet wird. ${ }^{121} \mathrm{Um}$ an dieser Stelle zumindest einen Ausblick auf diese Parallele zu geben, sei hier eine zusammenfassende Umschreibung des Ereignisverständnisses von Alain Badiou ${ }^{122}$ zitiert:

"An event is something that can be said to exist (or rather, to have existed) only insofar as it somehow inspires subjects to wager on its existence." ${ }^{123}$

Eine fundamentaltheologische Auseinandersetzung mit der Dekonstruktion des Christentums nach Jean-Luc Nancy (m. e. Geleitwort v. J.-L. Nancy; Regensburg: Pustet, 2018).

119 Judith ButLer, Raster des Krieges. Warum wir nicht jedes Leid beklagen (Frankfurt/ M.-New York: Campus, 2010 [amer. 2009]), bes. 9-38 (Kap. „Gefährdetes Leben, betrauerbares Leben“), sowie nun erhellend: Florian Pistrol, Vulnerabilität. Erläuterungen zu einem Schlüsselbegriff im Denken Judith Butlers, in: Zeitschrift für Praktische Philosophie, 3.1 (2016), 233-272, bes. 244 (futur antérieur) und den Sammelband: Gerald Posselt / Tatjana SchönwäLder-Kuntze / Sergej SeITz (Hg.), Judith Butlers Philosophie des Politischen. Kritische Lektüren (Bielefeld: transcript, 2018), bes. die Beiträge von Sergej Seitz (ebd. 71-98) und Matthias Flatscher / Florian Pistrol (ebd. 99-124).

120 Giorgio Agamben, Signatura rerum. Zur Methode (Frankfurt/M.: Suhrkamp, 2009 [ital. 2008]). - Zum Rückbezug sowohl von Agamben als auch von Michel Foucault auf frühchristliche Gemeinschaftspraktiken, die den Modus des futur antérieur in einem politikrelevanten Kontext erkennen lassen, vgl. Peter ZeILlinger, Disillusioning Reason - Rethinking Faith. Paul, Performative Speech Acts and the Political History of the Occident in Agamben and Foucault, in: Gert-Jan van der Heiden / George van Kooten / Antonio Cimino (Hg.), Saint Paul and Philosophy. The Consonance of Ancient and Modern Thought (Berlin-Boston: de Gruyter, 2017), 95-113.

121 Vgl. dazu ausführlich Zeillinger, Offenbarung als Ereignis, aaO. [Anm. 13].

122 Das Ereignis-Denken von Alain Badiou eignet sich in besonderer Weise dafür, die Struktur des monotheistischen Offenbarungsverständnisses zu beschreiben. Die jüdische Literaturwissenschaftlerin Regina M. Schwartz hat zudem - unter dem Titel „Offenbarung und Revolution“ - die große Nähe dieses Ereignisverständnisses zur Ethik und Politik der Alterität bei Emmanuel Levinas gerade im Kontext des Sinai-Ereignisses hervorgehoben: Regina Mara Schwartz, Revelation and Revolution, in: Creston Davis / John Milbank / Slavoj Zizek (Hg.), Theology and the Political. The New Debate (Durham-London: Duke UP, 2005), 102-124. Zur näheren Darstellung des Badiou'schen Ereignis-Denkens siehe Zeillinger, Dem Ereignis nach-denken, aaO. [Anm. 117].

123 Peter Hallward, Badiou. A Subject to Truth (Minneapolis-London: University of Minnesota Press, 2003), hier: 115. Hallward zitiert hier Alain Badiou, Das Sein und das Ereignis (Berlin: diaphanes, 2005 [fr. 1988]), 220. 
„Since the event has no present and leaves no durable trace, the temporality of the event as such is necessarily confined to the time of a future anterior: thanks to a subsequent subjective intervention, the event „,will have been presented“.“124

Das Ereignishafte, das sich in der herrschenden Ordnung weder unmittelbar präsentieren noch mit den Mitteln der gegebenen Ordnung repräsentieren lässt und dennoch als nicht-einordenbare Störung (Spur) diese bereits in Frage stellt, ${ }^{125}$ kann nur dadurch vermittelt werden und eine zukünftige Ordnung schon jetzt repräsentieren, dass das Wagnis eingegangen wird, dieser Zukunft schon jetzt einen bekenntnishaften, an der spurhaften Erfahrung der Störung zu messenden Ausdruck zu verleihen. Wird dieses Wagnis nicht eingegangen oder wieder mit einer präsentischen Repräsentation identifiziert, so findet diese Öffnung de facto nicht statt, sondern es wird neuerlich ein klassisches Herrschaftsregime - welcher Art auch immer - etabliert.

Eben dies bringt das Exodus-Narrativ gegen die Identifikation der Repräsentation einer Souveränität, wie sie in der neuassyrischen Königsideologie politisch wirksam war, in Stellung: das Selbstverständnis, eine nicht-darstellbare Souveränität nur in Gestalt einer gewagten und immer wieder neu zu interpretierenden und zu konkretisierenden Erzählung repräsentieren zu können, in der eine verheißungsvolle Zukunft schon jetzt politisch und gesellschaftlich relevant wird und die herrschende Ordnung wirksam und sichtbar verändert. Eine solche identitätsstiftende Erzählung und zugleich politikrelevante Kriteriologie besitzt so lässt sich nun zusammenfassend formulieren - stets den Charakter der symbolischen Repräsentation einer leeren Stelle.

\section{Auszug ins Reale: Die Struktur der Exoduserzählung und die zeitgenössische Politische Philosophie}

Was bleibt nun aus diesen Beobachtungen zum historischen Kontext und zur spezifischen Struktur des Exodus-Narrativs für die gegenwärtigen Herausforderungen einer Grundlegung des Politischen vor dem Hintergrund des eingangs zitierten Problems einer „Krise der Repräsentation“? Lässt sich - und wenn ja: wie - heute eine Politik des Exodus denken? Lässt sich das biblische ExodusMotiv für eine heutige Politik fruchtbar machen?

124 Hallward, Badiou, 115 (Kursiv v. Verf.), mit Verweis auf Badiou, Das Sein und das Ereignis, 224.

125 „Ein Ereignis ist aber eine Störung der Ordnung der Welt [...]“ (Alain BADIOU, Zweites Manifest für die Philosophie (Wien-Berlin: Turia+Kant, 2010 [fr. 2009]), hier: 85.) 
Repräsentation einer Leerstelle, oder: Auszug ins Reale

Drei grundlegende Aspekte müsste jede künftige Politische Theorie, die das biblische Exodus-Motiv entweder affirmativ oder auch kritisch aufgreift, berücksichtigen, um das Niveau der biblischen Erzählung nicht zu unterbieten:

1. Der Exodus hat historisch nicht stattgefunden im Sinne eines Migrationsereignisses in ferner Vergangenheit.

2. Das Exodus-Narrativ kann nicht auf eine mythische Erzählung, ein poetisches Motiv oder ein kollektives Wunschdenken reduziert werden.

3. Stattdessen stellt der Exodus - sowohl in der Sicht der Schreiber als auch aus der Sicht der Rezipienten, die ihr Selbstverständnis und ihre Identität damit verbunden haben - eine historisch verortete und wirksam gewordene Transformation der Legitimation und Repräsentation grundlegender Souveränität, politischer Macht und juridischer Entscheidung dar. Im Sinn dieses, im Alten Israel wirkmächtig gewordenen Gegenentwurfs zur mythischen Repräsentation souveräner Macht hat der Exodus sehr wohl stattgefunden und offeriert seitdem nicht nur ein (in seiner späteren Rezeption leider nur selten ausgeschöpftes) Modell eines je neu zu konkretisierenden revolutionären „Auszugs aus ... " einem Herrschaftsregime, sondern auch eine bislang fast unbemerkt gebliebene Kriteriologie für den „Einzug in ..." eine zukunftsorientierte Ordnung im Sinne einer „Gemeinschaft-ohne-Souveränität“, eines Gemeinschaftsverständnisses also, das nicht mehr auf einer Repräsentation von Souveränität, sondern auf der Repräsentation des „ohne-Souveränität“ gebaut ist. ${ }^{126}$ Dieses „ohne-Souveränität“ hat sich im Exodus-Narrativ als gleichbedeutend mit dem Charakter von Textualität erwiesen. ${ }^{127}$

Dieser letzte Aspekt ist der Grund dafür, dass ich das biblische Exodus-Motiv als höchst relevant angesichts der gegenwärtigen politischen Herausforderungen hervorhebe. Es wäre an dieser Stelle nun reizvoll, diese Studie in eine ausführliche Lektüre der zentralen Aussagen und der Performativität der monotheistischen Traditionen überzuführen und zu fragen, inwiefern den traditionellen Lektüren dieser Überlieferungen inner- und außerhalb der sich geschichtlich entfaltenden monotheistischen Religionen ein zusätzlicher Blickwinkel zur Seite gestellt werden könnte und wie daraus ein gegenwärtiger Ansatz politischer Theorie zu gewinnen wäre. Da ein solches Projekt an dieser Stelle jedoch nicht geleistet werden kann, muss ich mich auf die Hervorhebung der gewonnenen Kriteriologie, deren Grundzüge in den Titeln der Unterkapitel des vorigen Abschnitts formuliert sind, beschränken: (1.) Das Kriterium des Aufzeigens der leeren Stelle der

126 Das „Ohne“ in dieser Formulierung bezieht sich nicht auf eine simple Negation von Souveränität, sondern auf die Notwendigkeit, einen Diskurs ohne Rückgriff auf eine fassbare Souveränität führen zu müssen. Siehe dazu auch oben Anm. 21.

127 Zum Verständnis von Textualität im biblischen Kontext vgl. nochmals Zeillinger, Dekonstruktive Bibellektüre, aaO. [Anm. 64], sowie Zeillinger, Geschichtliche Erinnerung und textuelle Autorität, aaO. [Anm. 64]. 
Souveränität, (2.) das Verständnis der unhintergehbaren Textualisierung der Macht und der damit notwendigen Haltung der aktualisierenden Auslegung, und schließlich (3.) die Repräsentation der Zukunft, die weder in Gestalt eines Aufschubs oder einer Vertröstung noch in Gestalt einer eindeutigen Identifizierung gelingen kann, sondern stets dem Modus des futur antérieur verpflichtet bleibt, der auf das zweite Kriterium einer notwendigen ,aktualisierenden Auslegung und Konkretisierung" rückverweist.

Gerade im Sinn dieses dritten Kriteriums ist ein Aufschub des Projekts der Formulierung einer sich aus dem Exodus-Motiv speisenden Politischen Theorie allerdings indiskutabel. Daher sollen zum Abschluss dieser Studie zumindest einige Hinweise auf AutorInnen gegeben werden, in deren Werken sich bereits Ansätze formuliert und entfaltet finden, die den gerade genannten Kriterien einer Exodus-Politik im Sinn des geschichtlichen Exodus-Narrativs der monotheistischen Traditionen entsprechen.

Das Konzept der Leere, das die Position der souveränen Macht markiert, die nicht präsentiert und nicht repräsentiert, sondern nur bezeugt (Zeugnis, Bekenntnis, Wagnis) werden kann, findet sich in zahlreichen sogenannten poststrukturalistischen, postphänomenologischen oder dekonstruktiven Zugängen zum Politischen. Eine Schwierigkeit der gegenwärtigen Rezeption besteht darin, den gerade im deutschsprachigen Raum durch zum Teil haarsträubende Misslektüren verstellten Zugang zu diesen immer wieder in einer zu berücksichtigenden Performativität formulierten Texten wiederzugewinnen. Insbesondere in den Arbeiten von Alain Badiou, Jacques Derrida, Emmanuel Levinas, Giorgio Agamben oder Jean-Luc Nancy finden sich affirmative Bezüge auf das Unbenennbare und das Unrepräsentierbare, die nichtsdestotrotz in die Fähigkeit münden, einen ethischen oder politischen Diskurs grundzulegen.

- Alain Badious Paulus-Lektüren ${ }^{128}$ und seine Ethik des Realen ${ }^{129}$, die auf seinem ausdrücklich politisch orientierten Ereignisverständnis beruhen, folgen in vielerlei Hinsicht jenem Zugang zum Politischen, den ich aus der Begegnung mit dem Exodus-Narrativ herauszuarbeiten versucht habe.

Ein politisches Subjekt bei Badiou entsteht dadurch, ${ }^{130}$ dass es einem „Ereignis“, das nur als Störung der gegebenen Ordnung bezeichnet werden kann, in einem nachträglichen interventionistischen Akt eine Benennung (d. h. eine konkretisie-

128 Alain BADIou, Paulus. Die Begründung des Universalismus (München: sequenzia, 2002 [fr. 1997]).

129 Alain BADIou, Ethik. Versuch über das Bewusstsein des Bösen (Wien: Turia+Kant, 2003 [fr. 1993]).

130 Vgl. dazu Peter Zeillinger, Badiou und Paulus. Das Ereignis als Norm?, in: Mitteilungen des Instituts für Wissenschaft und Kunst, 61.3-4 (2006) H.2, 6-12., sowie Ders., Dem Ereignis nach-denken, aaO. [Anm. 117]. Siehe dazu auch Schwartz, Revelation and Revolution, aaO. [Anm. 122]. 
rende Interpretation, eine intervention interprétante ${ }^{131}$ ) gibt, die ihrerseits die herrschende Ordnung stört, in sie aber einen neuen Diskurs (eine „neue Wahrheit") einbringt, der aus der Interpretation des Ereignisses politische Konsequenzen ableitet. Das Subjekt darf sich seiner Sache dabei aber nicht unhinterfragbar sicher sein, sondern muss seine „Treue zur Wahrheit“ im laufenden Diskurs bewähren. ${ }^{132}$

- Giorgio Agambens Bezug auf die messianische Temporalität des futur antérieur hat ebenfalls in einer Paulus-Lektüre einen prominenten biblischen Bezugspunkt. ${ }^{133}$

So lässt etwa Paulus' Verwendung der Formulierung hos mé, „als ob nicht“, in 1 Kor 7 („Die Frauen-habenden sollen sein als ob nicht Frauen-habende, die Weinenden als ob nicht Weinende, ...") im Kontext einer - in der theologischen Tradition oft im Sinne einer „kurzen Dauer“ missverstandenen - christlichen „Naherwartung“ erkennen, dass es ihm nicht darum geht, die gegebene Situation in irgendeiner Form physisch zu verlassen, sondern die Bedeutung allen Lebens und Handelns im Hier-und-Jetzt, von einer Zukunft her zu bestimmen, der ChristInnen aus ihrem Bezug auf das Auferstehungsereignis, die Treue halten und auf diese Weise die Situation zu verändern.

- Emmanuel Levinas' Verständnis radikaler Alterität und ihrer Wahrnehmbarkeit im Phänomen der Spur als „, dérangement der herrschenden Ordnung “ wie sie nach mehreren scheiternden Anläufen in seinem berühmten Artikel Rätsel und Phänomen (1965) ${ }^{134}$ entwickelt wurde und damit sein Spätwerk Jenseits des

131 Alain Badiou, Das Sein und das Ereignis (Berlin: diaphanes, 2005 [fr. 1988]), 208: „[A]llein eine interpretierende Intervention (intervention interprétante) [kann] ausdrücken, dass das Ereignis in der Situation präsentiert ist, insofern es vom Nicht-Sein ins Sein gekommen (аdvепие), aus dem Unsichtbaren zum Sichtbaren gekommen (advenue) ist." (Übers. mod.)

132 In seinem Ethik-Buch (s.o. Anm. 129) entwirft Badiou eine eingängige Kriteriologie einer dreifachen politischen „Verfehlung des Ereignisses“: (1.) „Wenn sich unter Namen, die den wirklichen Wahrheitsprozessen entlehnt sind, ein in einer Situation radikaler Bruch statt auf die Leere auf die ,volle“ Besonderheit oder die hypostasierte Substanz dieser Situation beruft, dann wird man sagen, dass man vor einem Trugbild der Wahrheit steht.“ (ebd. 97) Wenn (2.) die „Benennung“ eines Ereignis letztlich von einem Interesse geleitet ist, spricht Badiou von einem „Verrat“ (ebd. 102-104), und wenn (3.) der Ereignis-Diskurs als solcher verabsolutiert wird, dann ,werden wir diese Form des Bösen ein Desaster nennen, Desaster der Wahrheit, das durch die Verabsolutierung ihrer Macht induziert wurde." (vgl. ebd. 110-112).

133 Giorgio Agamben, Die Zeit, die bleibt. Ein Kommentar zum Römerbrief(Frankfurt/ M.: Suhrkamp, 2006 [ital. 2000]).

134 Vgl. Emmanuel Levinas, Rätsel und Phänomen (1965), in: Die Spur des Anderen. Untersuchungen zur Phänomenologie und Sozialphilosophie (Freiburg/Br.-München: Alber, 1983), 236-260. Zu einer textnahen Rekonstruktion des entscheidenden Ver- 
Seins oder anders als sein geschieht $(1974)^{135}$ und die darin implizierten politischen Konsequenzen erst möglich werden ließen, laufen ebenfalls sowohl auf eine Repräsentation einer Leerstelle hinaus (Levinas spricht von der Notwendigkeit des „Zeugnisgebens“ von einem nicht-identifizierbaren Anderen, sowie vom „Anderen-im-Selben“ als Störung der eigenen Identität), als auch auf Kriterien einer Politik der Alterität, ${ }^{136}$ die sich allerdings erst von seinem im Spätwerk entfalteten Verständnis der „Alterität-im-Plural“ her ergeben. Sie macht es notwendig, dass das Zeugnisgeben vom Anderen zugleich den nochmals ganz anderen „anderen Anderen“, also den „Dritten“, mitberücksichtigt ${ }^{137}$ und so zur notwendig gewordenen Erfindung einer Ordnung führt, die die Wahrnehmung der Alterität bewahrt und nicht wieder im Sinne eines alter ego vom Eigenen her bestimmt. ${ }^{138}$ Nur selten werden allerdings in der sich meist auf das Frühwerk beschränkenden Rezeption des Levinas'schen Werks diese Ansätze einer politischen Theorie der Alterität bei Levinas wahrgenommen und entsprechend gewürdigt ${ }^{139}$.

ständnisses der Spur vgl. Peter Zeillinger, Phänomenologie des Nicht-Phänomenalen. Spur und Inversion des Seins bei Emmanuel Levinas, in: Michael Blamauer / Wolfgang Fasching / Matthias Flatscher (Hg.), Phänomenologische Aufbrüche (Frankfurt/M. u. a.: Lang, 2005), 161-179.

135 Emmanuel Levinas, Jenseits des Seins oder anders als Sein geschieht (Freiburg/Br.München: Alber, 1992 [fr. 1974]).

136 Vgl. zu einer Politik der Alterität und ihrem Bezug zur Zukunft nun: Matthias Flatscher, Derridas „Politik der Alterität“. Zur normativen Dimension des Kommenden, in: Artur R. Boelderl / Monika Leisch-Kiesl (Hg.), „Die Zukunft gehört den Phantomen“. Kunst und Politik nach Derrida (Bielefeld: transcript, 2018), 297-325, sowie vorbereitend: Peter ZeILlinger, Politik der Alterität? - Versuch einer Antwort, in: Flatscher / Loidolt (Hg.), Das Fremde im Selbst, aaO. [Anm. 137]), 305-310.

137 Vgl. dazu Peter Zeillinger, „eins, zwei, viele, ...“- oder: Ohne Selbst aber in Gemeinschaft. Der Einbruch des Anderen-im-Plural bei Levinas, in: Matthias FlaTSCher / Sophie Loidolt (Hg.), Das Fremde im Selbst - Das Andere im Selben. Transformationen der Phänomenologie (Würzburg: Königshausen \& Neumann, 2010), 225 247, sowie Matthias Flatscher, Das Verhältnis zwischen dem Ethischen und dem Politischen. Überlegungen zu Levinas' Figur des Dritten, in: Alfred BodenheIMER / Miriam Fischer-Geboers (Hg.), Lesarten der Freiheit. Zur Deutung und Bedeutung von Emmanuel Lévinas' „Difficile Liberté“ (Freiburg/Br.-München: Alber, 2015), 182-214, und Ders., Was heißt Verantwortung? Zum alteritätsethischen Ansatz von Emmanuel Levinas und Jacques Derrida, in: Zeitschrift für Praktische Philosophie, 3 (2016) 1, 125-164. 138 Vgl. Emmanuel Levinas, Frieden und Nähe (1984), in: Ders., Verletzlichkeit und Frieden. Schriften über die Politik und das Politische (Hgg. u.m.e. Vorw. v. Pascal Delhom u. Alfred Hirsch; Zürich: Diaphanes, 2007), 137-149.

139 Vgl. die nähere Entfaltung des politischen Ansatzes von Levinas in: Pascal DeLном / Alfred Hirsch (Hg.), Im Angesicht des Anderen. Levinas' Philosophie des Politischen (Zürich-Berlin: diaphanes, 2005), insbesondere die Ausarbeitung einer politischen 
- Jacques Derridas Verständnis der différance (mit $a$ ) als Markierung einer Abwesenheit, von der man nicht unmittelbar sprechen, sondern die man nur lesen kann, sowie seine Arbeiten zum ereignishaften Zeugnis, ${ }^{140}$ verbunden mit seiner Berücksichtigung von performativen sprachlichen Gesten wie dem französischen donc (also, daher, lat. ergo), das einen nachträglichen (bekenntnisartigen) Diskurs einleitet, oder dem deutschen vielleicht (von mhd. vil lîhte, "[es kann] sehr leicht [sein, dass ...]) ${ }^{141}$ das nicht einen Diskurs der Unsicherheit markiert, sondern die Bindung an eine Zukunft zum Ausdruck bringt, kommen der Struktur des Exodus-Narrativs wohl am nächsten. Bei ihm wird die Verknüpfung von Zukunft und Gegenwart auch am deutlichsten politisch zum Ausdruck gebracht - und zwar u. a. im Begriff der démocratie à-venir, der Demokratie im-Kommen ${ }^{142}$ in der es entgegen einem verbreiteten Missverständnis nicht um einen chronologischen Aufschub, sondern um ein Ankommen-lassen der Zukunft schon jetzt geht, also genau um jenen Modus des futur antérieur, den auch das Exodus-Narrativ performativ entfaltet. Alle diese Themen finden sich bei Derrida gebündelt in seinem sorgsam entwickelten Verständnis von Textualität, ${ }^{143}$ das sich ebenfalls mit dem im Alten Israel kulturgeschichtlich neu entdeckten Verständnis textueller Autorität ${ }^{144}-$ im Un-

Kriteriologie bei Levinas in dem Beitrag von Miguel Abensour, Der Staat der Gerechtigkeit, in: ebd., 45-60.

140 Jacques Derrida, Eine gewisse unmögliche Möglichkeit, vom Ereignis zu sprechen (Berlin: Merve, 2003 [fr. 1997]), sowie die Entfaltung von Derridas Ereignis-Verständnis in: Peter Zeillinger, Das Ereignis als Symptom. Annäherung an einen entscheidenden Horizont des Denkens, in: Ders. / Dominik Portune (Hg.), nach Derrida. Dekonstruktion in zeitgenössischen Diskursen (Wien: Turia+Kant, 2006), 173-199.

141 Zur Genealogie des „Vielleicht“ bei Derrida vgl. Zeillinger, Nachträgliches Denken, aaO. [Anm. 143], 134-150, sowie Derridas nachträgliche Erläuterungen in: Jacques Derrida, Perhaps or Maybe. Jacques Derrida in conversation with Alexander García Düttmann (1996), in: Jonathan Dronsfield / Nick Midgley (Hg.), Responsibiities of Deconstruction (Pli. Warwick Journal of Philosophy 6; Coventry: Warwick UP, 1997), 118.

142 Jacques Derrida, Schurken. Zwei Essays über die Vernunft (Frankfurt/M.: Suhrkamp, 2003 [fr. 2003]).

143 Zur chronologischen Rekonstruktion der Entwicklung des Derrida'schen Denkens und der performativen Begrifflichkeit seines Werkes vgl. Peter ZeILlinger, Nachträgliches Denken. Skizze eines philosophisch-theologischen Aufbruchs im Ausgang von Jacques Derrida. Mit einer genealogischen Bibliographie der Werke von Jacques Derrida (Münster: Lit, 2002).

144 Paradigmatisch dafür ist die Erzählung von der Entdeckung einer Schriftrolle im Jerusalemer Tempel (2 Kön 22+23), deren kritischer Autorität sich auch der König beugen muss. 
Peter Zeillinger

terschied zum altorientalischen Verständnis von Schrift als Aufzeichnung identifizieren lässt. ${ }^{145}$

Auf eine, all den hier genannten Diskursen gemeinsame und sie mit dem ExodusMotiv verbindende Struktur sei zum Schluss noch verwiesen: auf die titelgebende Struktur des „Auszugs ins Reale“. Mit dem Begriff des Realen wird hier auf das Verständnis in der Lacan'schen Psychoanalyse verwiesen, in der das Reale niemals als solches angesprochen werden kann, sondern allein dadurch, dass es sich der Ordnung der Vorstellung und des Diskurses, also dem Imaginären und dem Symbolischen entzieht. Das Reale kann demnach nicht eigenständig erfahren werden, sondern nur indirekt. Es ist nur innerhalb des Imaginären und des Symbolischen erfahrbar, aber dort als das, was nicht darin aufgeht und damit die Ordnung stört. ${ }^{146}$ Nimmt man die Struktur eines solchen Diskurses ernst, so bezeichnet die Formulierung „Auszug ins Reale“ genau das, was auch das ExodusNarrativ der altorientalischen Königsideologie und den daran anschließenden Traditionen entgegenhält: einen Exodus hinein in die Wahrnehmung und Anerkennung des Nicht-Fassbaren und Nicht-Repräsentierbaren.

Eine durchaus auch selbstkritisch ernstzunehmende Warnung sei am Ende ebenfalls noch formuliert: Ein Diskurs, wie derjenige, der hier zu führen versucht wurde, muss sich davor hüten, den Eindruck zu erwecken, die Leere, von der er spricht, die „leere Stelle der Macht“ oder die unrepräsentierbare Souveränität, unter der Hand doch wieder zu substantialisieren oder zu hypostasieren. Gerade in der Nähe eines theologischen Kontextes ist diese Gefahr besonders groß. Wenn es Sinn macht, von einer Leere im Zentrum eines zukunftseröffnenden politischen Projekts zu sprechen, so dürfte dieser Begriff in dem zu entfaltenden Diskurs nicht zuviel Platz einnehmen. Vielleicht ist dies der Grund, warum in der jüdischen Tradition das Tetragramm JHWH, der biblische Name für Gott, nicht ausgesprochen wird, und warum das $a$ in der différance bei Derrida nicht hörbar ist, sondern nur gelesen werden kann, und warum diejenigen der hier genannten AutorInnen, die konkrete politische Konsequenzen formulieren, dies so oft nicht mit einer präsentischen Formulierung tun, sondern im Modus des futur antérieur, der die Position des Subjekts depotenziert und es in Gestalt eines Versprechens

145 Vgl. zum Verständnis dieser Besonderheit von Textualität in Abhebung vom altorientalischen Verständnis von Schriftlichkeit auch Derridas Rekurs auf jüdische textuelle Performances: Peter Zeillinger, „ “. (52) Leerstellen, die gelesen werden müssen, in: Matthias Schмidт (Hg.), Rücksendungen zu Jacques Derridas „Die Postkarte“. Ein essayistisches Glossar (Wien-Berlin: Turia+Kant, 2015), 13-38.

146 Zur Verknotung des Realen im Symbolischen bei Lacan, vgl. Jacques LaCAN, Das Seminar - Buch XXII (1974-1975). R. S.I. (Manuskript; deutsche Übersetzung v. Max Kleiner, hgg. v. Lacan-Archiv Bregenz; Arbeitsmaterialien 2; Bregenz 2012), hier: 11. Sitzung (April 1975). 
(Bekenntnisses, Zeugnisses) an eine Zukunft bindet, ${ }^{147}$ deren neue Ordnung es bereits hier-und-jetzt sichtbar werden lassen soll. Vielleicht ist dies auch die Motivation, die Levinas in einer Radioansprache die Formulierung aufgreifen lässt: Die Tora mehr zu lieben als Gott. ${ }^{148}$

\section{Literaturverzeichnis}

Abensour, Miguel: „Der Staat der Gerechtigkeit“, in: Pascal Delhom / Alfred Hirsch (Hg.), Im Angesicht des Anderen. Levinas' Philosophie des Politischen, Zürich-Berlin: diaphanes, 2005, 45-60.

Agamben, Giorgio: Homo sacer. Die souveräne Macht und das nackte Leben, Frankfurt/ M., Suhrkamp, 2002 [ital. 1995].

Agamben, Giorgio: Die Zeit, die bleibt. Ein Kommentar zum Römerbrief, Frankfurt/M., Suhrkamp, 2006 [ital. 2000].

Agamben, Giorgio: Das Sakrament der Sprache. Eine Archäologie des Eides, Homo Sacer II.3, Berlin, Suhrkamp, 2010 [ital. 2008].

Agamben, Giorgio: Signatura rerum. Zur Methode, Frankfurt/M., Suhrkamp, 2009 [ital. 2008].

Assmann, Jan: „Monotheismus als Politische Theologie“, in: Brokoff, Jürgen / Fohrmann, Jürgen (Hg.), Politische Theologie. Formen und Funktionen im 20. Jahrhundert, Paderborn-München-Wien-Zürich: Schöningh, 2003, 13-27.

Assmann, Jan: Exodus. Die Revolution der Alten Welt, München, Beck, 2015.

Assmann, Jan: „Die sakralstaatliche Rechtskultur des Alten Orients und die frühjüdische Theologisierung des Rechts“, in: Graulich, Markus / Weimann, Ralph (Hg.), Ewige Ordnung in sich verändernder Gesellschaft? Das göttliche Recht im theologischen Diskurs, QD 287, Freiburg i.Br., Herder, 2018, 11-30.

Badiou, Alain: Das Sein und das Ereignis, Berlin: diaphanes, 2005 [fr. 1988].

Badiou, Alain: Ethik. Versuch über das Bewusstsein des Bösen, Wien, Turia+Kant, 2003 [fr. 1993].

Badiou, Alain: Paulus. Die Begründung des Universalismus, München, sequenzia, 2002 [fr. 1997].

147 Zur Figur der politik- und rechtbegründenden Gestalt dieser Bindung in der abendländischen Geistesgeschichte siehe: Giorgio Agamben, Das Sakrament der Sprache. Eine Archäologie des Eides (Homo Sacer II.3) (Berlin: Suhrkamp, 2010 [ital. 2008]). 148 Emmanuel Levinas, Die Thora mehr lieben als Gott (1955), in: Schwierige Freiheit. Versuch über das Judentum (Frankfurt/M.: Jüdischer Verlag, 1992), 109-113. Wiederabgedruckt in: Michael Brocke / Herbert Jochum (Hg.), Wolkensäule und Feuerschein. Jüdische Theologie des Holocaust (Gütersloh: Kaiser, 1993), 213-217. - Levinas zitiert hier aus dem berühmten Text von Zvi Kolitz (der zunächst mehrmals anonym publiziert wurde) Jossel Rackower spricht zu Gott und erkennt in der Passage den „Widerhall des ganzen Talmud“: „Ich habe ihn [Gott] lieb, aber seine Thora habe ich noch lieber. Und selbst hätte ich mich in ihm getäuscht - seine Thora werde ich weiterhüten." (Levinas, Schwierige Freiheit, 112.) 
Badiou, Alain: Zweites Manifest für die Philosophie, Wien-Berlin: Turia+Kant, 2010 [fr. 2009].

Baltussen, Han: „From Polemic to Exegesis. The Ancient Philosophical Commentary“, in: Poetics Today 28, 2/2007, 247-281.

Behnke, Kerstin: „Repräsentation V. Krise der Repräsentation“, in: Historisches Wörterbuch der Philosophie 8, 1992, 846-853.

Berlejung, Angelika: Die Theologie der Bilder. Herstellung und Einweihung von Kultbildern in Mesopotamien und die alttestamentliche Bilderpolemik, OBO 612; Göttingen, Vandenhoeck \& Ruprecht, 1998.

Bieberstein, Klaus: „Sargon und Mose im Binsenkörbchen. Geschichten schreiben und lesen“, in: Lindner, Konstantin / Kabus, Andrea / Bergold, Ralph / Schwillus, Harald (Hg.): Erinnern und Erzählen. Theologische, geistes-, human- und kulturwissenschaftliche Perspektiven, Münster, Lit, 2013, 125-136.

Bosshard-Nepustil, Erich: Schriftwerdung der Hebräischen Bibel. Thematisierungen der Schriftlichkeit biblischer Texte im Rahmen ihrer Literaturgeschichte, AThANT 106; Zürich, TVZ, 2015.

Bottéro, Jean: Mesopotamia. Writing, Reasoning, and the Gods, Chicago-London, University of Chicago Press, 1992.

Butler, Judith: Raster des Krieges. Warum wir nicht jedes Leid beklagen, Frankfurt/M.New York, Campus, 2010 [amer. 2009].

Charpin, Dominique: Writing, Law, and Kingship in Old Babylonian Mesopotamia, Chicago-London, University of Chicago Press, 2010.

Delhom, Pascal / Hirsch, Alfred (Hg.): Im Angesicht des Anderen. Levinas' Philosophie des Politischen, Zürich-Berlin, diaphanes, 2005.

Derrida, Jacques: „Platons Pharmazie“ (1968), in: Dissemination (übers. v. Hans-Dieter Gondek), Wien, Passagen, 1995, 69-190.

Derrida, Jacques: „Sendung“ (1980), in: Psyche. Erfindungen des Anderen I, Wien, Passagen, 2012, 95-142.

Derrida, Jacques: Psyche. Erfindung des Anderen, Wien, Passagen, 2011 [fr. 1987].

Derrida, Jacques: „Perhaps or Maybe. Jacques Derrida in conversation with Alexander García Düttmann“ (1996), in: Dronsfield, Jonathan / Midgley, Nick (Hg.): Responsibilities of Deconstruction, Pli. Warwick Journal of Philosophy 6; Coventry, Warwick UP, 1997, 1-18.

Derrida, Jacques: Eine gewisse unmögliche Möglichkeit, vom Ereignis zu sprechen, Berlin, Merve, 2003 [fr. 1997].

Derrida, Jacques: Schurken. Zwei Essays über die Vernunft, Frankfurt/M., Suhrkamp, 2003 [fr. 2003].

Dohmen, Christoph: Das Bilderverbot. Seine Entstehung und seine Entwicklung im Alten Testament, BBB 62; Königstein/Ts.-Bonn: P. Hanstein Verlag, 1985.

Dohmen, Christoph: Exodus 19-40, HThK.AT; Freiburg i.Br., Herder, 2004.

Dohmen, Christoph: Studien zu Bilderverbot und Bildtheologie des Alten Testaments, SBAB 51; Stuttgart, Katholisches Bibelwerk, 2012.

Dohmen, Christoph: Exodus 1-18, HThK.AT; Freiburg i.Br., Herder, 2015.

Dohmen, Christoph / Ederer, Matthias: „Wie Exodus zum Exodus wurde. Ein Buch und sein Thema“ in: Gärtner, Judith / Schmitz, Barbara (Hg.): Exodus. Rezeptionen in 
Repräsentation einer Leerstelle, oder: Auszug ins Reale

deuterokanonischer und frühjüdischer Literatur, Deuterocanonical and Cognate Literature Studies 32; Berlin-Boston: de Gruyter, 2016, 1-16.

Dozeman, Thomas B. / Evans, Craig A. / Lohr, Joel N. (Hg.): The Book of Exodus. Composition, Reception, and Interpretation, Vetus Testamentum, Supplements 164; Leiden-Boston, Brill, 2014.

Ederer, Matthias / Schmitz, Barbara (Hg.): Exodus. Interpretation durch Rezeption, SBB 74; Stuttgart: Katholisches Bibelwerk, 2017.

Finkelstein, Israel / Silberman, Neil A.: The Bible Unearthed. Archaeology's New Vision of Ancient Israel and the Origin of Its Sacred Texts, New York, The Free Press, 2001.

Fischer, Georg: Jahwe unser Gott. Sprache, Aufbau und Erzähltechnik in der Berufung des Mose (Ex 3-4), OBO 91; Göttingen, Vandenhoeck \& Ruprecht, 1989.

Flatscher, Matthias: „Das Verhältnis zwischen dem Ethischen und dem Politischen. Überlegungen zu Levinas' Figur des Dritten“, in: Bodenheimer, Alfred / FischerGeboers, Miriam (Hg.): Lesarten der Freiheit. Zur Deutung und Bedeutung von Emmanuel Lévinas' „Difficile Liberté“, Freiburg/Br.-München: Alber, 2015, 182-214.

Flatscher, Matthias: „Was heißt Verantwortung? Zum alteritätsethischen Ansatz von Emmanuel Levinas und Jacques Derrida“, in: Zeitschrift für Praktische Philosophie 3, 1/2016, 125-164.

Flatscher, Matthias: „Derridas „Politik der Alterität“. Zur normativen Dimension des Kommenden“, in: Boelderl, Artur R. / Leisch-Kiesl, Monika (Hg.): „Die Zukunft gehört den Phantomen “. Kunst und Politik nach Derrida, Bielefeld: transcript, 2018, 297-325.

Foucault, Michel: Was ist Kritik? [27. Mai 1978], Berlin: Merve, 1992.

Frevel, Christian: Geschichte Israels, Stuttgart, Kohlhammer, 2016.

Gärtner, Judith / Schmitz, Barbara (Hg.): Exodus. Rezeptionen in deuterokanonischer und frühjüdischer Literatur, Deuterocanonical and Cognate Literature Studies 32; Berlin-Boston, de Gruyter, 2016.

Haarmann, Harald: Universalgeschichte der Schrift, Frankfurt/M.-New York, Campus, 1991.

Hallward, Peter: Badiou. A Subject to Truth, Minneapolis-London, University of Minnesota Press, 2003.

Hardt, Michael: Three Keys to Understanding Constituent Power, in: Negri, Antonio: Insurgencies. Constituent Power and the Modern State, Minneapolis-London, Univ. of Minnesota Press, 2009, vi-xii.

Heidegger, Martin: Die Zeit des Weltbildes (1938), in: Holzwege [= GA 5]; Frankfurt/ M., Klostermann, 1994, 75-113.

Heither, Theresia: Biblische Gestalten bei den Kirchenvätern. Mose, Münster, Aschendorff, 2010.

Jacob, Benno: Das Buch Exodus, hgg. im Auftrag des Leo Baeck Instituts von Shlomo Mayer; Stuttgart, Calwer, 1997 [1943].

Jeremias, Jörg: „Das Proprium der alttestamentlichen Prophetie“ (1994), in: Jeremias, Jörg: Hosea und Amos. Studien zu den Anfängen des Dodekapropheton, FAT 13; Tübingen: Mohr, 1996, 20-33.

Jeremias, Jörg: „Das Rätsel der Schriftprophetie“ (2013), in: Studien zur Theologie des Alten Testaments, hgg. v. Hartenstein, Friedhelm / Krispenz, Jutta; FAT 99; Tübingen: Mohr Siebeck, 2015, 288-310. 
Kaiser, Otto: Glaube und Geschichte im Alten Testament. Das neue Bild der Vor- und Frühgeschichte Israels und das Problem der Heilsgeschichte, Biblisch-Theologische Studien 150; Neukirchen-Vluyn: Neukirchener, 2014.

Kalyvas, Andreas: „Popular Sovereignty, Democracy, and the Constituent Power“, in: Constellations 12, 2/2005, 223-244.

Keel, Othmar: Die Geschichte Jerusalems und die Entstehung des Monotheismus, 2 Bde.; Orte und Landschaften der Bibel IV,1+2; Göttingen: Vandenhoeck \& Ruprecht, 2007.

Kienpointner, M.: Inventio, in: Historisches Wörterbuch der Rhetorik IV, hgg. v. Gert Ueding; Tübingen: Niemeyer, 1998, 561-587.

Kratz, Reinhard G.: Die Komposition der erzählenden Bücher des Alten Testaments. Grundwissen der Bibelkritik, Göttingen: Vandenhoeck \& Ruprecht, 2000.

Kratz, Reinhard G.: „Das Neue in der Prophetie des Alten Testaments“ (2001), in: Ders, Prophetenstudien. Kleine Schriften II, FAT 74; Tübingen: Mohr Siebeck, 2011, 49-70.

Kühnlein, Michael (Hg.): Exodus, Exilpolitik und Revolution. Zur Politischen Theologie Michael Walzers, Tübingen: Mohr Siebeck, 2017.

Kuschel, Karl-Josef: Die Bibel im Koran. Grundlagen für das interreligiöse Gespräch, Ostfildern: Patmos, 2017.

Lacan, Jacques: Das Seminar - Buch XXII (1974-1975). R.S.I., Manuskript; deutsche Übersetzung v. Max Kleiner, hgg. v. Lacan-Archiv Bregenz; Arbeitsmaterialien 2; Bregenz 2012.

Lambert, Wilfred G.: Enuma Elisch, in: O. Kaiser u. a. (Hg.), TUAT III, Lfg. 4, 1994, 565604.

Leibholz, Gerhard: Das Wesen der Repräsentation und der Gestaltwandel der Demokratie im 20. Jahrhundert, Berlin: de Gruyter, 1966 [1929].

Levinas, Emmanuel: „Die Thora mehr lieben als Gott“ (1955), in: Schwierige Freiheit. Versuch über das Judentum, Frankfurt/M.: Jüdischer Verlag, 1992, 109-113. [wiederabgedruckt in: Michael Brocke / Herbert Jochum (Hg.), Wolkensäule und Feuerschein. Jüdische Theologie des Holocaust, Gütersloh: Kaiser, 1993, 213-217.]

Levinas, Emmanuel: „Rätsel und Phänomen“ (1965), in: Levinas, Emmanuel: Die Spur des Anderen. Untersuchungen zur Phänomenologie und Sozialphilosophie, Freiburg/ Br.-München, Alber: 1983, 236-260.

Levinas, Emmanuel: Jenseits des Seins oder anders als Sein geschieht, Freiburg/Br.München: Alber, 1992 [fr. 1974].

Levinas, Emmanuel: „Bilderverbot und „Menschenrechte““ (1984), in: Verletzlichkeit und Frieden. Schriften über die Politik und das Politische, Hgg. u.m.e. Vorw. v. Pascal Delhom u. Alfred Hirsch; Zürich: Diaphanes, 2007, 115-123.

Levinas, Emmanuel: „Frieden und Nähe“ (1984), in: Levinas, Emanuel: Verletzlichkeit und Frieden. Schriften über die Politik und das Politische, Hgg. u.m.e. Vorw. v. Pascal Delhom u. Alfred Hirsch; Zürich: Diaphanes, 2007, 137-149.

Levy, Thomas E. / Schneider, Thomas / Propp, William H.C. (Hg.): Israel's Exodus in Transdisciplinary Perspective. Text, Archaeology, Culture, and Geoscience, ChamHeidelberg-New York: Springer, 2015.

Löhr, Hermut: „Steintafeln. Tora-Traditionen in 2Kor 3“, in: Dieter Sänger (Hg.), Der zweite Korintherbrief. Literarische Gestalt, historische Situation, theologische Argumentation, Göttingen: Vandenhoeck \& Ruprecht, 2012, 175-187. 
Lorey, Isabell: Figuren des Immunen. Elemente einer politischen Theorie, Zürich: diaphanes, 2011.

Lorey, Isabell: Die Regierung der Prekären, mit e. Vorwort v. Judith Butler; Wien-Berlin: Turia+Kant, 2012.

Lyotard, Jean-François: Beantwortung der Frage: Was ist postmodern?, in: Postmoderne für Kinder. Briefe aus den Jahren 1982-1985, Wien: Passagen, 1987, 11-31.

Marchart, Oliver: Der Auszug aus Ägypten. Eine Einleitung, in: Chantal Mouffe, Exodus und Stellungskrieg. Die Zukunft radikaler Politik, Wien: Turia+Kant, 2005, 7-23.

Markl, Dominik: „Moses Prophetenrolle in Dtn 5;18; 34. Strukturelle Wendepunkte von rechtshermeneutischem Gewicht", in: Fischer, Georg / Markl, Dominik / Paganini, Simone (Hg.), Deuteronomium - Tora für eine neue Generation, BZAR 17; 2011, 5168.

Markl, Dominik: Gottes Volk im Deuteronomium, BZAR 18; Wiesbaden: Harrassowitz, 2012.

Markl, Dominik: „Gottes Gesetz und die Entstehung des Monotheismus“, in: Graulich, Markus / Weimann, Ralph (Hg.): Ewige Ordnung in sich verändernder Gesellschaft? Das göttliche Recht im theologischen Diskurs, QD 287; Freiburg i.Br.: Herder, 2018, 49-67.

Maul, Stefan M.: „Der assyrische König - Hüter der Weltordnung“, in: Assmann, Jan / Janowski, Bernd / Welker, Michael (Hg.): Gerechtigkeit. Richten und Retten in der abendländischen Tradition und ihren altorientalischen Ursprüngen, München: Fink, 1998, 65-78.

Maul, Stefan M.: „Altorientalische Schöpfungsmythen“, in: Brandt, Reinhard / Schmidt, Steffen (Hg.): Mythos und Mythologie, Berlin: Akademie, 2004, 43-54.

Maul, Stefan M.: „Die Wissenschaft von der Zukunft. Überlegungen zur Bedeutung der Divination im Alten Orient", in: Cancik-Kirschbaum, Eva / van Ess, Margarete / Mahrzahn, Joachim (Hg.): Babylon. Wissenskultur in Orient und Okzident, BerlinNew York: de Gruyter, 2011, 135-151.

Maul, Stefan M.: Die Wahrsagekunst im Alten Orient. Zeichen des Himmels und der Erde, München: Beck, 2013.

Mayer, W. R.: Ein Mythos von der Erschaffung des Menschen und des Königs, in: Orientalia 56, 1987, 55-68.

Mouffe, Chantal: Exodus und Stellungskrieg. Die Zukunft radikaler Politik, Wien: Turia+Kant, 2005.

Müller, H.-P.: „Eine neue babylonische Menschenschöpfungserzählung im Licht keilschriftlicher und biblischer Parallelen. Zur Wirklichkeitsauffassung im Mythos“, in: Orientalia 58, 1989, 69-85.

Najman, Hindy: „The Symbolic Significance of Writing in Ancient Judaism“, in: Najman, Hindy / Newman, Judith H. (Hg.): The Idea of Biblical Interpretation. Essays in Honor of James L. Kugel, Supplements to the Journal for the Study of Judaism 83; LeidenBoston: Brill, 2004, 139-176.

Nancy, Jean-Luc: Dekonstruktion des Christentums, Zürich-Berlin: Diaphanes, 2009 [fr. 2005].

Neundlinger, Klaus: „Social Media und \#brennender Dornbusch. Politisch-theologische Skizze zum Exodusbegriff“", in: Lorey, Isabell / Nigro, Roberto / Raunig, Gerald (Hg.): 
Peter Zeillinger

Inventionen 2. Exodus, Reale Demokratie, Immanenz, Territorium, Maßlose Differenz, Biopolitik, Zürich: diaphanes, 2012, 27-41.

Neuwirth, Angelika: Der Koran als Text der Spätantike. Ein europäischer Zugang, Berlin: Verlag der Weltreligionen, 2010.

Neuwirth, Angelika: Der Koran 1: Frühmekkanische Suren. Poetische Prophetie, Berlin: Verlag der Weltreligionen, 2011.

Neuwirth, Angelika: Koranforschung - eine Politische Philologie? Bibel, Koran und Islamentstehung im Spiegel spätantiker Textpolitik und moderner Philologie, Litterae et Theologia 4; Berlin-Boston: de Gruyter, 2014.

Neuwirth, Angelika: Die koranische Verzauberung der Welt und ihre Entzauberung in der Geschichte, Freiburg i.Br.: Herder, 2017.

Otto, Eckart: „Die Ursprünge der Bundestheologie im Alten Testament und im Alten Orient“, in: Zeitschrift für altorientalische und biblische Rechtsgeschichte 4, 1998,1-84.

Otto, Eckart: „Political Theology in Judah and Assyria. The Beginning of the Hebrew Bible as Literature“, in: Svensk Exegetisk Arsbok (SEA), 65 (2000), 59-76.

Otto, Eckart: „Die Geburt des Mose. Die Mose-Figur als Gegenentwurf zur neuassyrischen Königsideologie im 7. Jh. v. Chr.“ (2000), in: Otto, Eckart: Die Tora. Studien zum Pentateuch, BZAR 9; Wiesbaden: Harrassowitz, 2009, 9-45.

Otto, Eckart: Die Tora des Mose. Die Geschichte der literarischen Vermittlung von Recht, Religion und Politik durch die Mosegestalt, Berichte aus den Sitzungen der Joachim Jungius-Gesellschaft der Wiss. E.V., Hamburg 19, 2/2001; Göttingen: Vandenhoeck \& Ruprecht, 2001.

Otto, Eckart: „Politische Theologie in den Königspsalmen zwischen Ägypten und Assyrien. Herrscherlegitimation in den Psalmen 2 und 18 in ihren altorientalischen Kontexten“, in: Otto, Eckart / Zenger, Erich (Hg.), „Mein Sohn bist du“ (Ps 2,7). Studien zu den Königspsalmen, SBS 192; Stuttgart: Katholisches Bibelwerk, 2002, 33 65.

Otto, Eckart: Gottes Recht als Menschenrecht. Rechts- und literaturhistorische Studien zum Deuteronomium, BZAR 2; Wiesbaden: Harrassowitz, 2002.

Otto, Eckart: „Mose, der erste Schriftgelehrte. Deuteronomium 1,5 im Narrativ des Pentateuch" (2005), in: Die Tora. Studien zum Pentateuch. Gesammelte Schriften, BZAR 9; Wiesbaden: Harrassowitz, 2009, 480-489.

Otto, Eckart: „Staat - Gemeinde - Sekte. Soziallehren des antiken Judentums“, in: Zeitschrift für altorientalische und biblische Rechtsgeschichte 12, 2006, 312-343.

Otto, Eckart: Das Gesetz des Mose, Darmstadt: WBG, 2007.

Otto, Eckart: „Law and Ethics“, in: Johnston, Sarah Iles (Hg.): Ancient Religions, Cambridge-London: Harvard UP, 2007, 84-97.

Otto, Eckart: Tora für eine neue Generation in Dtn 4. Die hermeneutische Theologie des Numeruswechsels in Deuteronomium 4,1-40, in: Fischer, Georg / Markl, Dominik / Paganini, Simone (Hg.): Deuteronomium. Tora für eine neue Generation, BZAR 17; Wiesbaden: Harrassowitz, 2011, 105-122.

Otto, Eckart: Deuteronomium, 4 Bde.; HThK.AT; Freiburg i.Br.: Herder, 2012-2017. Parpola, Simo: „Neo-Assyrian Concepts of Kingship and Their Heritage in Mediterranean Antiquity“, in: Lanfranchi, Giovanni B. / Rollinger, Robert (Hg.), Concepts of Kingship in Antiquity, Winona Lake, IN: Eisenbrauns, 2010, 35-44. 
Repräsentation einer Leerstelle, oder: Auszug ins Reale

Petry, Sven: „Das Gottesbild des Bilderverbots“, in: Groneberg, Brigitte / Spieckermann, Hermann (Hg.): Die Welt der Götterbilder, BZaW 376; Berlin-New York: de Gruyter, 2007, 257-271.

Petry, Sven: Die Entgrenzung JHWHs. Monolatrie, Bilderverbot und Monotheismus im Deuteronomium, in Deuterojesaja und im Ezechielbuch, FAT II.27; Tübingen: Mohr Siebeck, 2007.

Pistrol, Florian: Vulnerabilität. Erläuterungen zu einem Schlüsselbegriff im Denken Judith Butlers, in: Zeitschrift für Praktische Philosophie 3 1/2016, 233-272.

Pitkin, Hanna Fenichel: The Concept of Representation, Berkeley-Los Angeles-London: Univ. of California Press, 1972 [1967].

Posselt, Gerald / Schönwälder-Kuntze, Tatjana / Seitz, Sergej (Hg.): Judith Butlers Philosophie des Politischen. Kritische Lektüren, Bielefeld: transcript, 2018.

Radner, Karen: „Assyrian and Non-Assyrian Kingship in the First Millenium BC“, in: Lanfranchi, Giovanni B. / Rollinger, Robert (Hg.): Concepts of Kingship in Antiquity, Winona Lake, IN: Eisenbrauns, 2010, 25-34.

Rahner, Karl: Von der Unbegreiflichkeit Gottes. Erfahrungen eines katholischen Theologen, hg.v. Albert Raffelt; Freiburg / Br.-Basel-Wien: Herder, 2005.

Raschke, Carl A.: Force of God. Political Theology and the Crisis of Liberal Democracy, New York: Columbia UP, 2015.

Renz, Johannes: „Die vor- und ausserliterarische Texttradition. Ein Beitrag der palästinischen Epigraphik zur Vorgeschichte des Kanons“, in: Schaper, Joachim (Hg.): Die Textualisierung der Religion, FAT 62; Tübingen: Mohr Siebeck, 2009, 53-81.

Sanders, Seth L.: The Invention of Hebrew, Urbana-Chicago: University of Illinois Press, 2009.

Sasson, Jack M.: „Water beneath Straw. Adventures of a Prophetic Phrase in the Mari Archives“, in: Gitin, S. / Sokoloff, M. / Zevit, Z. (Hg.): Solving Riddles and Untying Knots. Biblical, Epigraphic, and Semitic Studies in Honor of Jonas C. Greenfield, Winona Lake, IN: Eisenbrauns, 1995, 599-608.

Schaper, Joachim: „A Theology of Writing. The Oral and the Written, God as Scribe, and the Book of Deuteronomy“, in: Lawrence, Louise Joy / Aguilar, Mario I. (Hg.), Anthropology and Biblical Studies. Avenues of Approach, Leiden: Deo Publishing, 2004, 97-119.

Schaper, Joachim: „The Literary History of the Hebrew Bible“, in: The New Cambridge History of the Bible Vol. I: From the Beginnings to 600, hg.v. Paget, James Carleton / Schaper, Joachim, Cambridge: Cambridge UP, 2013, 105-144.

Schaper, Joachim: „Anthropologie des Schreibens als Theologie des Schreibens. Ein medienarchäologischer Gang durch das Buch Exodus“, in: Focken, Friedrich-Emanuel / Ott, Michael R. (Hg.), Metatexte. Erzählungen von schrifttragenden Artefakten in der alttestamentlichen und mittelalterlichen Literatur, Materiale Textkulturen 15; Berlin-Boston: de Gruyter, 2016.

Schiefen, Fana: Öffnung des Christentums? Eine fundamentaltheologische Auseinandersetzung mit der Dekonstruktion des Christentums nach Jean-Luc Nancy (m. e. Geleitwort v. J.-L. Nancy); Regensburg: Pustet, 2018.

Schmandt-Besserat, Denise: How Writing Came About, Austin: Univ. of Texas Press, 1996. 
Schmid, Konrad: Erzväter und Exodus. Untersuchungen zur doppelten Begründung der Ursprünge Israels innerhalb der Geschichtsbücher des Alten Testaments, WMANT 81; Neukirchen-Vluyn: Neukirchener, 1999.

Schmid, Konrad: Literaturgeschichte des Alten Testaments. Eine Einführung, Darmstadt: Wissenschaftliche Buchgesellschaft, 2008.

Schmid, Konrad: „Der Pentateuch und seine Theologiegeschichte“, in: ZThK 111, 2014, 239-270.

Schmitz, Barbara: Geschichte Israels, Paderborn: Schöningh, 2015.

Schwartz, Regina Mara: „Revelation and Revolution“, in: Davis, Creston / Milbank, John / Zizek, Slavoj (Hg.): Theology and the Political. The New Debate, DurhamLondon: Duke UP, 2005, 102-124.

Schwartz, Regina Mara: Revelation and Revolution. Law, Justice, and Politics in the Hebrew Bible, in: Sterman Sabbath, Roberta (Hg.): Sacred Tropes. Tanakh, New Testament, and Qur'an as Literature and Culture, Biblical Interpretation Series 98; Leiden-Boston: Brill, 2009, 485-792.

Selz, Gebhard J.: „Über mesopotamische Herrschaftskonzepte. Zu den Ursprüngen mesopotamischer Herrscherideologie im 3. Jahrtausend“, in: Dietrich, Manfried / Loretz, Oswald (Hg.): dubsar anta-men. Studien zur Altorientalistik, Münster: UgaritVerlag, 1998, 281-344.

Söding, Thomas: Das Gesetz der Freiheit. Neutestamentliche Impulse in der Debatte um das ius divinium, in: Graulich, Markus / Weimann, Ralph (Hg.): Ewige Ordnung in sich verändernder Gesellschaft? Das göttliche Recht im theologischen Diskurs, QD 287; Freiburg i.Br., erder, 2018, 68-115.

Steins, Georg: „Zwei Konzepte - ein Kanon. Neue Theorien zur Entstehung und Eigenart der Hebräischen Bibel“", in: Steins, Georg / Taschner, Johannes (Hg.): Kanonisierung - die Hebräische Bibel im Werden, Biblisch-Theologische Studien 110; Neukirchen-Vluyn: Neukirchener Verlag, 2010, 8-45.

Stemberger, Günter: Mose in der rabbinischen Tradition, Freiburg i.Br.: Herder, 2016. Taschner, Johannes: Die Mosereden im Deuteronomium. Eine kanonorientierte Untersuchung, FAT 59; Tübingen: Mohr Siebeck, 2008.

Toorn, Karel van der: „From the Oral to the Written. The Case of Old Babylonian Prophecy“, in: Ben Zvi, Ehud / Floyd, Michael H. (Hg.): Writings and Speech in Israelite and Ancient Near Eastern Prophecy, SBL Symposium Series 10; Atlanta: Society of Biblical Literature, 2000, 219-234.

Toorn, Karel van der: Scribal Culture and the Making of the Hebrew Bible, Cambridge: Harvard UP, 2007.

Vesting, Thomas: Die Medien des Rechts: Schrift, Weilerswist: Velbrück, 2011.

Virno, Paolo: Exodus, Wien-Berlin: Turia+Kant, 2010.

Walzer, Michael: Exodus und Revolution, Berlin: Rotbuch, 1988 [amer. 1985].

Zeillinger, Peter: Nachträgliches Denken. Skizze eines philosophisch-theologischen Aufbruchs im Ausgang von Jacques Derrida. Mit einer genealogischen Bibliographie der Werke von Jacques Derrida, Münster: Lit, 2002.

Zeillinger, Peter: „Phänomenologie des Nicht-Phänomenalen. Spur und Inversion des Seins bei Emmanuel Levinas“, in: Blamauer, Michael / Fasching, Wolfgang / Flatscher, Matthias (Hg.): Phänomenologische Aufbrüche, Reihe der Österreichischen Gesellschaft für Phänomenologie 11; Frankfurt/M. u. a.: Lang, 2005, 161-179. 
Zeillinger, Peter: „Das Ereignis als Symptom. Annäherung an einen entscheidenden Horizont des Denkens“, in: Zeillinger, Peter / Portune, Dominik (Hg.): nach Derrida. Dekonstruktion in zeitgenössischen Diskursen, Wien: Turia+Kant, 2006, 173-199.

Zeillinger, Peter: „Badiou und Paulus. Das Ereignis als Norm?“, in: Mitteilungen des Instituts für Wissenschaft und Kunst 61, 3-4/2006, 6-12.

Zeillinger, Peter: „Jacques Derrida: Gott im-Kommen“, in: Hardt, Peter / von Stosch, Klaus (Hg.): Für eine schwache Vernunft? Beiträge zu einer Theologie nach der Postmoderne, Ostfildern: Grünewald, 2007, 66-83.

Zeillinger, Peter: ,,,eins, zwei, viele, ...“ - oder: Ohne Selbst aber in Gemeinschaft. Der Einbruch des Anderen-im-Plural bei Levinas“, in: Flatscher, Matthias / Loidolt, Sophie (Hg.): Das Fremde im Selbst - Das Andere im Selben. Transformationen der Phänomenologie, Würzburg: Königshausen \& Neumann, 2010, 225-247.

Zeillinger, Peter: „Politik der Alterität? - Versuch einer Antwort“, in: Flatscher, Matthias / Loidolt, Sophie (Hg.): Das Fremde im Selbst - Das Andere im Selben. Transformationen der Phänomenologie, Würzburg: Königshausen \& Neumann, 2010, 305310.

Zeillinger, Peter: „Dem Ereignis nach-denken. Hat Badious Philosophie eine Zukunft?", in: Knipp, Jens / Meier, Frank (Hg.): Treue zur Wahrheit. Die Begründung der Philosophie Alain Badious, Münster: Unrast, 2010, 221-237.

Zeillinger, Peter: „Über das Lesen. Heidegger und die Vermeidung des Aussagesatzes“, in: Baur, Patrick / Bösel, Bernd / Mersch, Dieter (Hg.): Die Stile Martin Heideggers, Freiburg/Br.-München: Alber, 2013, 243-264.

Zeillinger, Peter: „Das christliche „Pastorat“. Elemente einer Relecture der politischen Kultur des Abendlandes im Spätwerk Michel Foucaults“, in: Geist und Leben 86, 4/ 2013, 351-373.

Zeillinger, Peter: ,” “. (52) Leerstellen, die gelesen werden müssen“, in: Schmidt, Matthias (Hg.), Rücksendungen zu Jacques Derridas „Die Postkarte“. Ein essayistisches Glossar, Wien-Berlin: Turia+Kant, 2015, 13-38.

Zeillinger, Peter: „Dekonstruktive Bibellektüre. Aufmerksamkeiten für die Textualität monotheistischer Schriften“, in: Roth, Ursula / Seip, Jörg (Hg.): Schriftinszenierungen. Bibelhermeneutische und texttheoretische Zugänge zur Predigt, Ökumenische Studien zur Predigt 10; München: Don Bosco, 2016, 143-164.

Zeillinger, Peter: „Disillusioning Reason - Rethinking Faith. Paul, Performative Speech Acts and the Political History of the Occident in Agamben and Foucault", in: van der Heiden, Gert-Jan / van Kooten, George / Cimino, Antonio (Hg.): Saint Paul and Philosophy. The Consonance of Ancient and Modern Thought, Berlin-Boston: de Gruyter, 2017, 95-113.

Zeillinger, Peter: „Geschichtliche Erinnerung und textuelle Autorität. Beantwortung der Frage „Was ist gute Theologie ?““”, in: Kirschner, Martin (Hg.): Dialog und Konflikt. Erkundungen zu Orten theologischer Erkenntnis, Stuttgart: Grünewald, 2017, 149_ 173.

Zeillinger, Peter: „Offenbarung als Ereignis. Zeitgenössische Philosophie, die Rede von Gott und das Sprechen der Bibel“, in: Salzburger Theologische Zeitschrift 21, 1/2017, 25-101. 
Peter Zeillinger, Neustiftgasse 71/31, 1070 Vienna, Austria, e-mail: peter.zeillinger@ univie.ac.at

Citation: Zeillinger, Peter: „Repräsentation einer Leerstelle, oder: Auszug ins Reale. Zur politischen Bedeutung des biblischen Exodus, der historisch nicht stattgefunden hat", in: Appel, Kurt / Raschke, Carl (eds.): The Crisis of Representation (J-RaT 2018 / 2) pp. 212-282.

Datum der Publikation: 21.01.2019 